Wildlife Program

\title{
An Integrated Population Model for Southern Sea Otters
}

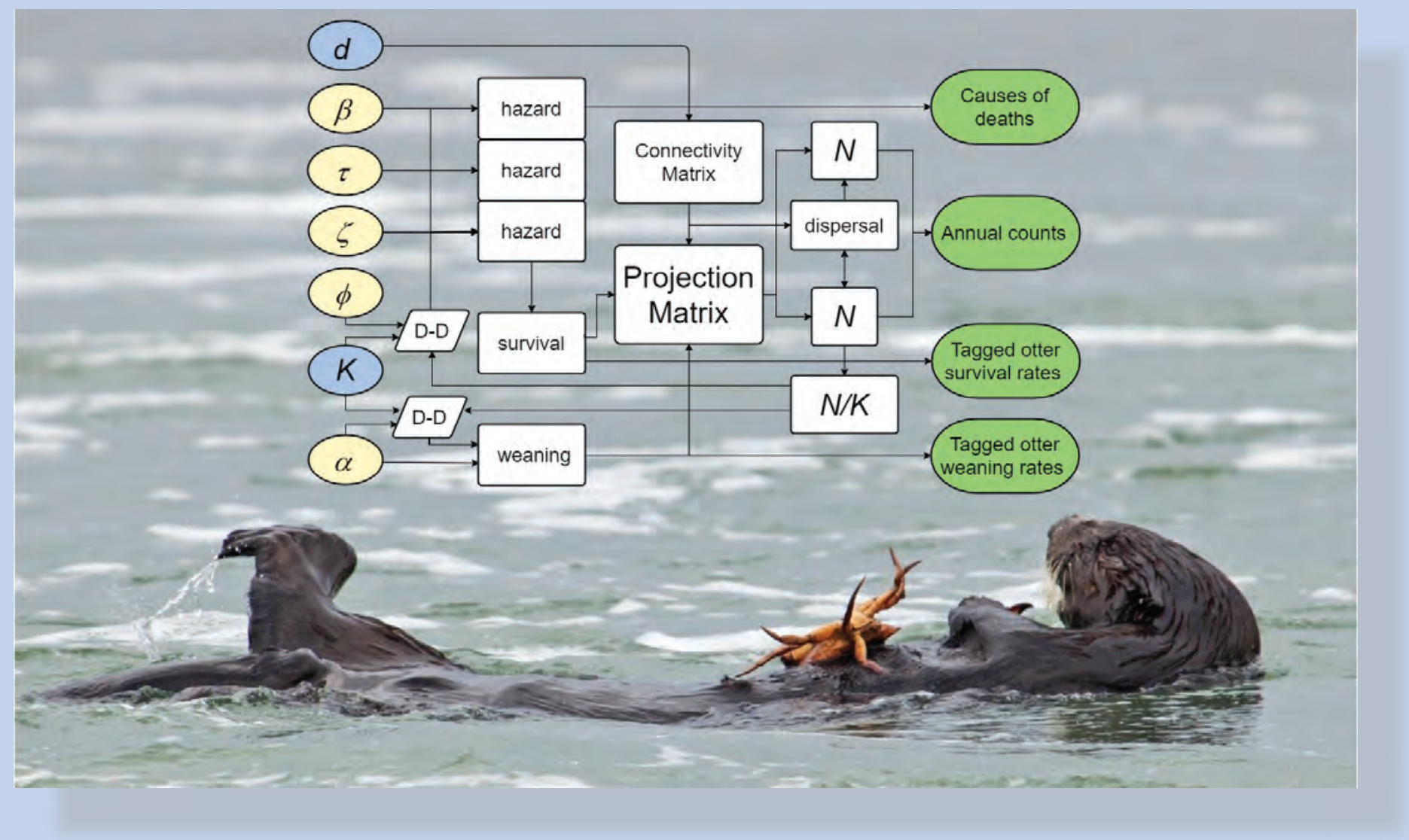

Open-File Report 2021-1076 
Cover: Southern sea otter eating a rock crab in Moss Landing, California, with conceptual diagram of integrated population model. Photograph taken by Joe Tomoleoni, U.S. Geological Survey, January 30, 2011. 


\section{An Integrated Population Model for Southern Sea Otters}

By M. Tim Tinker, Lilian P. Carswell, Joseph A. Tomoleoni, Brian B. Hatfield, Michael D. Harris, Melissa A. Miller, Megan E. Moriarty, Christine K. Johnson, Colleen Young, Laird A. Henkel, Michelle M. Staedler, A. Keith Miles, and Julie L. Yee

Wildlife Program

Open-File Report 2021-1076 


\section{U.S. Geological Survey, Reston, Virginia: 2021}

For more information on the USGS - the Federal source for science about the Earth, its natural and living resources, natural hazards, and the environment—visit https://www.usgs.gov or call 1-888-ASK-USGS.

For an overview of USGS information products, including maps, imagery, and publications, visit https://store.usgs.gov/.

Any use of trade, firm, or product names is for descriptive purposes only and does not imply endorsement by the U.S. Government.

Although this information product, for the most part, is in the public domain, it also may contain copyrighted materials as noted in the text. Permission to reproduce copyrighted items must be secured from the copyright owner.

Suggested citation:

Tinker, M.T., Carswell, L.P., Tomoleoni, J.A., Hatfield, B.B., Harris, M.D., Miller, M.A., Moriarty, M.E., Johnson, C.K., Young, C., Henkel, L.A., Staedler, M.M., Miles, A.K., and Yee, J.L., 2021, An integrated population model for southern sea otters: U.S. Geological Survey Open-File Report 2021-1076, 50 p., https://doi.org/10.3133/ofr20211076.

ISSN 2331-1258 (online) 


\section{Acknowledgments}

This work could not have been completed without all the participants of the Southern Sea Otter Stranding Network, the annual range-wide southern sea otter survey, and multiple telemetry-based tagging studies of southern sea otters completed over the past two decades. Participants and supporters of these efforts include the U.S. Geological Survey, California Department of Fish and Wildlife Marine Wildlife Veterinary Care and Research Center, Monterey Bay Aquarium, U.S. Fish and Wildlife Service, Bureau of Ocean Energy Management, Marine Mammal Center, University of California Santa Cruz, UC Davis, and the UC Natural Reserve System. We thank the many staff and volunteers of these organizations, with special thanks to Jack Ames, Dave Jessup, Francesca Batac and Erin Dodd of the California Department of Fish and Wildlife; Dr. Mike Murray, Andrew Johnson, Marissa Young, Teri Nicholson, Jessica Fujii, and Karl Mayer of the Monterey Bay Aquarium; Mark Readdie and Don Canestro (in memoriam) of the UC Natural Reserve system; James Bodkin, Dan Monson, George Esslinger, Mike Kenner, Liz Bowen, and Kim Kloecker of the U.S. Geological Survey; and James Estes, Gena Bentall, Heather Coletti, Julie Stewart, Ben Weitzman, Sarah Espinosa, Sarah Chinn, Nicole LaRoche, and Zach Randell. Funding for this study was provided by grants from the California Coastal Conservancy, Oiled Wildlife Care Network, Bureau of Ocean Energy Management, and the U.S. Fish and Wildlife Service. Megan Moriarty was supported by the Morris Animal Foundation Fellowship Training Grant (D17Z0-413) during this study. 



\section{Contents}

Acknowledgments ……...................................................................................................................

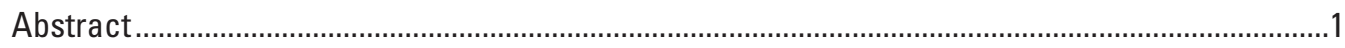

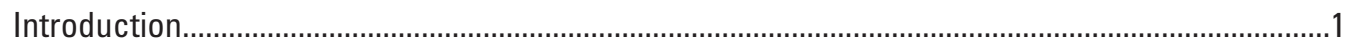

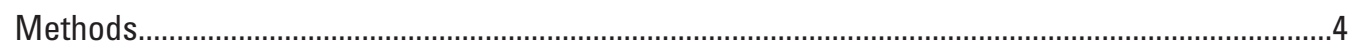

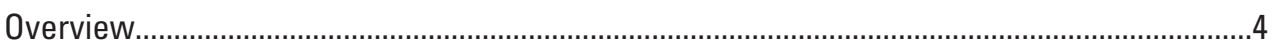

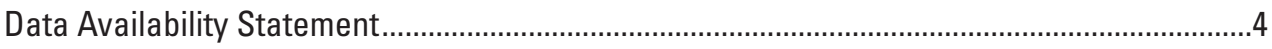

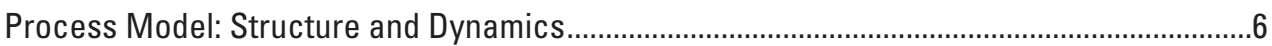

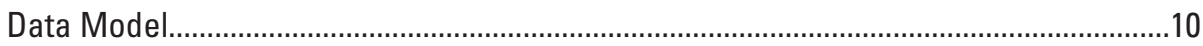

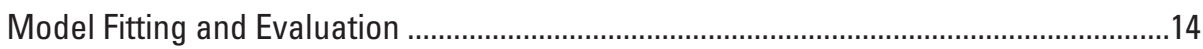

Population Projections Using the Fitted Integrated Population Model ............................15

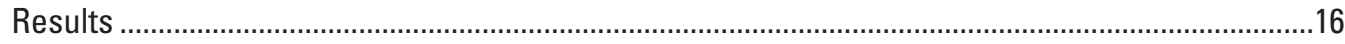

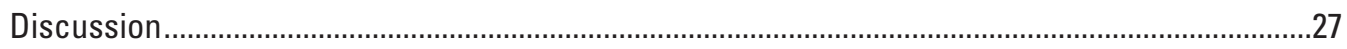

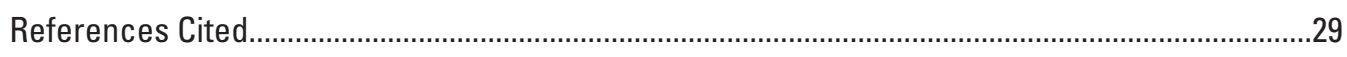

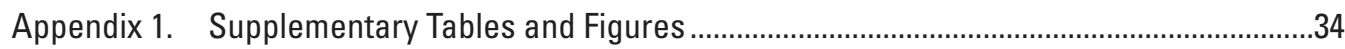

\section{Figures}

1. Map showing the coast of California current and potential habitat of southern sea otters .

2. Diagram showing the life history stages and demographic transitions tracked as part of an integrated population model for southern sea otters

3. Diagram showing the conceptual framework for an integrated population model for southern sea otters

4. Graphs showing estimated trends in population abundance of southern sea otters between 1998 and 2013, plotted for five coastal areas and the combined population of the mainland coast based on survey data and estimates from an integrated population model

5. Graphs showing estimated vital rates for southern sea otters plotted as functions of relative density, based on the results of an integrated population model

6. Boxplots showing the effects of relative density on log hazard rates for each of the nine causes of death for southern sea otters.

7. Graphs showing the relative impacts on stage-specific survival for nine causes of death, based on an integrated population model for southern sea otters.

8. Graphs showing future projection of population dynamics for southern sea otters, based on iterated posterior predictive simulations using an integrated population model, with all parameters set to their default distributions

9. Graph showing future projections of population dynamics for southern sea otters based on iterated posterior predictive simulations using an integrated population model.

10. Bar chart showing the relative impacts on population growth for nine categories of cause of death for southern sea otters, estimated based on a perturbation analysis using an integrated population model.. 
11. Bar chart showing the relative impacts on population growth for a targeted re-introduction of southern sea otters to a specific coastal area, estimated based on a perturbation analysis using an integrated population model.

12. Graphs showing projected spatiotemporal variation in southern sea otter abundance and distribution predicted by an integrated population model.

\section{Tables}

1. Descriptions of nine categories of cause of death for southern sea otters, each of which corresponds to a competing hazard used in an integrated population model

2. Summary of survey counts of independent southern sea otters for each of five coastal areas, 1998-2013

3. Summary of the number of necropsy cases assigned to nine different primary cause of death categories for southern sea otters between 1998 and 2012, for each of five coastal areas.

4. Summary of previously published southern sea otter survival and weaning success rates estimated from population studies

\section{Conversion Factors}

International System of Units to U.S. customary units

\begin{tabular}{lll}
\hline \multicolumn{1}{c}{ Multiply } & By & \multicolumn{1}{c}{ To obtain } \\
\hline \multicolumn{3}{c}{ Length } \\
\hline kilometer $(\mathrm{km})$ & 0.6214 & mile $(\mathrm{mi})$ \\
kilometer $(\mathrm{km})$ & 0.5400 & mile, nautical $(\mathrm{nmi})$ \\
kilometer/year $(\mathrm{km} / \mathrm{yr})$ & 0.6214 & mile/year $(\mathrm{mi} / \mathrm{yr})$ \\
kilometer/year $(\mathrm{km} / \mathrm{yr})$ & 0.5400 & mile, nautical/year $(\mathrm{nmi} / \mathrm{yr})$ \\
\hline
\end{tabular}




\section{Abbreviations}

\begin{tabular}{|c|c|}
\hline AN & Año Nuevo area \\
\hline C1 & Northern Channel Islands area \\
\hline C2 & Santa Catalina Island area \\
\hline C3 & San Clemente Island area \\
\hline CC & Central Coast area \\
\hline COD & cause of death \\
\hline DE & Drake's Estero area \\
\hline ELS & End Lactation Syndrome \\
\hline ES & Elkhorn Slough area \\
\hline HAB & harmful algal blooms \\
\hline HB & Half Moon Bay area \\
\hline IPM & integrated population model \\
\hline MB & Monterey Bay area \\
\hline MCMC & Markov Chain Monte Carlo \\
\hline N1 & Marin County area \\
\hline N2 & Sonoma County area \\
\hline N3 & Southern Mendocino County area \\
\hline N4 & Northern Mendocino County area \\
\hline N5 & Humboldt County area \\
\hline N6 & Del Norte County area \\
\hline PC & Point Conception area \\
\hline psrf & Potential scale reduction factor \\
\hline $\mathrm{RC}$ & Range Center area \\
\hline S1 & Ventura County area \\
\hline S2 & Los Angeles County area \\
\hline S3 & Orange County area \\
\hline S4 & Northern San Diego County area \\
\hline S5 & Southern San Diego County area \\
\hline SB & Southern Santa Barbara County area \\
\hline SF & San Francisco Bay area \\
\hline SN & San Nicolas Island area \\
\hline USGS & U.S. Geological Survey \\
\hline
\end{tabular}





\title{
An Integrated Population Model for Southern Sea Otters
}

\author{
By M. Tim Tinker, Lilian P. Carswell, Joseph A. Tomoleoni, Brian B. Hatfield, Michael D. Harris, \\ Melissa A. Miller, Megan E. Moriarty, Christine K. Johnson, Colleen Young, Laird A. Henkel, \\ Michelle M. Staedler, A. Keith Miles, and Julie L. Yee
}

\section{Abstract}

Southern sea otters (Enhydra lutris nereis) have recovered slowly from their near extinction a century ago, and their continued recovery has been challenged by multiple natural and anthropogenic factors. Development of an integrated population model (IPM) for southern sea otters has been identified as a management priority, to help in evaluating the relative impacts of known threats and guide best management options for species recovery. An IPM represents an analytical modeling framework where various types of data relevant to animal health, population trends, and survival can be evaluated collectively to project future population dynamics under different resource management scenarios. Here, we describe the development of a spatially explicit IPM for southern sea otters that is fit by using Bayesian methods to multiple datasets including a time series of range-wide survey counts, estimated survival rates of tagged animals from telemetry-based population studies, and cause-of-death data from comprehensive necropsies of beach-cast carcasses. The core of the model is a stage-structured matrix, in which survival rates for a given life history stage, year, and location are computed as the outcome of multiple 'competing risks,' or hazards, allowing for spatiotemporal variation in each hazard, density-dependence, and stochasticity. The parameterized IPM was used to (1) examine how age and sex-specific hazards vary over space and time, (2) gain insights into density-dependent variation in specific hazards, (3) assess population-level effects of known mortality hazards in the past and in future projections, and (4) evaluate the relative benefits of various potential management actions to address these hazards.

Our results indicated that different types of hazards have variable impacts at different life history stages of sea otters; for example, shark-bite mortality had a strong impact on mortality of subadult females but relatively low impacts on aged adult female survival, whereas End Lactation Syndrome showed just the opposite age-based pattern. There also was spatial and temporal variation in exposure to different hazards; for example, shark-bite mortality generally was highest at the north and south ends of the sea otter range, End Lactation Syndrome and cardiac disease were highest in the center part of the range, and harmful algal bloom intoxication and protozoal infection mortalities were highest around Morro Bay. The relative impacts of hazards depended on population density; for example, shark-bite mortality had the greatest effect on male survival when population abundance was low, but as densities increased the impacts of cardiac disease (for aged adults) and acanthocephalan peritonitis (for subadults) exceeded the effects of shark-bite mortality. Sensitivity analyses showed that modifying certain hazard rates can have substantial impacts on future population growth; for example, if the shark-bite hazard rate were to decrease by 20 percent, projected abundance after 50 years is predicted to be 18-percent higher, on average, than under baseline conditions. We used the IPM to evaluate the possible impacts of a potential management action: the reintroduction of sea otters to currently unoccupied parts of their historical range. We found that there were large increases in expected growth potential associated with reintroduction programs to various locations to the north and south of the currently occupied range, although a reintroduction to San Francisco Bay was projected to have the greatest potential impacts on future population growth.

The IPM for southern sea otters presented here provides resource managers with a useful tool for evaluating the impacts of specific hazards, forecasting future population dynamics and range expansion, and evaluating alternative management scenarios.

\section{Introduction}

Integrated Population Models (IPM) have emerged in recent years as important tools for wildlife management (Besbeas and others, 2005; Chandler and Clark, 2014). An IPM represents an analytical modeling framework where various types of data relevant to animal health, population trends, and survival can be evaluated collectively to project future population dynamics under different resource management scenarios (Rhodes and others, 2011; Schaub and Abadi, 2011). An IPM often is structured as a population projection matrix model (Caswell, 2001). What distinguishes an IPM from a more conventional population model is that the model parameters are fit to multiple independent (or semi-independent) data sources, such as survey data and 
mark-recapture survival data (Abadi and others, 2010; Tempel and others, 2014). The result is a more comprehensive and, in many cases, more robust population model that can be used to examine causes of decline, measure population-level impacts of specific threats, explore spatial patterns and metapopulation dynamics, and compare the likely efficacy of alternative management strategies (Rhodes and others, 2011; Chandler and Clark, 2014; Zipkin and Saunders, 2018).

The southern sea otter (Enhydra lutris nereis) is a sub-species of sea otter inhabiting nearshore coastal waters of California (fig. 1) that is federally listed as 'Threatened' and state listed as 'Fully Protected.' Southern sea otters (hereafter sea otter unless otherwise noted) have recovered slowly from their near-extinction a century ago, but their continued recovery has been challenged by multiple natural and anthropogenic factors (Kreuder and others, 2003, 2005; Miller and others, 2010b, c, 2020; Tinker and others, 2016a, 2019). Developing an IPM was identified as a management priority to help in evaluating the relative impacts of known threats in order to guide management options for species recovery (U.S. Fish and Wildlife Service, 2012). An IPM for sea otters should ideally utilize all available data on sea otter trends, vital rates, and mortality risk factors. A review of published information on sea otter biology and conservation suggested that a robust IPM should capture the following essential features of sea otter population biology:

(1) age and sex variation in vital rates, including density dependence and stochastic variation over time and space; (2) spatial structuring of demographic processes (semi-distinct sub-populations with demographic connectivity between sub-populations); (3) a mechanistic treatment of dispersal and range expansion over time; (4) spatially explicit information on key threats (for example, shark-bite mortality and domoic acid intoxication); (5) a biologically and analytically sound approach for integrating combined effects of threats on relevant demographic processes; and (6) appropriate levels of uncertainty in factors $1-5$.

The six requirements mentioned earlier were incorporated into an IPM that was founded on previously published examples of spatially structured sea otter population models
(Tinker and others, 2006a; U.S. Fish and Wildlife Service, 2013; Tinker, 2015). Previous sea otter population models incorporated inter-area movements and range expansion described using diffusion or integrodifference equations (Tinker and others, 2008b; Williams and others, 2017), as well as density-dependent variation in vital rates (Tinker and others, 2019; Monson and others, 2000). We expanded upon these models to create a spatially explicit IPM in which survival rates for a given year and location within California were computed as the net outcome of multiple 'competing risks' or hazards (Gerber and others, 2004; Joly and others, 2009), allowing for spatiotemporal variation in each hazard, differences among age and sex classes in the relative effects of hazards, density-dependence, and stochasticity. We then fit the model to multiple datasets that included a time series of range-wide survey counts (Tinker and Hatfield, 2017), estimated survival rates of tagged animals from various telemetry-based population studies (Tinker and others, 2017a, 2019), and cause-of-death data from comprehensive necropsies carried out for beach-cast carcasses collected throughout the mainland range between 1998 and 2012 (Miller and others, 2020). By differentiating mortality into specific causes of death, it is possible to evaluate and compare the population-level impacts of increases or decreases in specific risk factors (Rhodes and others, 2011). The explicit incorporation of spatial structure improves model performance and allows for evaluation of management scenarios applied to specific locations (Chandler and Clark, 2014).

Herein, we describe the formulation and fitting of an IPM for southern sea otters. The IPM can be used to (1) examine how age and sex-specific hazards vary over space and time, (2) gain insights into density-dependence and correlations among various hazards, (3) assess population-level effects of known mortality hazards both in the past and in future projections, and (4) evaluate and compare the relative impacts of modifying specific hazards to help support decision making. 


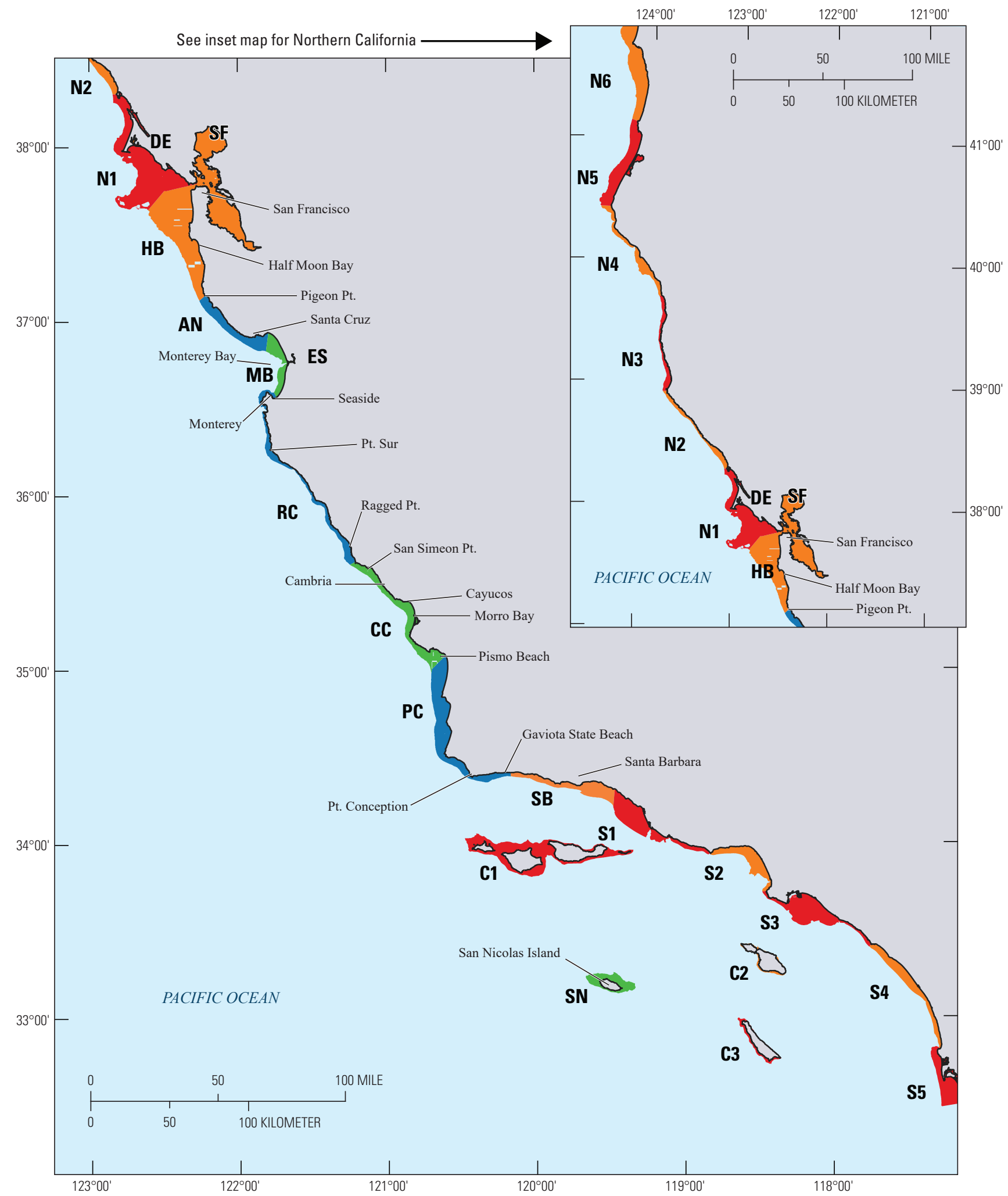

Figure 1. The coast of California showing current and potential habitat of southern sea otters (Enhydra lutris nereis): inset map shows the coast north of San Francisco Bay. The spatial distribution of 25 coastal habitat areas (used for tracking abundance over time in an integrated population model, IPM) are shown as color-coded polygons, labeled with two-letter codes in bold typeface. Sea otter populations are currently established in subpopulation areas Año Nuevo (AN), Monterey Bay (MB), Elkhorn Slough (ES), Range Center (RC), Central Coast (CC), Point Conception (PC) and San Nicolas Island (SN; blue and green polygons), and the remaining coastal areas (red and orange polygons) represent historical sea otter habitat that is currently unoccupied. 


\section{Methods}

\section{Overview}

The sea otter IPM was structured as a projection matrix model (Caswell, 2001) that tracks abundance of six distinct life history stages: $1=$ subadult females, $2=$ adult females, $3=$ aged adult females, $4=$ subadult males, $5=$ adult males, $6=$ aged adult males. The subadult age class includes animals from post-weaning ( 6 months) through 3 years, the adult age class spans $4-10$ years, and the aged adult class includes animals more than 10 years. We incorporated spatial structure by dividing the mainland population into semi-distinct sub-populations, delineated by a contiguous series of coastal areas, $a$, each of which was large enough to encompass sufficient sample sizes of data (annual population counts of greater than or equal to 100 animals and greater than or equal to 2 cases for each cause of death) but small enough to be considered a demographically homogenous unit (fig. 1). Demographic processes within each area were tracked by sub-matrices that form the diagonal of a larger "metapopulation matrix" that also accounts for dispersal of animals among areas (Caswell, 2001). Vital rates for area $a$ (reproduction, survival, and growth transitions; fig. 2) were computed as functions of density and, for survival and growth, functions of exposure to multiple competing hazards (Heisey and Patterson, 2006; Joly and others, 2009) that can vary over time (fig. 3). Dispersal of animals between areas was determined by stage-specific movement rates (measured from radio-tagged study animals) and the pairwise distances between areas. These steps comprise a process model that predicts metapopulation dynamics and cause-specific mortality rates. Model predictions are then compared to several independent empirical datasets (fig. 3) by using Bayesian Markov Chain Monte Carlo (MCMC) methods to find the parameter values (table 1.1) for the process model most likely to have produced the observed data. Using the fitted demographic model, we then projected future population dynamics, while accounting for covariation between multiple causes of death, environmental stochasticity, density dependence, and dispersal of animals between areas.

\section{Data Availability Statement}

All datasets used as part of the development, fitting, and application of the sea otter IPM are available from previous publications or as part of publicly available data repositories, including survey data on sea otter distribution and abundance (Hatfield and others, 2018a); sea otter mortality and cause-of-death data (Hatfield and others, 2017; Miller and others, 2020); data on sea otter movements (Tinker and others, 2016b); and estimates of location-specific and time-specific sea otter survival rates and weaning success rates (Tinker and others, 2017a, b, 2019, 2021).

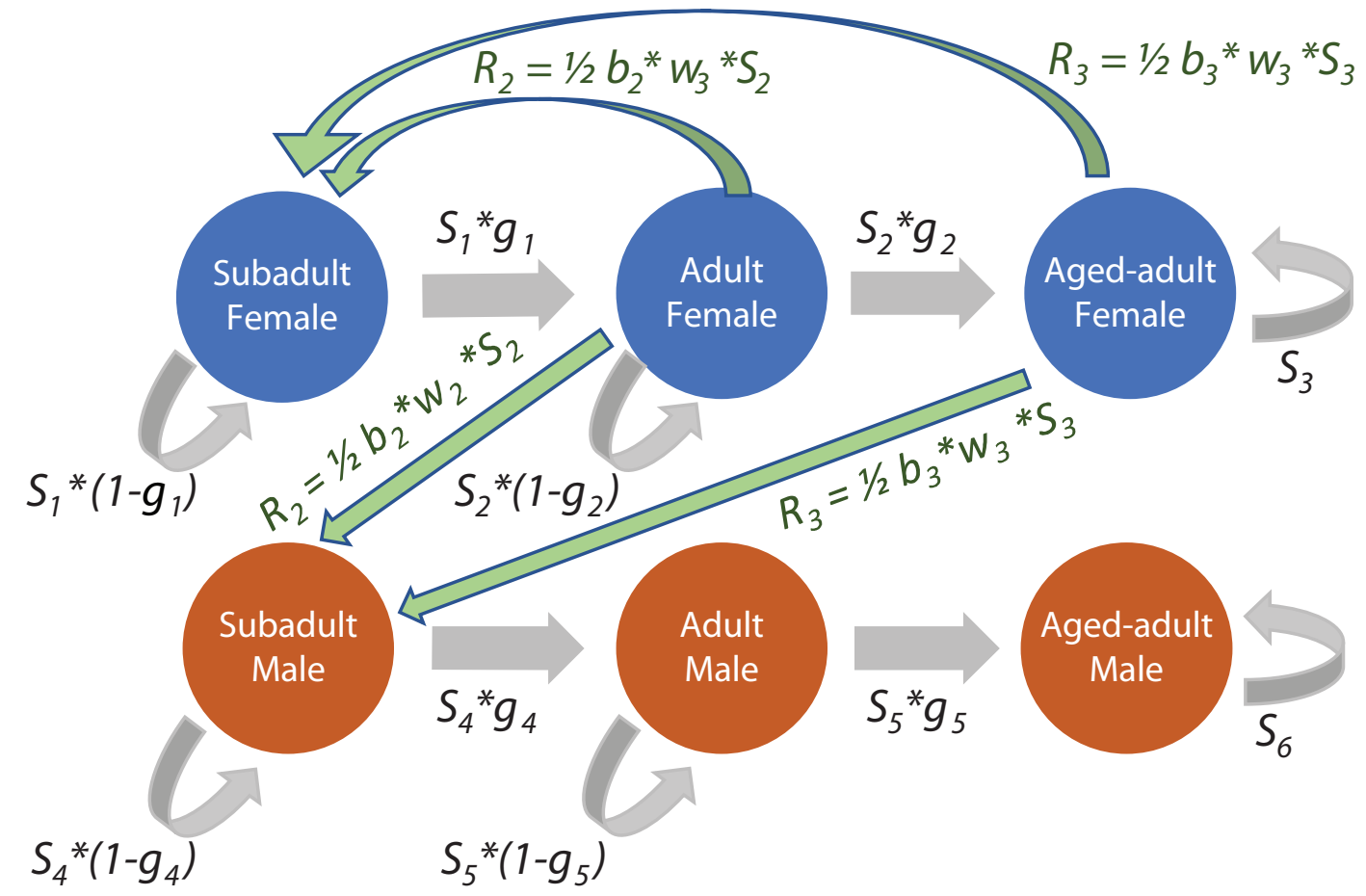

Figure 2. Stylized loop diagram illustrating the life history stages (colored circles) and demographic transitions (arrows) tracked as part of an integrated population model for southern sea otters. The formulas for the rate of each transition are shown adjacent to each arrow, with alphanumeric symbols corresponding to vital rates that are estimated as parameters (table 1.1) in the integrated population model. 


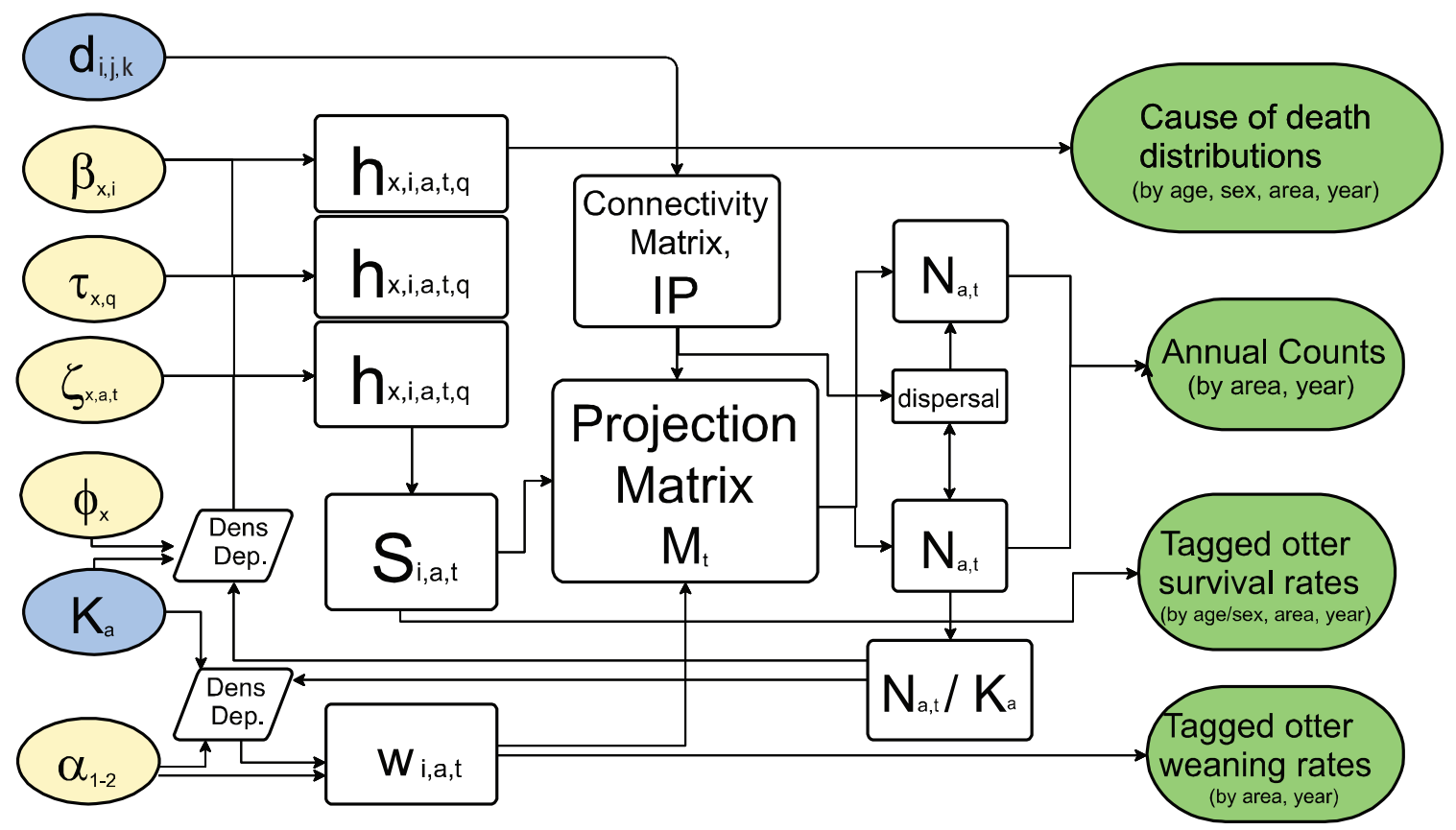

Figure 3. The conceptual framework for an integrated population model (IPM) for southern sea otters. Geometric shapes are used to represent (1) base parameters of the model (blue and yellow-shaded ovals at left); (2) derived parameters and latent variables (hollow polygons at center) that are computed from the base parameters as part of the process model; and (3) observed data variables (green shaded ovals at right) that are used for fitting the model. Refer to the "Methods" section or table 1.1 for full descriptions of each parameter (indicated by Greek or Roman letter codes), variable, and dataset. Connecting arrows indicate the functional relationships between parameters, latent variables and observed data which are described by equations in the text. In the case of base parameters, the yellow-shaded ovals represent parameters that were estimated as part of the current analysis, and blue-shaded ovals represent parameters whose values were estimated as part of previously published analyses. Abbreviation: Dens dep, density dependent effects. 


\section{Process Model: Structure and Dynamics}

We estimated survival rates of sea otters using a proportional hazards model that differentiates sea otter mortality into multiple competing hazards (Heisey and Patterson, 2006; Joly and others, 2009), which we define operationally in terms of primary cause of death (COD) as would be assessed by a veterinary pathologist at time of necropsy. We note that there are a large number of specific COD diagnoses, and in many cases the necropsies of individual animals reveal multiple contributing COD (Miller and others, 2020). However, for reasons of sample size and computational tractability, we defined nine COD categories - some of which correspond to a single, distinct cause of death and others that represent collections of generally similar diagnoses - which we considered exhaustive and mutually exclusive for the purpose of this analysis and which spanned the full range of known mortality causes for sea otters (table 1). Because the frequency of different COD can vary seasonally (Miller and others, 2020), we modeled the dynamics of mortality using a 3-month time step, with four seasonal quarters $(q)$ comprising one annual time step $(t)$ spanning January 1-December 31 . We define $h_{0}$ as the "baseline" hazard rate (accounting for minimal levels of mortality in the absence of any other cause-specific hazards) and we set this to an arbitrarily low value $\left(h_{0}=0.0005\right)$, noting that this is a nuisance parameter to facilitate data fitting and parameter interpretability, rather than a distinct cause of death (Heisey and Patterson, 2006). Cause-specific hazard rates $\left(h_{x}\right.$, where $x=1,2, \ldots, 9)$ are then defined as the rates of mortality from a single type of hazard. For analytical tractability, we work with log-transformed hazard ratios, $\gamma$, where a hazard ratio greater than 1 (log hazard ratio greater than 0$)$ represents an increase in the hazard of death due to COD $x$ relative to baseline hazards, $h_{0}$. We calculate the cause-specific log hazard ratio for a given COD $x$, for an otter of stage $i$ in area $a$ at year $t$ and in season $q$ in equation 1 as:

$$
\gamma_{x, i, a, t, q}=\beta_{x, i}+\phi_{x} \cdot\left(\frac{N_{a, t}}{K_{a}}\right)+\tau_{x, q}+\zeta_{x, a, t}
$$

where

$\beta_{x, i} \quad$ determines the average hazard due to COD $x$ for individuals of stage $i$ at low population densities,

$N_{a, t} \quad$ is population density in area $a$ at year $t$,

$K_{a} \quad$ is population density at carrying capacity in area $a$,

$\phi_{x} \quad$ determines additional density-dependent impacts on hazard due to COD $x$ (the degree to which mortality from the cause-specific hazard increases as $N_{a, t}$ increases toward $K_{a}$ ),

$\tau_{x, q} \quad$ is a random effect, with mean 0 and standard deviation $\sigma_{t}$, that describes seasonal variation in hazard due to COD $x$ in season $q$, and $\zeta_{x, a, t} \quad$ is a random effect, with mean 0 and standard deviation $\sigma_{\zeta}$, that describes annual variation in hazard due to COD $x$ in area $a$ at year $t$.

The variables $\beta_{x, i}, \phi_{x}$, and standard deviations of both random effects $\left(\sigma_{t}\right.$ and $\left.\sigma_{\zeta}\right)$ are treated as parameters to be fit. The formulation of equation 1 allows for variability in the magnitude of relative impacts of each type of hazard for each life history stage, differing magnitudes and patterns of variation in hazards over time and space, and differing degrees of density-dependent variation in each COD. Values of area-specific carrying capacity $\left(K_{a}\right)$ were based on the results of a separate study (Tinker and others, 2021).

We next use the log hazard ratios to define cause-specific hazard rates in equation 2 :

$$
h_{x, i, a, t, q}=\exp \left(\gamma_{0}+\gamma_{x, i, a, t, q}\right)
$$

where

$$
\begin{gathered}
\gamma_{0} \quad \text { is the log of the baseline hazard, } h_{0} \text {, and } \\
\gamma_{x, i, a, t, q} \quad \text { is the cause-specific log hazard ratio of } \\
\text { COD } x \text { for a stage } i \text { otter in area } a \text { at year } \\
t \text { and season } q \text {, relative to the baseline } \\
\text { hazard } \left.\gamma_{0} \text { (eq. } 1\right) .
\end{gathered}
$$

Although the cause-specific hazard rates, $h_{x, i, a, t, q}$, are unmeasurable quantities (Heisey and Patterson, 2006), these formulas are useful for defining both the frequency distribution of observed COD cases and the cumulative mortality from all hazards and thereby realized survival rates. Specifically, the relative probability that a randomly selected carcass of stage $i$ in area $a$ at year $t$ and in season $q$ has died from COD $x$ is defined in equation 3:

$$
\pi_{x, i, a, t, q}=\frac{h_{x, i, a, t, q}}{\sum_{x} h_{x, i, a, t, q}}
$$

where

$$
h_{x, i, a, t, q} \quad \text { is the hazard rate for COD } x \text { for a stage } i \text { otter }
$$
in area $a$ at time $t$ and season $q$ (eq. 2).

The annual survival probability for an otter of stage $i$ in area $a$ at year $t$ is defined in equation 4 as:

$$
S_{i, a, t}=\exp \left(-\sum_{q} \sum_{x} h_{x, i, a, t, q}\right)
$$

where

$$
\begin{aligned}
& h_{x, i, a, t, q} \quad \text { is the hazard rate for COD } x \text { for a } \\
& \text { stage } i \text { animal in area } a \text { at time } t \text { and } \\
& \text { season } q \text { (eq. 2). }
\end{aligned}
$$

Equations 3 and 4 describe derived parameters that can then be compared with observed data as part of model fitting (see "Data Model" and "Model Fitting and Evaluation" sections). 
Table 1. Descriptions of nine categories of cause of death (COD) for southern sea otters, each of which corresponds to a competing hazard used in an integrated population model.

[Also shown are the specific primary COD diagnoses that contribute to each category, as well as the number of necropsy cases documented for each diagnosis. Abbreviation: HAB, harmful algal bloom]

\begin{tabular}{|c|c|}
\hline COD specific (primary) & Case count \\
\hline \multicolumn{2}{|l|}{ Shark_Bite } \\
\hline Shark bite (presumed or confirmed) & 156 \\
\hline \multicolumn{2}{|l|}{ End_Lactation } \\
\hline End Lactation Syndrome & 42 \\
\hline \multicolumn{2}{|l|}{ HAB_Intoxication } \\
\hline Domoic acid intoxication- probable & 52 \\
\hline Domoic acid intoxication- possible & 8 \\
\hline Microcystin intoxication- possible & 5 \\
\hline \multicolumn{2}{|l|}{ Cardiac_Disease } \\
\hline Cardiomyopathy & 44 \\
\hline Other cardiac disease & 1 \\
\hline \multicolumn{2}{|l|}{ Protozoal_Infection } \\
\hline Systemic protozoal infection (Sarcocystis neurona) & 33 \\
\hline Systemic protozoal infection (Sarcocystis neurona + Toxoplasma gondii) & 11 \\
\hline Systemic protozoal infection (Toxoplasma gondii) & 6 \\
\hline \multicolumn{2}{|l|}{ Acantho_Peritonitis } \\
\hline Acanthocephalan peritonitis & 61 \\
\hline \multicolumn{2}{|l|}{ Infection_Other } \\
\hline Primary bacterial infection & 33 \\
\hline Coccidioidomycosis & 9 \\
\hline Viral infection & 3 \\
\hline \multicolumn{2}{|l|}{ Natural_Causes } \\
\hline Fight trauma & 11 \\
\hline Mating trauma & 9 \\
\hline Gastroenterocolitis & 8 \\
\hline Gastrointestinal (GI) impaction/displacement & 8 \\
\hline Neoplasia & 5 \\
\hline Trauma-unidentified & 5 \\
\hline Dental disease & 3 \\
\hline Brain and spinal cord disease (undetermined cause) & 2 \\
\hline Hepatic, renal, and myocardial lipidosis/hepatopathy & 2 \\
\hline Emaciation/starvation & 1 \\
\hline Abortion and uterine torsion & 1 \\
\hline Miscellaneous & 1 \\
\hline Undetermined & 1 \\
\hline \multicolumn{2}{|l|}{ Human_Caused } \\
\hline Direct anthropogenic & 34 \\
\hline Medical complication & 5 \\
\hline
\end{tabular}


In addition to estimates of survival, the IPM requires estimates of reproductive rates, including density-dependent variation in fecundity. Female sea otters contribute to recruitment by giving birth to a single pup and then successfully weaning it as an independent subadult, which usually occurs after a 6-month dependency period (Jameson and Johnson, 1993). It has been found that birth rates $(b)$ are relatively invariant, with most females giving birth to one pup per year after reaching reproductive maturity (approximately 3-4 years of age), although birth rates decline for older females; in contrast, weaning success rates $(w)$ are highly variable and tend to decline as populations approach $K$ (Monson and others, 2000). In equation 5, we calculate the weaning success rate for a reproductive female in area $a$ and at year $t$ as:

$$
w_{a, t}=\exp \left(-\alpha_{1} \cdot \exp \left(\alpha_{2} \cdot\left[\frac{N_{a, t}}{K_{a}}\right]^{\frac{1}{2}}+\varepsilon_{a, t}\right)\right)
$$

where

$$
\begin{aligned}
& N_{a, t} \quad \text { is population density in area } a \text { at year } t \text {, } \\
& K_{a} \text { is population density at carrying capacity in area } a \text {, } \\
& \alpha_{1} \text { and } \alpha_{2} \quad \text { determine (respectively) the intercept and shape of the functional relationship between weaning rate and local } \\
& \text { population density with respect to carrying capacity }\left(N_{a, t} / K_{a}\right) \text {, and } \\
& \varepsilon_{a, t} \quad \text { is a random effect, with mean } 0 \text { and standard deviation } \sigma_{\varepsilon} \text {, that describes environmental stochasticity in area } a \\
& \text { at year } t \text {. }
\end{aligned}
$$

The variables $\alpha_{1}, \alpha_{2}$, and $\sigma_{\varepsilon}$ are treated as parameters to be fit. We structured equation 5 such that the weaning rate must vary between 0 and 1 and will decline with increasing density so long as $\alpha_{1}$ and $\alpha_{2}$ are constrained to be greater than 0 (the absolute values and rate of decline with density are completely flexible). We assume that only adult and aged adult females produce pups, with annual birth rates of 0.98 pups per adult female and 0.85 pups per aged adult female ( $b_{2}$ and $b_{3}$ in eq. 6 , respectively), based on previously published estimates (Riedman and others, 1994; Gerber and others, 2004; Tinker and others, 2006a; Staedler, 2011), and we assume weaning rate is equivalent for adult and aged adult females.

Estimated vital rates are used to parameterize projection matrix $A_{a, t}$, which describes demographic transitions between sex and age classes within area $a$ from year $t$ to year $t+1$. Equation 6 displays transition rates among six stages: (1) subadult females, (2) adult females, (3) aged adult females, (4) subadult males, (5) adult males, and (6) aged adult males, in a $6 \times 6$ matrix where the $i^{\text {th }}$ column and $j^{\text {th }}$ row element represents the contribution of stage $i$ otters in year $t$ to stage $j$ otters in year $t+1$ :

$$
A_{a, t}=\left[\begin{array}{cccccc}
S_{1} \cdot\left(1-g_{1}\right) & \frac{b_{2}}{2} \cdot w \cdot S_{2} & \frac{b_{3}}{2} \cdot w \cdot S_{3} & 0 & 0 & 0 \\
S_{1} \cdot g_{1} & S_{2} \cdot\left(1-g_{2}\right) & 0 & 0 & 0 & 0 \\
0 & S_{2} \cdot g_{2} & S_{3} & 0 & 0 & 0 \\
0 & \frac{b_{2}}{2} \cdot w \cdot S_{2} & \frac{b_{3}}{2} \cdot w \cdot S_{3} & S_{4} \cdot\left(1-g_{4}\right) & 0 & 0 \\
0 & 0 & 0 & S_{4} \cdot g_{4} & S_{5} \cdot\left(1-g_{5}\right) & 0 \\
0 & 0 & 0 & 0 & S_{5} \cdot g_{5} & S_{6}
\end{array}\right]
$$

where subscripts for area $a$ at year $t$ are implied for $S_{i}, g_{i}$, and $w$ but have been dropped from the matrix for clarity of presentation,

$S_{i} \quad$ is the probability of survival at stage $i\left(S_{i, a, t}\right.$ in eq. 4$)$,

$g_{1} \quad$ is the probability of a subadult female transitioning to an adult female (eq. 7),

$g_{2}$ is the probability of an adult female transitioning to an aged adult female (eq. 7),

$g_{4}$ is the probability of a subadult male transitioning to an adult male (eq. 7),

$g_{5} \quad$ is the probability of an adult male transitioning to an aged adult male (eq. 7),

$b_{2} \quad$ is the rate of pup births per adult female (assumed 0.98),

$b_{3} \quad$ is the rate of pup births per aged adult female (assumed 0.85), and

$w \quad$ is the rate of pup weaning ( $w_{a, t}$ in eq. 5). 
Equation 6 is a standard two-sex projection matrix (Caswell, 2001), and we note that reproductive contributions of adult and aged adult females (columns 2 and 3 ) to the subadult age classes (rows 1 and 4) assume a 1:1 sex ratio at birth and were conditional upon survival of the mothers (the mother must survive the 6-month gestation followed by a 6-month pup dependency period in order to produce an independent subadult at the start of the next year). To estimate the probabilities of transitioning from the subadult to adult stage $\left(g_{1}\right.$ and $\left.g_{4}\right)$ or from the adult to aged adult stage ( $g_{2}$ and $g_{5}$ ), we used a standard equation (eq. 7) for fixed-duration age classes (Caswell, 2001):

$$
g_{i}=\left(\frac{\left(\frac{S_{i}}{\lambda}\right)^{T_{i}}-\left(\frac{S_{i}}{\lambda}\right)^{T_{i}-1}}{\left(\frac{S_{i}}{\lambda}\right)^{T_{i}}-1}\right)
$$

where subscripts for area $a$ at year $t$ are implied for $g_{i}, S_{i}$, and $\lambda$, but have been dropped here for clarity of presentation,

$S_{i} \quad$ is the probability of survival at stage $i\left(S_{i, a, t}\right.$ in eq. 4),

$\lambda \quad$ is the annual rate of population growth (associated with matrix $A_{a, t}$, eq. 6), and

$T_{i} \quad$ represents duration (in years) an otter is in stage $i$.

Because the subadult stage spans from post-weaning (6 months) to 3 years, adults $4-10$ years, and aged adults more than 10 years, we assigned $T_{1}=T_{4}=3$ and $T_{2}=T_{5}=7$. Equations 6 and 7 must be solved iteratively: the value of $\lambda$ in equation 7 is initially set to 1 , the resulting value of $g_{i}$ is used to parameterize and solve equation $6, \lambda$ is re-computed as the dominant eigenvalue of $A_{a, t}$ and used to re-parameterize equation 7 , and the calculations repeated until the value of $\lambda$ stabilizes to 2 decimal places.

The subpopulations of each coastal area are embedded within a larger population. We next scale the projection model from the subpopulation level to the population level by using familiar techniques for scaling from population projection models to metapopulation projection models (Caswell, 2001). For clarity of distinction between smaller and larger scales, we refer to the entire southern sea otter population as a metapopulation. Mathematically, the spatial structure of the coastal areas is accommodated by taking the block diagonal of matrix $A_{a, t}$ across $P$ different subpopulations (eq. 8):

$$
L_{t}=\left[\begin{array}{cccc}
A_{1, t} & \varnothing & \cdots & \varnothing \\
\varnothing & A_{2, t} & \cdots & \varnothing \\
\vdots & \vdots & \ddots & \vdots \\
\varnothing & \varnothing & \cdots & A_{P, t}
\end{array}\right]
$$

where

$$
\begin{aligned}
& A_{a, t} \quad \begin{array}{l}
\text { is the projection matrix for area } a \text { at year } t, \text { for } \\
a=1, \ldots, P(\text { eq. } 6), \text { and }
\end{array} \\
& \varnothing \quad \text { represents a } 6 \text { x6 matrix of zeros. }
\end{aligned}
$$

To allow for stage-specific dispersal between subpopulations, we define an inter-subpopulation connectivity matrix, $I P$, which is a block matrix with the same dimensions as $L_{t}$ (eq. 9):

$$
I P=\left[\begin{array}{cccc}
D_{1,1} & D_{2,1} & \cdots & D_{P, 1} \\
D_{1,2} & D_{2,2} & \cdots & D_{P, 2} \\
\vdots & \vdots & \ddots & \vdots \\
D_{1, P} & D_{2, P} & \cdots & D_{P, P}
\end{array}\right]
$$

where

$$
\begin{gathered}
D_{j, k} \quad \text { is a } 6 \times 6 \text { diagonal matrix (eq. 10) describing } \\
\text { stage-specific contributions of otters from } \\
\text { area } j \text { dispersing to area } k \text { (eq. 10): }
\end{gathered}
$$

$$
D_{j, k}=\left[\begin{array}{cccccc}
d_{1, j, k} & 0 & 0 & 0 & 0 & 0 \\
0 & d_{2, j, k} & 0 & 0 & 0 & 0 \\
0 & 0 & d_{3, j, k} & 0 & 0 & 0 \\
0 & 0 & 0 & d_{4, j, k} & 0 & 0 \\
0 & 0 & 0 & 0 & d_{5, j, k} & 0 \\
0 & 0 & 0 & 0 & 0 & d_{6, j, k}
\end{array}\right]
$$

where

$$
\begin{aligned}
& d_{i, j, k} \quad \text { is the probability that a stage } i \text { otter in area } j \\
& \text { at one time step is in area } k \text { at the next } \\
& \text { time step. }
\end{aligned}
$$

When $j \neq k$, the value $d_{i, j, k}$ is the probability of movement from area $j$ to area $k$ in any given time step, and, when $j=k$, then $d_{i, j, k}$ is the probability of remaining in area $j$ over the time step.

We calculated $d_{i, j, k}$ following previously described methods (Tinker and others, 2008b, 2019), and we specifically (1) fit Weibull probability density functions to published data on annual net displacement distances of radio-tagged sea otters (Tinker and others, 2016b), classified by age and sex; (2) evaluated the Weibull density functions at the inter-centroid distances of all pairwise combinations of areas where $j \neq k$; (3) rescaled the resulting probability densities to sum to 1 for each value of $j$; and (4) multiplied the rescaled probability densities by $\left(1-\theta_{i, j}\right)$, where $\theta_{i, j}$ is the probability that an otter of stage $i$ remains within its current area and is calculated as the cumulative Weibull distribution function evaluated at the distance between the centroid of area $j$ and the boundary of the nearest neighboring area. In the case of $j=k$, we set $d_{i, j, k}=\theta_{i, j}$, so that column sums of matrix $I P=1$. 
To describe annual dynamics of the entire metapopulation, including both demographic transitions and dispersal, we took the matrix product of $L$ and $I P$ (Caswell, 2001) to create meta-population projection matrix $M_{t}$ (eq. 11):

$$
M_{t}=I P \times L_{t}
$$

where

IP is the inter-subpopulation connectivity matrix for dispersals (eq. 9), and

$L_{t} \quad$ is the demographic stage transitions matrix at year $t$ (eq. 8).

Annual population dynamics were computed using standard methods of matrix multiplication (eq. 12):

$$
[n]_{t+1}=M_{t} \times[n]_{t}
$$

where

$M_{t} \quad$ is the integrated metapopulation projection matrix at year $t$ (eq. 11), and

$[n]_{t} \quad$ is a metapopulation vector defined as a vertical numeric array of length $6 P$, comprised of $P$ vectors, $\left[n_{a}\right]_{t}$ indexed to area $a$ for areas $a=1,2, \ldots P$, with each of these vectors having 6 elements, $n_{i, a, t}$ equal to the number of individuals of stage $i$ in area $a$ at time $t$.

Lastly we defined $N_{a, t}$ as the total expected number of otters in area $a$ at year $t$, derived as the sum of the elements of $\left[n_{a}\right]_{t}$ except for the first timestep $(t=1)$ where $N_{a, 1}$ was treated as a fitted parameter.

\section{Data Model}

The process model predicts dynamics of four key latent variables, calculated as derived parameters: $N_{a, t}$ (expected abundance by area and year), $\bar{\psi}_{x, i, a, t, q}$ (proportional mortality by COD, for a given stage, area, year and season), $S_{i, a, t}$ (stage-specific survival rates by area and year) and $w_{a, t}$ (weaning success rates by area and year). To fit the IPM model, we compare these latent variables to four observed datasets: (1) sea otter survey counts, (2) carcass COD distributions, (3) survival rates of radio-tagged study animals (across multiple field studies), and (4) weaning success rates of radio-tagged animals (fig. 3).

In the case of abundance, we used annual range-wide survey data for sea otters along the mainland coast of California (Tinker and Hatfield, 2017) to extract counts of independent sea otters by area and year $\left(C_{a, t}\right)$. These counts (table 2) were assumed to follow a negative binomial distribution as parameterized in Plummer, 2017 (eq. 13):

$$
C_{a, t} \sim \operatorname{Negative~binomial}\left(\operatorname{probability}=\frac{N_{a, t}}{V_{a, t}}, \text { size }=\frac{N_{a, t}^{2}}{V_{a, t}-N_{a, t}}\right)
$$

where

$N_{a, t} \quad$ is the expected sea otter abundance in area $a$ at year $t$, and

$V_{a, t} \quad$ is the variance in counts due to detection error in area $a$ at year $t$.

Previous analyses (Tinker and others, 2021) have reported that sea otter survey counts are over-dispersed relative to a Poisson distribution (variance is greater than mean), but that the degree of over-dispersion varies by coastal area. Accordingly, we treated the variance inflation factor $(\psi)$ as a spatially varying random effect (eq. 14):

$$
V_{a, t}=\psi_{a} \cdot N_{a, t}
$$

where

$$
\begin{aligned}
& N_{a, t} \text { is the expected sea otter abundance in area } a \text { at year } t \text {, and } \\
& \psi_{a} \text { is a random effect, with mean } \bar{\psi} \text { and standard deviation } \sigma_{\psi} \text {, that describes spatial variation in the variance } \\
& \text { inflation factor, } V_{a, t} / N_{a, t} \text {, in area } a .
\end{aligned}
$$

In equation $14, \bar{\psi}$ and $\sigma_{\psi}$ are model parameters to be fit, subject to the constraint that $\bar{\psi}$ is greater than 1 and the normal distribution for $\psi_{a}$ is truncated with lower bound equal to 1 . 
Table 2. Summary of survey counts of independent (non-pup) southern sea otters (Enhydra lutris nereis) for each of five coastal areas, 1998-2013.

[Refer to figure 1 for geographic locations and extent of each coastal area. Note that other coastal areas along the mainland are not systematically surveyed but are assumed not to have consistent occupation by sea otters at the current time. Survey counts for San Nicolas Island are not shown here as they were not used for integrated population model fitting (the 2019 survey estimate from San Nicolas Island was used for parameterizing future simulations). Abbreviations: AN, Año Nuevo; MB, Monterey Bay; RC, Range Center; CC, Central Coast; PC, Point Conception]

\begin{tabular}{lrrrrr}
\hline \multirow{2}{*}{ Year } & \multicolumn{5}{c}{ Coastal area } \\
\cline { 2 - 6 } & AN & MB & RC & CC & PC \\
\hline 1998 & 126 & 102 & 955 & 523 & 249 \\
1999 & 153 & 96 & 830 & 530 & 249 \\
2000 & 148 & 122 & 917 & 583 & 283 \\
2001 & 119 & 104 & 973 & 573 & 94 \\
2002 & 131 & 170 & 931 & 502 & 112 \\
2003 & 282 & 353 & 926 & 578 & 131 \\
2004 & 195 & 230 & 1,006 & 839 & 225 \\
2005 & 180 & 201 & 1,071 & 700 & 265 \\
2006 & 170 & 183 & 923 & 803 & 290 \\
2007 & 154 & 307 & 1,050 & 745 & 381 \\
2008 & 203 & 228 & 1,033 & 577 & 393 \\
2009 & 173 & 206 & 939 & 616 & 329 \\
2010 & 210 & 218 & 839 & 782 & 403 \\
2012 & 214 & 322 & 1,044 & 652 & 254 \\
2013 & 160 & 271 & 1,155 & 634 & 224 \\
\hline
\end{tabular}

The results of a recent comprehensive necropsy analysis of 560 fresh sea otter carcasses (Miller and others, 2020) were used as observed data for cause-of-death distributions (table 3). We assumed that the frequency distribution of primary COD category for this large sample of minimally decomposed carcasses was described by a multinomial distribution (eq. 15):

$$
\left[Z_{1, i, a, t, q}, Z_{2, i, a, t, q} \ldots Z_{9, i, a, t, q}\right] \sim \operatorname{Multinomial}\left(\text { probabilities }=\left[\pi_{1, i, a, t, q}, \pi_{2, i, a, t, q} \ldots \pi_{9, i, a, t, q}\right] \text {, size }=\sum_{x} Z_{x, i, a, t, q}\right. \text { ) }
$$

where

$Z_{x, i, a, t, q} \quad$ is the number of observed cases for each COD $x$ for stage $i$ in area $a$ in year $t$ and season $q$, and

$\pi_{x, i, a, t, q} \quad$ is the probability that a stage $i$ animal observed dead in area $a$ at year $t$ in season $q$ was classified as having died by COD $x$ (eq. 3). 


\section{An Integrated Population Model for Southern Sea Otters}

Table 3. Summary of the number of necropsy cases assigned to nine different primary cause of death (COD) categories for southern sea otters between 1998 and 2012, for each of five coastal areas.

[Refer to figure 1 for geographic locations and extent of each coastal area, and to table 1 for COD definitions. Abbreviations: AN, Año Nuevo; MB, Monterey Bay; RC, Range Center; CC, Central Coast; PC, Point Conception]

\begin{tabular}{lcccrrrrrrr}
\hline Coastal area & Total cases & COD1 & COD2 & COD3 & COD4 & COD5 & COD6 & COD7 & COD8 & COD9 \\
\hline AN & 67 & 33 & 3 & 6 & 2 & 5 & 2 & 2 & 10 & 4 \\
MB & 143 & 31 & 4 & 19 & 12 & 18 & 20 & 14 & 13 & 12 \\
RC & 106 & 13 & 21 & 6 & 12 & 3 & 15 & 9 & 16 & 11 \\
CC & 149 & 36 & 12 & 21 & 13 & 16 & 21 & 10 & 12 & 8 \\
PC & 95 & 43 & 2 & 13 & 6 & 8 & 3 & 10 & 6 & 4 \\
\hline
\end{tabular}

Observed data on survival and weaning success rates of sea otters were available from a number of mark-recapture population studies in California over the past several decades (Tinker and others, 2006b, 2017a, 2019). Analyses of the individual survival and reproductive histories of tagged study animals were performed previously using Bayesian proportional hazards survival analysis, resulting in posterior distributions of estimated stage-specific survival and weaning success rates for a subset of study areas and years between 1998 and 2012 (table 4). After logit-transforming the vital rate posterior distributions to normalize them, we computed means and standard deviations of logit-transformed observed survival $\left(\lg S_{i, a, t}^{o b s}\right.$ and $\left.\sigma_{s, i, a, t}\right)$ and observed weaning rates $\left(\lg w_{a, t}^{o b s}\right.$ and $\left.\sigma_{w, i, a, t}\right)$. We assumed that $\lg S_{i, a, t}^{o b s}$ and $\lg w_{a, t}^{o b s}$ were drawn from normal distributions with means corresponding to the logit-transformed survival and weaning rates described by equations 4 and 5 of the process model (eqs. 16, 17):

$$
\lg S_{i, a, t}^{\text {obs }} \sim \operatorname{Normal}\left(\text { mean }=\operatorname{logit}\left(S_{i, a, t}\right), \mathrm{SD}=\sigma_{s, i, a, t}\right)
$$

where

$S_{i, a, t} \quad$ is the probability of survival at stage $i$ in area $a$ at year $t$ (eq. 4), and

$\sigma_{s, i, a, t}$ is the standard deviation (SD) of the posterior distribution of the logit-transformed observed survival rates;

and

$$
\lg w_{a, t}^{o b s} \sim \operatorname{Normal}\left(\text { mean }=\operatorname{logit}\left(w_{a, t}\right), \mathrm{SD}=\sigma_{w, a, t}\right)
$$

where
$w_{a, t} \quad$ is the rate of pup weaning in area $a$ at year $t$ (eq. 5), and
$\sigma_{w, a, t}$ is the standard deviation (SD) of the posterior distribution of the logit-transformed observed weaning rates.

In equations 16 and 17, the standard deviation parameters $\left(\sigma_{s, i, a, t}\right.$ and $\left.\sigma_{w, a, t}\right)$ are not parameters to be fit, but rather represent the parameter estimation uncertainties associated with the original analyses of survival and weaning success. 
Table 4. Summary of previously published southern sea otter (Enhydra lutris nereis) survival (S) and weaning success rates (w) estimated from population studies.

[Vital rate estimates and logit-transformed values (mean and standard deviation) are based on Bayesian proportional hazards survival analysis of mark-recapture data (refer to cited references for details, full citations at bottom). Estimates are shown for 6 life history stages: $1=$ subadult females, $2=$ adult females, $3=$ aged adult females, $4=$ subadult males, $5=$ adult males, $6=$ aged adult males. Abbreviation: SD, standard deviation]

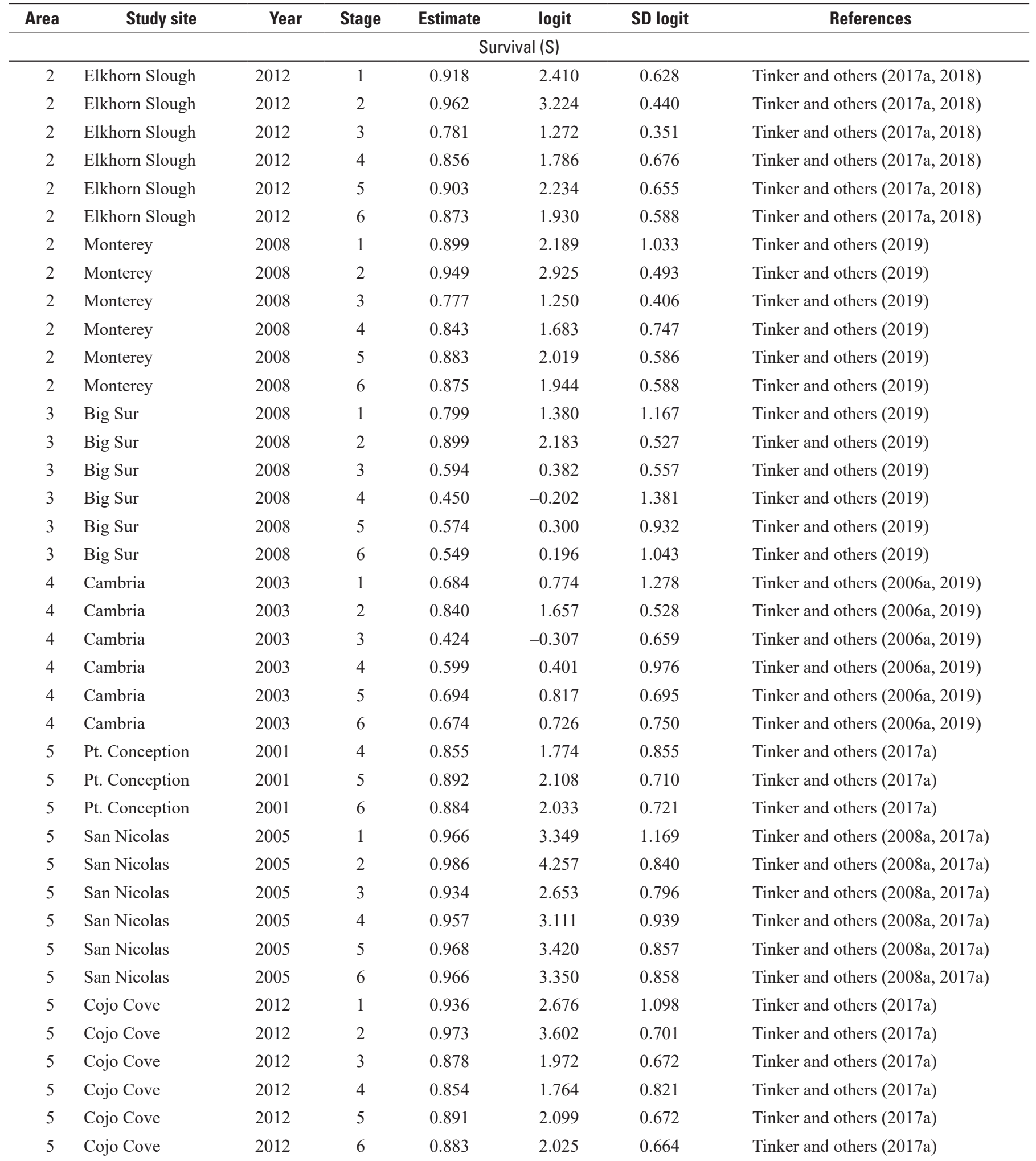


Table 4. Summary of previously published southern sea otter (Enhydra lutris nereis) survival (S) and weaning success rates (w) estimated from population studies.-Continued

[Vital rate estimates and logit-transformed values (mean and standard deviation) are based on Bayesian proportional hazards survival analysis of mark-recapture data (refer to cited references for details, full citations at bottom). Estimates are shown for 6 life history stages: $1=$ subadult females, $2=$ adult females, $3=$ aged adult females, $4=$ subadult males, $5=$ adult males, $6=$ aged adult males. Abbreviation: SD, standard deviation]

\begin{tabular}{rlcccccc}
\hline Area & \multicolumn{1}{c}{ Study site } & Year & Stage & Estimate & logit & SD logit & References \\
\hline & & & \multicolumn{5}{c}{ Weaning success rates $(\mathrm{w})$} \\
2 & Elkhorn Slough & 2012 & 2 & 0.629 & 0.528 & 0.500 & Tinker and others (2017a, 2018) \\
2 & Monterey & 2008 & 2 & 0.617 & 0.476 & 0.344 & Tinker and others (2019) \\
3 & Big Sur & 2008 & 2 & 0.597 & 0.392 & 0.348 & Tinker and others (2019) \\
4 & Cambria & 2003 & 2 & 0.553 & 0.213 & 0.341 & Tinker and others (2006a, 2019) \\
5 & Cojo Cove & 2012 & 2 & 0.647 & 0.608 & 0.509 & Tinker and others (2017a) \\
5 & San Nicolas & 2005 & 2 & 0.778 & 1.254 & 1.150 & Tinker and others (2008a, 2017a) \\
\hline
\end{tabular}

\section{Model Fitting and Evaluation}

We used Markov Chain Monte Carlo (MCMC) methods to estimate model parameters $\left(\sigma_{\tau}, \sigma_{\zeta}, \sigma_{\varepsilon}, \sigma_{\psi}, \bar{\psi}, \psi_{a}, N_{a, 1}, \alpha_{1}\right.$, $\alpha_{2}, \beta_{x, i}, \phi_{x}, \tau_{x, q}, \zeta_{x, a, t}$ and $\left.\varepsilon_{a, t}\right)$ by fitting the process model to the observed data variables $\left(C_{a, t}, Z_{x, i, a, t, q} \lg S_{i, a, t,}^{o b s} \lg w_{a, t}^{o b s}, \sigma_{s, i, a, t}\right.$ and $\sigma_{w, a, t}$ ) during the 1998-2012 study period (or 2013 in the case of expected counts versus expected abundance at the end of the study period). We used weakly informed priors consisting of log-normal distributions (location $=5$ and scale =1) for initial population size $\left(N_{a, 1}\right)$ and Cauchy distributions (location $=0$ and scale $=2.5$ ) for all other parameters except those constrained to be positive $(\sigma, \alpha, \psi)$, for which we used half-Cauchy priors with scale $=2.5$ (Gelman, 2006; Gelman and others, 2008). We used R (R Core Team, 2020, https://www.r-project.org/) and JAGS software (Plummer, 2017, https://sourceforge.net/projects/mcmc-jags/files/) to code and fit the model, saving 20,000 samples after a burn-in of 5,000 samples. We summarized results of model-fitting by reporting the mean and 95-percent credible interval (CI) of parameter posterior distributions. We evaluated model convergence by graphical examination of trace plots from 20 independent chains and by ensuring that Gelman-Rubin convergence diagnostic (percent scale reduction factor, or psrf) was less than or equal to 1.1 for all fitted model parameters. We performed posterior predictive checking (PPC) to evaluate model goodness-of-fit by using the $\chi^{2}$ statistic (sum of squared Pearson residuals of annual survey counts versus expected values and logit survival and weaning rates versus expected values) to compare fit of observed data and "new" data generated from the same distributions (Gelman and others, 2000). We examined scatter plots of the posterior distribution of $\chi^{2}$ scores for new versus observed data-in the case of well-fitting models, points in such a plot should be distributed around a line with slope 1 - and we computed the associated "Bayesian-P" value (the proportion of new observations more extreme than existing observations; Gelman, 2005; Ghosh and others, 2007), which should fall within the range of 0.2 to 0.8 for a well-fit model.
We graphically evaluated derived parameters and predicted dynamics of the model to assess model performance and to explore implications for sea otter conservation. We plotted model-predicted growth trajectories to compare with observed survey data for the 1998-2013 period for each coastal area in the established range (fig. 1). To examine model predictions of density-dependent variation in average survival and weaning success, we calculated and plotted the predicted vital rate values at densities ranging from 0 to 100 percent of $K$ by solving equations $1-5$ with all random effects set to 0 . To examine the degree to which different hazards varied as a function of population density, we created a boxplot to compare posterior distributions of $\phi_{x}$ for the nine classes of COD, with positive values indicating increasing impacts of the hazard with density (units of $\phi_{x}$ correspond to the change in the log hazard ratio as relative density increases from 0 to 100 percent of $K$ ). We consider values of $\phi_{x}$ for which the 95-percent CI does not span 0 to be evidence of strong density dependence, values of $\phi_{x}$ for which the 95-percent CI spans 0 but the 80-percent CI does not span 0 to be evidence of moderate density dependence and values of $\phi_{x}$ for which the 80-percent CI spans 0 to be evidence of weak or non-significant density dependence. We then calculated the expected log hazard ratios for each COD (relative to baseline hazards) by solving equation 1 with random effects set to 0 , for each of two population densities, 25 -percent of $K$ and 95-percent of $K$, and plotted the point estimates (with 95-percent CI) for each age class and sex, to examine how different hazards affect different life stages of the population and how these patterns vary as a function of population density. Finally, to evaluate spatial and temporal variation in the relative degree of exposure to different types of hazard, we generated composite figures for each COD showing (a) maps of the spatial trends in $\zeta_{x, a, t}$, together with (b) line plots of the temporal trends in $\zeta_{x, a, t}$ by coastal area. We note that positive values of $\zeta_{x, a, t}$ represent higher than average levels of risk from a given hazard, with units corresponding to the log of proportional change in hazard rate relative to the overall average for that COD. 


\section{Population Projections Using the Fitted Integrated Population Model}

Having parameterized the IPM for the 1998-2012 study period, we used the same model structure and drew randomly from the joint posterior distributions of all parameters to simulate future population dynamics by iteratively evaluating equations 1-12. A key assumption underlying the use of the IPM model structure and parameterization for forward simulations is that the values of fixed effects (in other words, $\left.\beta_{x, i}, \phi_{x}, \alpha_{1}, \alpha_{2}\right)$ and the mean values and magnitude of variation in random effects $\left(\tau_{x, q}, \zeta_{x, a, t}\right.$ and $\left.\varepsilon_{a, t}\right)$ that were observed in the 1998-2012 study period will persist in the future. However, these assumptions can be relaxed by evaluating alternative scenarios of directional change (for example, assuming an increase or decrease in the levels of exposure to a given hazard). To parameterize random effect values for forward simulations under the "baseline scenario" (in other words, assuming no directional change), we calculated means and covariance matrices from the fitted values of $\zeta_{x, a, t}$ for 1998-2012 in each coastal area (the covariance matrix consists of the realized variance in $\log$ hazard exposure values for each COD along the diagonal, and covariance between each pairwise combination of CODs on the sub-diagonal). The fitted means and covariance matrices were used to generate random values of $\zeta_{x, a, t}$ from a multivariate normal distribution: these "possible future values" adhere to realistic ranges for each area, maintaining appropriate means and correlations between different hazard types. For areas of the range outside the current distribution (fig. 1), we used the grand means and covariance matrices of $\zeta_{x, a, t}$ for each hazard (calculated across all years for all areas), which results in more variable distributions and thus greater uncertainty for population projections in these future potential habitats. A similar approach was used to generate random values of $\varepsilon_{a, t}$ for use in future simulations.

We incorporated dispersal in forward simulations of the IPM by expanding the inter-population connectivity matrix $(I P)$ to include currently occupied and currently unoccupied regions (fig. 1), with stage-specific dispersal rates and distribution of dispersing otters among recipient areas determined by the computed values of $d_{i, j, k}$ as described by equations 9 and 10. By allowing dispersal among all areas, future range expansion (the colonization of new habitat areas) becomes an emergent phenomenon rather than an additional step requiring additional parameters. Previous studies have reported a sporadic pattern of range expansion, with periodic colonization occurring after longer intervals of temporary, "exploratory" forays into unoccupied habitats by individuals or small groups of males (Tinker and others, 2008b; Lafferty and Tinker, 2014). To approximate these dynamics, we adjusted dispersal dynamics such that fractional values of projected immigration into unoccupied coastal areas for a given age/sex class $\left(n_{i, a, t}\right.$ less than 1 for an area that was unoccupied at year $t-1$ ) were treated as exploratory seasonal movements and redistributed back into occupied coastal areas for the next annual time step. Larger values $\left(n_{i, a, t}\right.$ greater than or equal to 1) were treated as permanent immigration into unoccupied areas for the age/sex class in question. New habitat areas were therefore considered to be part of the occupied range once permanently colonized by at least one individual from at least one age/sex class. Because females have lower dispersal rates than males (Tinker and others, 2008b), the initial colonizers of new areas are invariably males that do not produce intrinsic growth in the new area (matching empirically observed patterns: Lafferty and Tinker, 2014), with females arriving later when the neighboring source populations reach high enough densities to produce larger numbers of dispersing animals. Interestingly, this "emergent range expansion" approach produced realized rates of range expansion that were similar to those predicted by more elaborate diffusion or integrodifference equation models (Lubina and Levin, 1988; Tinker and others, 2008b).

We initiated forward simulations of the IPM by setting population abundances for each coastal area equal to the 3 -year-average values of independent otters reported for the 2019 range-wide census (Hatfield and others, 2019). Total numbers of independents were partitioned among age/sex classes according to the stable stage distribution associated with the mean survival schedule for each area (Caswell, 2001). To account for the continued increase in shark-bite mortality that has been observed since the 1998-2012 study period (Tinker and others, 2016a, 2017a), we used more recent stranding data (Hatfield and others, 2017) to update the predictive distributions of $\zeta_{x, a, t}$ for shark-bite hazards $(x=1)$. Specifically, we adjusted the mean values of $\zeta_{1, a, t}$ for areas within the currently occupied range such that the average predicted proportion of total mortalities caused by shark-bite matched the observed proportion of stranded carcasses with evidence of shark-bite during the 2013-17 period. For areas outside of the current range, we retained default values for $\zeta_{1, a, t}$, with the exception of areas Half Moon Bay and Marin County (HB and N1, respectively, in fig. 1), where $\zeta_{1, a, t}$ was set equal to the adjacent occupied coastal area Año Nuevo (AN), based on published evidence that shark predation rates will be similarly high in these areas (Klimley and others, 1992; Moxley and others, 2019; Miller and others, 2020). 
Forward simulations using the IPM structure and fitted parameter estimates were run for 50 years and iterated 1000 times in order to capture variability in results due to parameter uncertainty (achieved by drawing randomly from joint posterior distributions of all parameters) and environmental stochasticity (random variation in $\tau_{x, q}, \zeta_{x, a, t}$ and $\left.\varepsilon_{a, t}\right)$. We plotted the projected abundance over time as both the mean value and the 80 -percent $\mathrm{CI}$ of simulations and summarized results in terms of $N_{50}$, the mean projected abundance of the metapopulation after 50 years. We note that although the model dynamics are calculated in terms of independent otters (excluding dependent pups), the survey metrics typically used for assessing management criteria represent the 3-year average of independents and dependent pups (Hatfield and others 2018b, 2019). Accordingly, to simplify comparisons between model projections and management targets, we multiplied the model projected annual counts by a factor of 1.17 (corresponding to the observed long-term average ratio of pups to independents of 17 percent; Hatfield and others, 2019) to obtain expected abundance values that include dependent pups. To evaluate the relative impacts of different hazards on projected future population growth, we carried out a series of alternative scenarios in which we sequentially perturbed one cause-specific hazard $\left(h_{x}\right)$, forcing a 20 -percent decrease in $h_{x}$ below baseline levels while leaving all other hazard rates unchanged. For this analysis, we applied the perturbation equally across all areas, although we note that it would also be possible to evaluate localized perturbations. We iterated each alternative scenario 1000 times and calculated the response in terms of the proportional change in expected abundance after 50 years (eq. 18):

$$
\Delta N_{x}=\frac{\left(N_{50, x}^{a l t}-N_{50}\right)}{N_{50}}
$$

where

$$
\begin{array}{cc}
N_{50} & \text { is the mean projected abundance after } 50 \\
& \text { years, and } \\
N_{50, x}^{\text {alt }} & \text { is an alternative } N_{50} \text { for a scenario with a } \\
& \text { 20-percent lower hazard of COD } x .
\end{array}
$$

We compared $\Delta N_{x}$ values among different COD $x$ with larger values indicating greater population-level impacts. We also used IPM simulations to evaluate the effects of managed reintroductions of sea otters to a new habitat outside of the current range. We simulated the addition of five subadult sea otters (three females and two males) per year for 5 consecutive years (2021-2025) in one of four new areas $\left(a^{\prime}\right)$ : (1) San Francisco Bay (coastal area SF), (2) Drakes Estero Lagoon (coastal area DE), (3) Sonoma Coast State Park (in coastal area N2), and (4) Channel Islands National Park (coastal area C1; fig. 1). For each of these reintroduction scenarios we ran 1,000 iterations and calculated the response in terms of proportional increase in expected abundance after 50 years (eq. 19):

$$
\Delta N_{a^{\prime}}=\frac{\left(N_{50, a^{\prime}}^{a l t}-N_{50}\right)}{N_{50}}
$$

where

$$
\begin{gathered}
N_{50} \quad \text { is the mean projected abundance after } 50 \\
\text { years, and } \\
N_{50, a^{\prime}}^{a l t} \quad \text { is an alternative } N_{50} \text { for a scenario where } \\
\text { five subadults (three females and } \\
\text { two males) are added each year for } 5 \\
\text { consecutive years. }
\end{gathered}
$$

We compared $\Delta N_{a^{\prime}}$ values among reintroduction locations, with larger values indicating greater benefits in terms of potential increased growth of the metapopulation.

\section{Results}

Fitting the IPM to observed datasets resulted in excellent model fit and convergence: the goodness-of-fit statistics indicated consistency between observed and out-of-sample predictions (Bayesian $\mathrm{P}=0.65$; fig. 1.1) and all parameters had well-mixed posterior sample chains (psrf less than or equal to 1.1; table 1.2). The model predictions of population growth during the study period agreed well with survey counts (fig. 4), showing generally positive growth near the low-density northern and southern ends of the range (Año Nuevo [AN] and Point Conception [PC] areas and fluctuating trends in the higher-density areas near the center of the range (Range Center [RC] and Central California [CC] areas; fig. 1). Density-dependent variation in some hazard types resulted in survival rates that declined as a function of density, although density-dependent variation was strongest for subadults and aged adults and less pronounced for prime-aged adults (fig. $5 \mathrm{~A}$ ). Weaning success rates also declined as a function of density with respect to $K$ (fig. $5 B$ ). Comparison of posterior distributions for parameter $\phi_{x}$ showed that the degree of density dependence varied considerably among different hazards (table 1.2). In particular, End Lactation Syndrome (ELS) showed strong density dependence, consistent with previous findings (Chinn and others, 2016; Miller and others, 2020), as did acanthocephalan peritonitis (fig. 6). Other COD exhibited moderate levels of density dependence, including cardiac disease and "natural causes" (a catch-all category that includes a number of pathologies not covered by the other COD categories, including mating and fighting trauma, gastro-enterocolitis, gastrointestinal impaction, neoplasia and dental disease; table 1). In contrast, there was weak or non-significant density-dependence observed for shark-bite mortality, harmful algal bloom (HAB) intoxication (including acute poisoning from domoic acid, saxitoxins, or microcystins), protozoal and other infections, and human-caused mortality (fig. 6). 

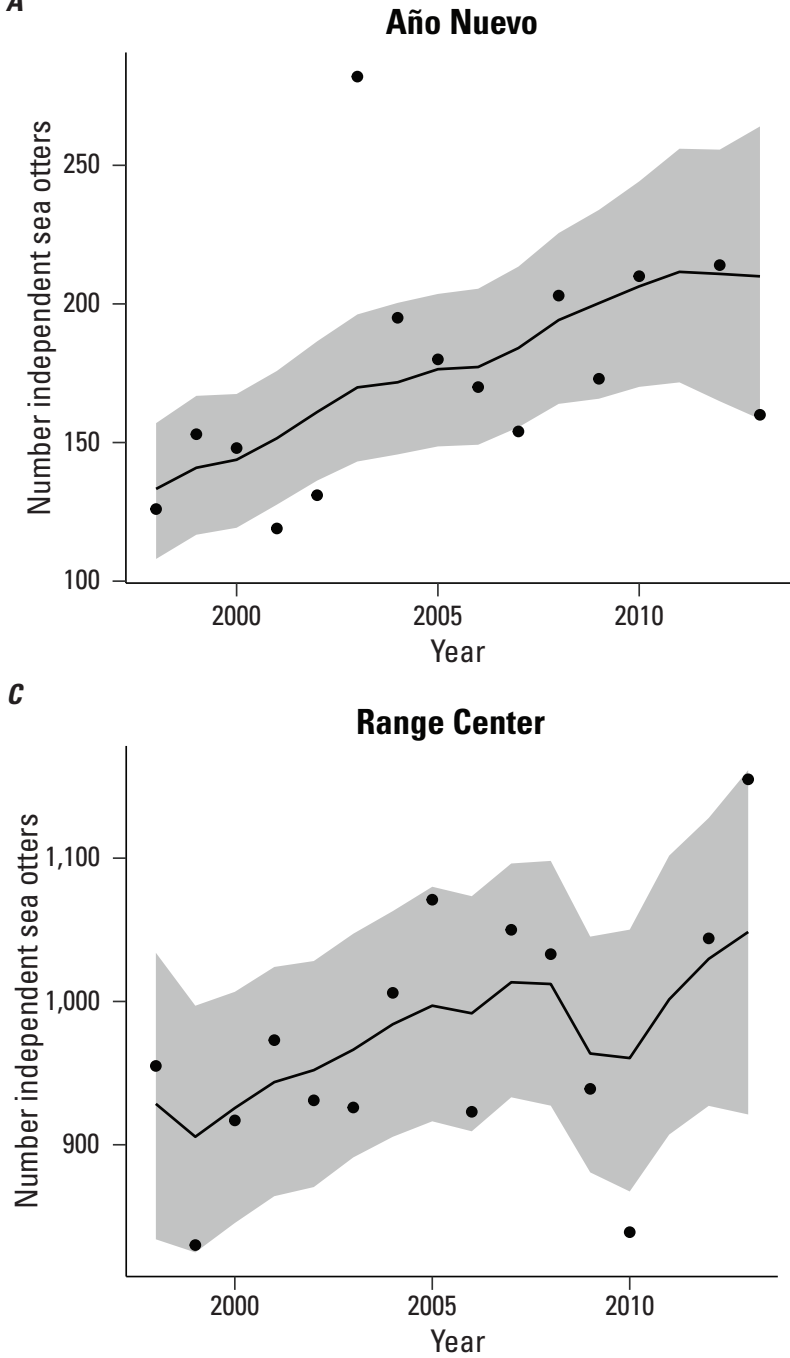

$\boldsymbol{E}$

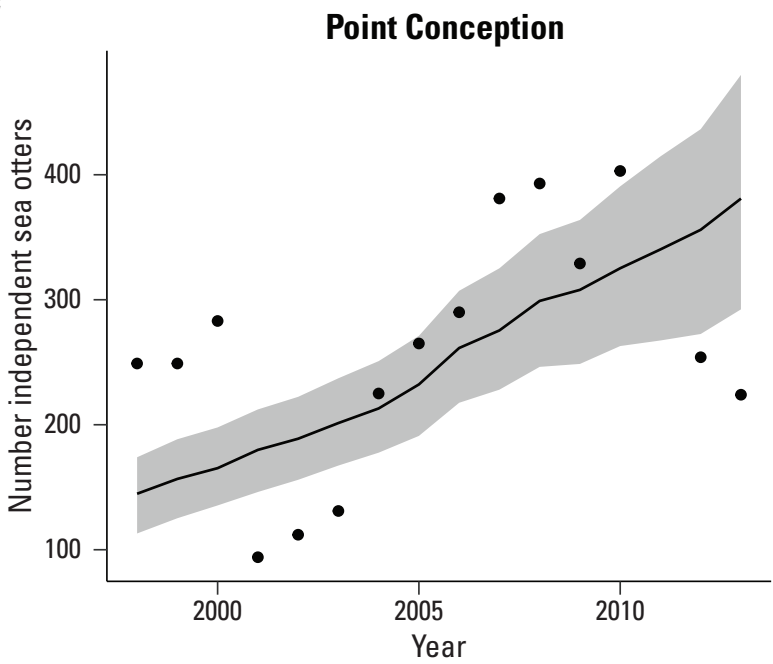

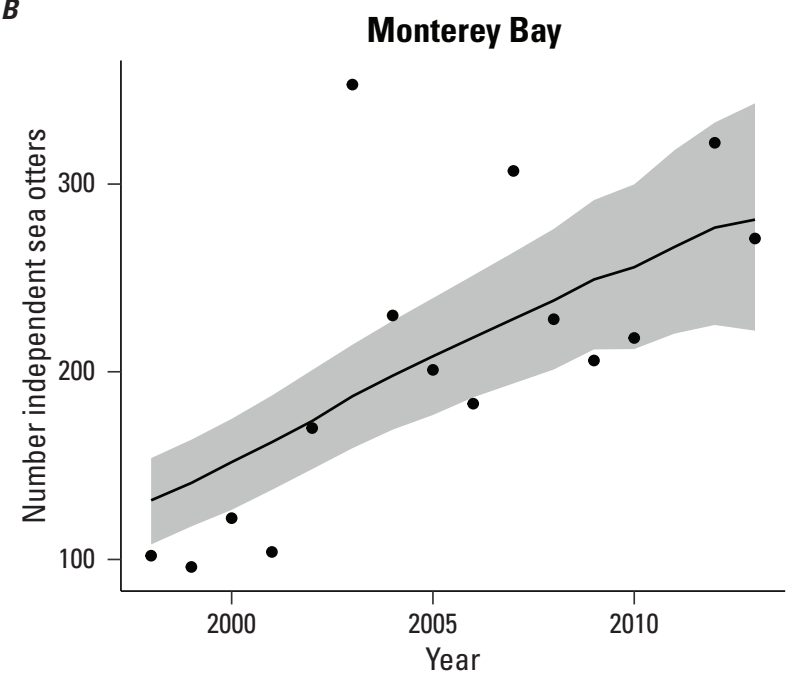

D

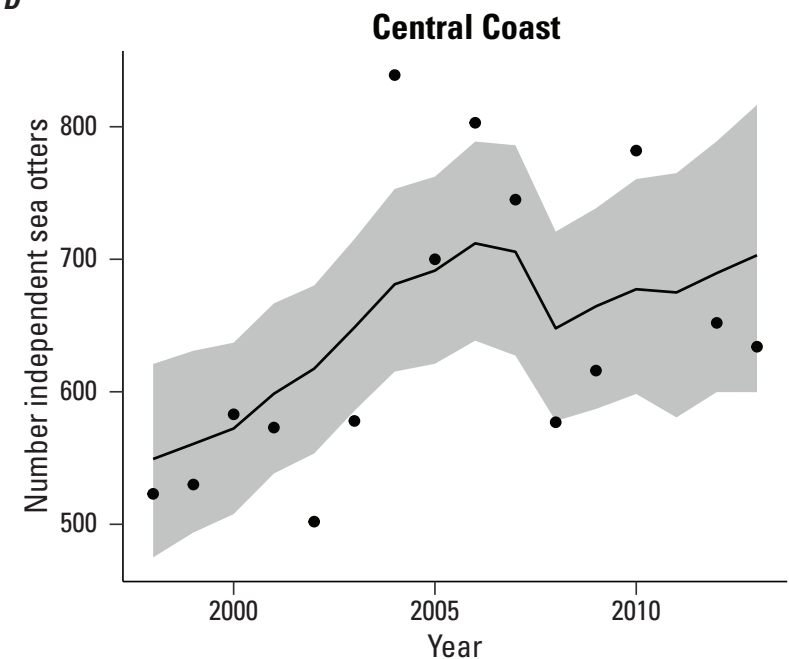

$\boldsymbol{F}$

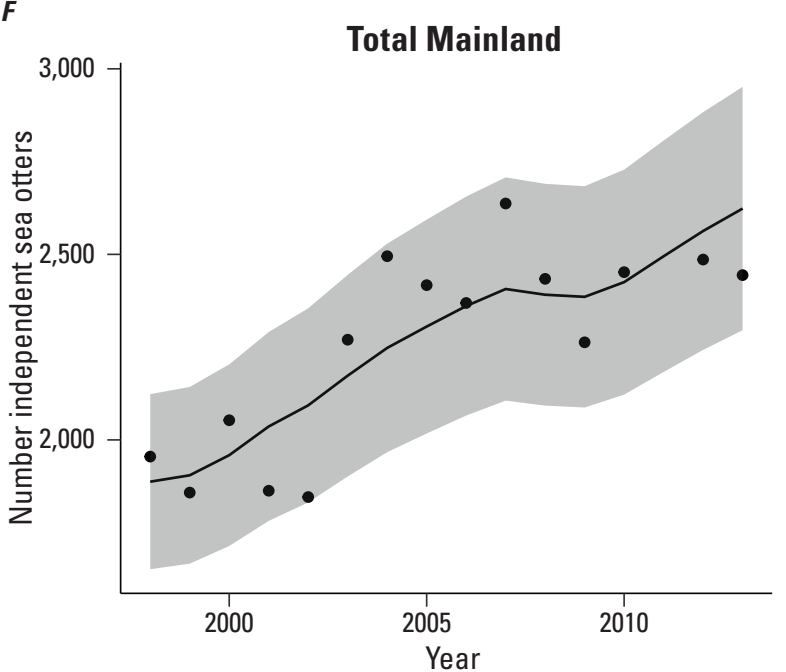

Figure 4. Estimated trends in population abundance of independent southern sea otters between 1998 and 2013, plotted for five coastal areas and the combined population of the mainland coast based on survey data and estimates from an integrated population model. $A$, Año Nuevo; $B$, Monterey Bay; $C$, Range Center; $D$, Central Coast; $E$, Point Conception; and $F$, Total Mainland. Model-based estimates are shown as solid lines (means of posterior distributions) with 95-percent credible intervals (Cl) shown as grey shaded bands. Raw survey counts are plotted as filled points. 
$\boldsymbol{A}$ Female survival versus density

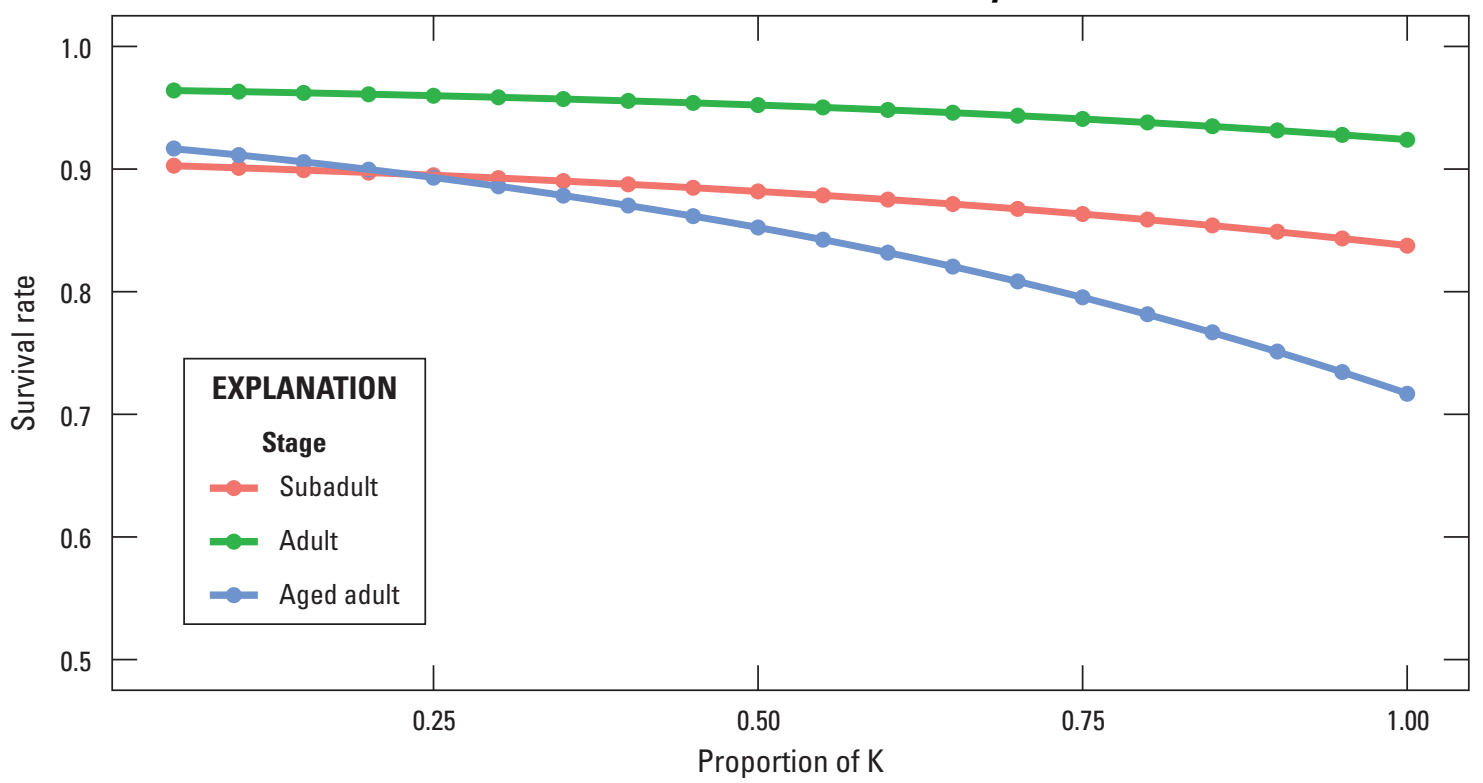

B

Wean success versus density

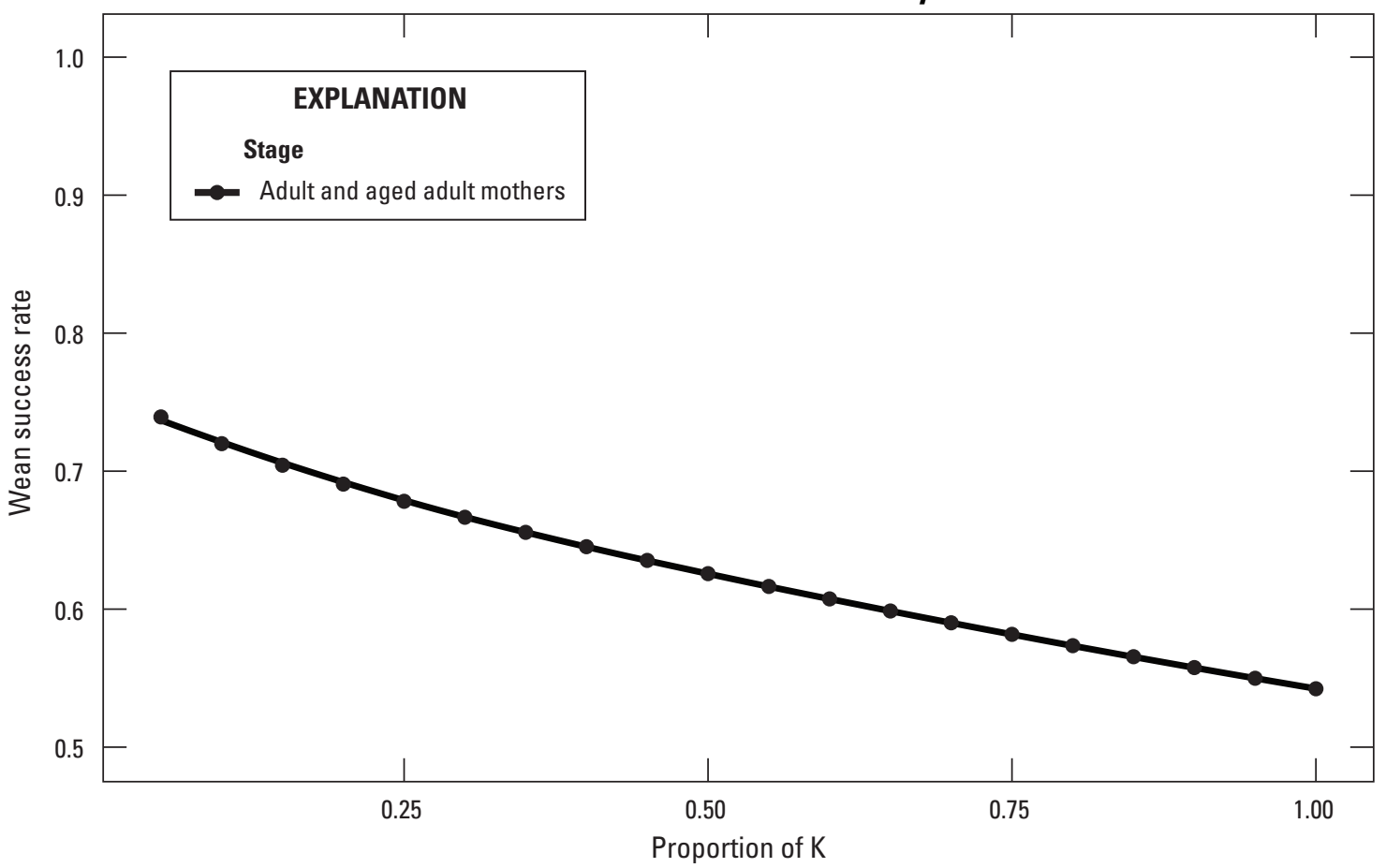

Figure 5. Estimated vital rates for southern sea otters (female survival and weaning success) plotted as functions of relative density (proportional abundance relative to local carrying capacity, or $K$ ), based on the results of an integrated population model (IPM). $A$, estimated annual female survival rate versus density for each of the three life history stages: subadults ( 6 months -3 years of age), adults ( $4-10$ years), and aged adults ( $>10$ years); and $B$, estimated weaning success rate for females, defined as the proportion of pups born to a female that are successfully reared and weaned as independent subadults. Note that age-specific effects of density on survival were similar for males, not shown here. 


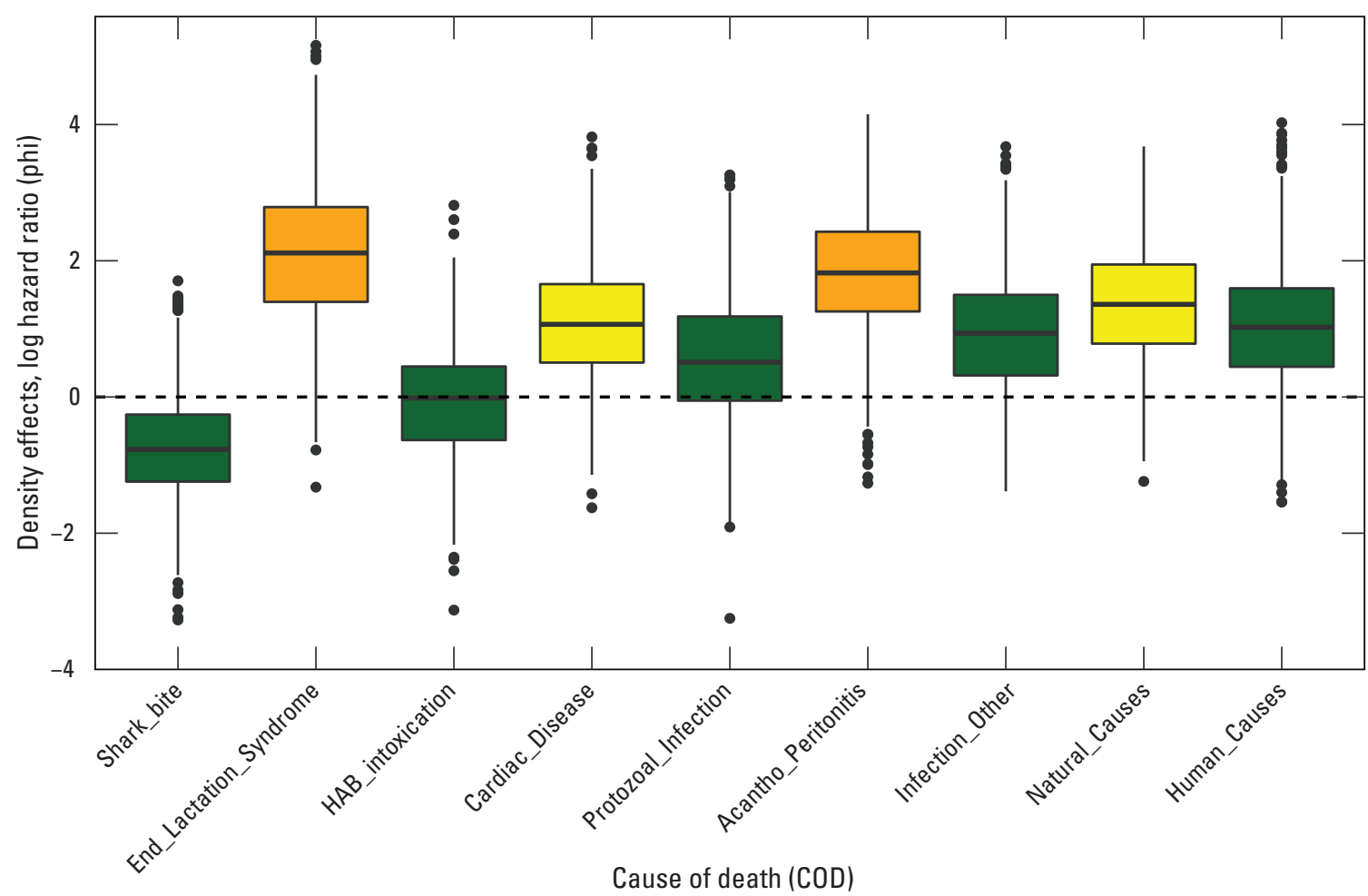

EXPLANATION

\section{Density-dependent effects by COD}

Weak density dependence

Strong density dependence

Figure 6. Effects of relative density (when increasing from 0 to 100 percent of local carrying capacity) on log hazard rates for each of the nine causes of death (COD) for southern sea otters, based on an integrated population model $\left(\phi_{x}\right.$ in eq. 1). Values greater than 0 (horizontal dashed line) indicate that increases in density are associated with an increase in hazard due to the indicated $\mathrm{COD}$, a functional relationship commonly referred to as density-dependence. Boxes encompass the interquartile range (IOR) of the posterior distributions of estimates generated by the model, whiskers encompass the full distribution excluding outliers (from the lower quartile minus 1.5 times IQR, to the upper quartile plus 1.5 times IQR), and points indicate outliers. Orange-shaded boxes indicate COD with strong density dependence (95-percent credible interval does not overlap 0), yellow-shaded boxes indicate COD with moderate density-dependence (80-percent credible does not overlap 0 ), and green shaded boxes indicate the remaining COD, with weak or non-significant density-dependence.

The IPM results indicated that hazards varied with respect to impacts on different life history stages of sea otters. The average stage-specific impacts of each hazard are represented by parameter $\beta_{x, i}$, which varied substantially among age/sex classes (table 1.2). For example, shark-bite had a strong impact on mortality of subadult females but decreased with age, exerting relatively low impacts on aged adult female survival; in contrast, the impacts of End Lactation Syndrome (ELS) and cardiac disease increased with age (fig. 7A). The realized impacts of certain hazards depended on population density; for example, shark-bite deaths had the greatest impact on adult females at low densities (25-percent of $K$ ), but at high densities (95-percent of $K$ ), the effects of shark-bite were exceeded by ELS, acanthocephalan peritonitis, and natural causes (fig. 7A). Similarly, for males, shark-bite mortality had the greatest effect on survival of all age classes at low densities, but as population densities approached $K$, the impacts of cardiac disease and natural causes (for aged adult males) and acanthocephalan peritonitis (for subadult males) all exceeded the effects of shark-bite (fig. $7 B$ ). 
$\boldsymbol{A}$

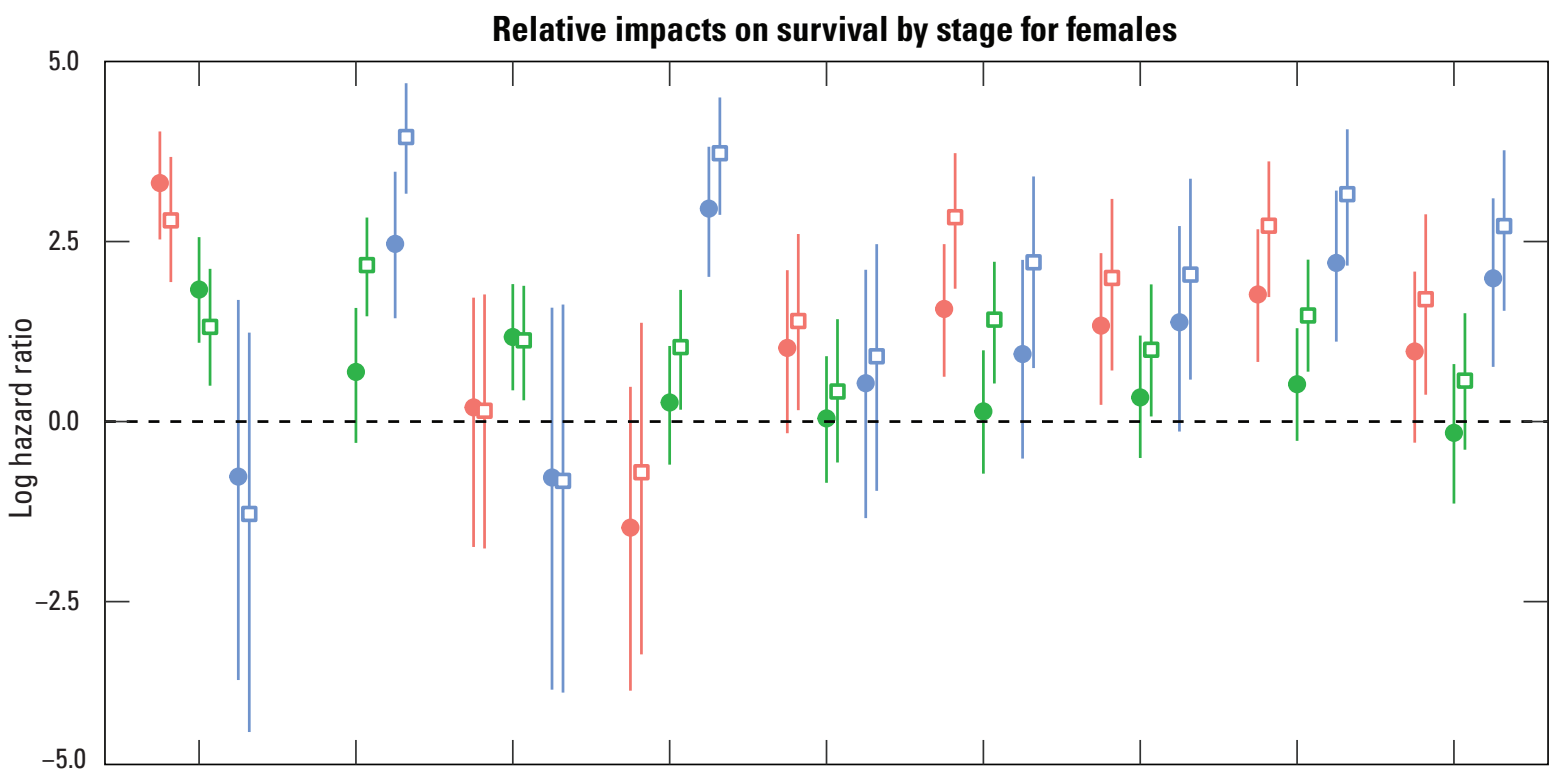

B Relative impacts on survival by stage for males

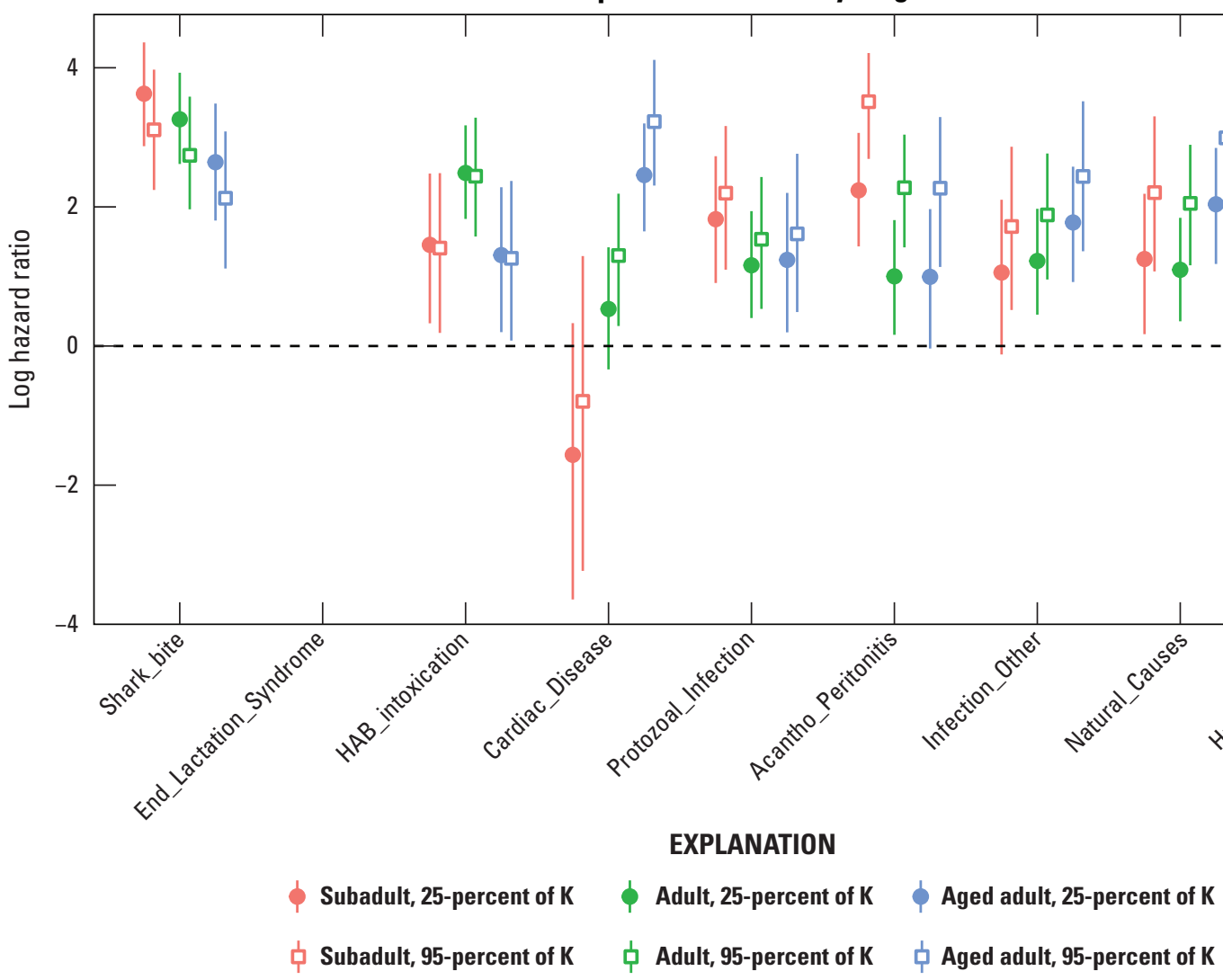

Figure 7. Relative impacts on stage-specific survival among nine causes of death (COD) for southern sea otters, based on an integrated population model. Plotted values represent the cause-specific log hazard ratios, excluding random effects, for each COD (horizontal axis) and age/sex combination, which are indicated by color and separate subplots for $A$, females; and $B$, males. Plotted points correspond to the mean of the posterior distributions of estimates generated by the model, and vertical error bars show the 95 -percent credible intervals. Values greater than 0 (horizontal dashed line) indicate an impact on stage-specific survival due to the indicated COD. Results are shown for $A$, relative impacts on survival by stage for females; and $B$, relative impacts on survival by stage for males (for low and high levels of population density: 25 percent of carrying capacity [filled circles] and 95 percent of carrying capacity [open squares], respectively). 
The spatial and temporal patterns of variation in exposure to hazards differed considerably among various COD (fig. 1.1). For example, shark-bite deaths were generally highest at the north and south ends of the current sea otter range (fig. 1.2A), in contrast to ELS and cardiac disease (fig. 1.2B, D), which were highest in the center portion of the range. Other hazards showed hotspots of exposure; for example, "Infection, Other" (a category that includes the fungal infection Coccidioidomycosis as well as viral and bacterial infections) was highest near Point Conception (fig. 1.2G), whereas harmful algal blooms (HAB) intoxication was highest in the Central Coast area around Morro Bay (fig. 1.2C). Temporal hotspots also occurred for some hazards, including a spike in protozoal infection mortality in 2004 in the Central Coast area (fig. 1.2E) that is attributable to a recognized epizootic caused by Sarcocystis neurona infections (Miller and others, 2010b), rather than by Toxoplasma gondii infections which are more dispersed throughout the range (Miller and others, 2002, 2007; Burgess and others, 2018). There was a period of elevated risk of cardiac disease mortality in the Central Coast from 2004 to 2008 (fig. 1.2D) and a trend of increasing shark-bite mortality after 2005, in most areas (fig. 1.2A).

Forward simulations of population dynamics using the IPM results indicate an expectation of continued slow positive growth of the southern sea otter meta-population during the next 50 years $\left(N_{50}=4,563\right.$ versus $\left.N_{l}=2,962\right)$, although the range of uncertainty in model projections (95-percent $\mathrm{CI}=2,267-7,278)$ also includes the potential for negative growth (fig. 8). A perturbation-based sensitivity analysis indicated that changes in the rate of shark bite mortality were expected to have a greater impact on future population growth than similar perturbations in other hazards (figs. 9, 10), with a 20-percent reduction in shark-bite hazard rate leading to a 19-percent increase in projected abundance after 50 years (95-percent CI=0.4-39.2; fig. 9). Simulations of managed reintroductions of sea otters to currently unoccupied habitats suggested that these actions could have substantial effects on future population growth and range expansion (figs. 11, 12), although the magnitude of these effects varied between potential reintroduction sites. 
$\boldsymbol{A}$

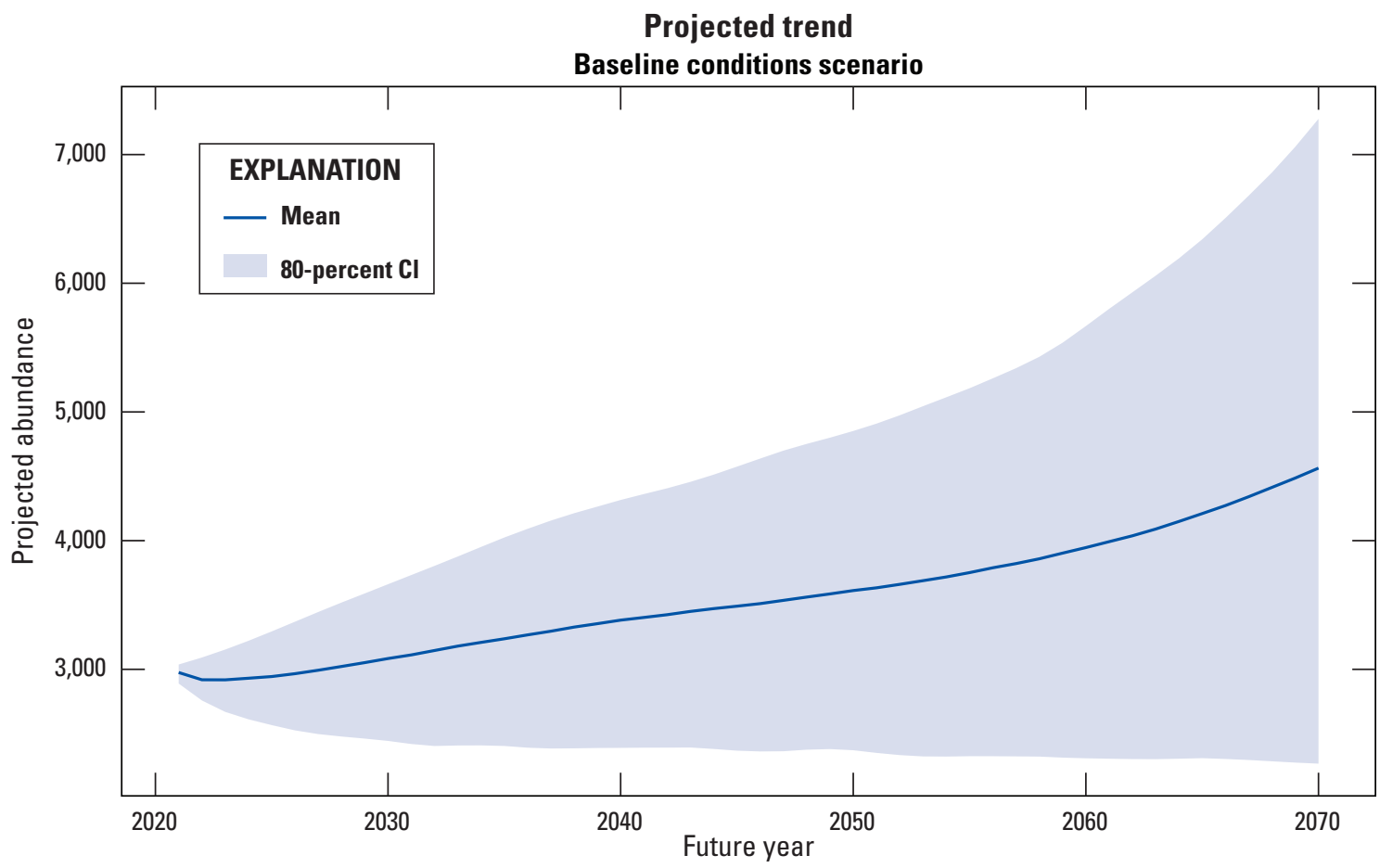

B

Projected population growth by area

Baseline conditions scenario

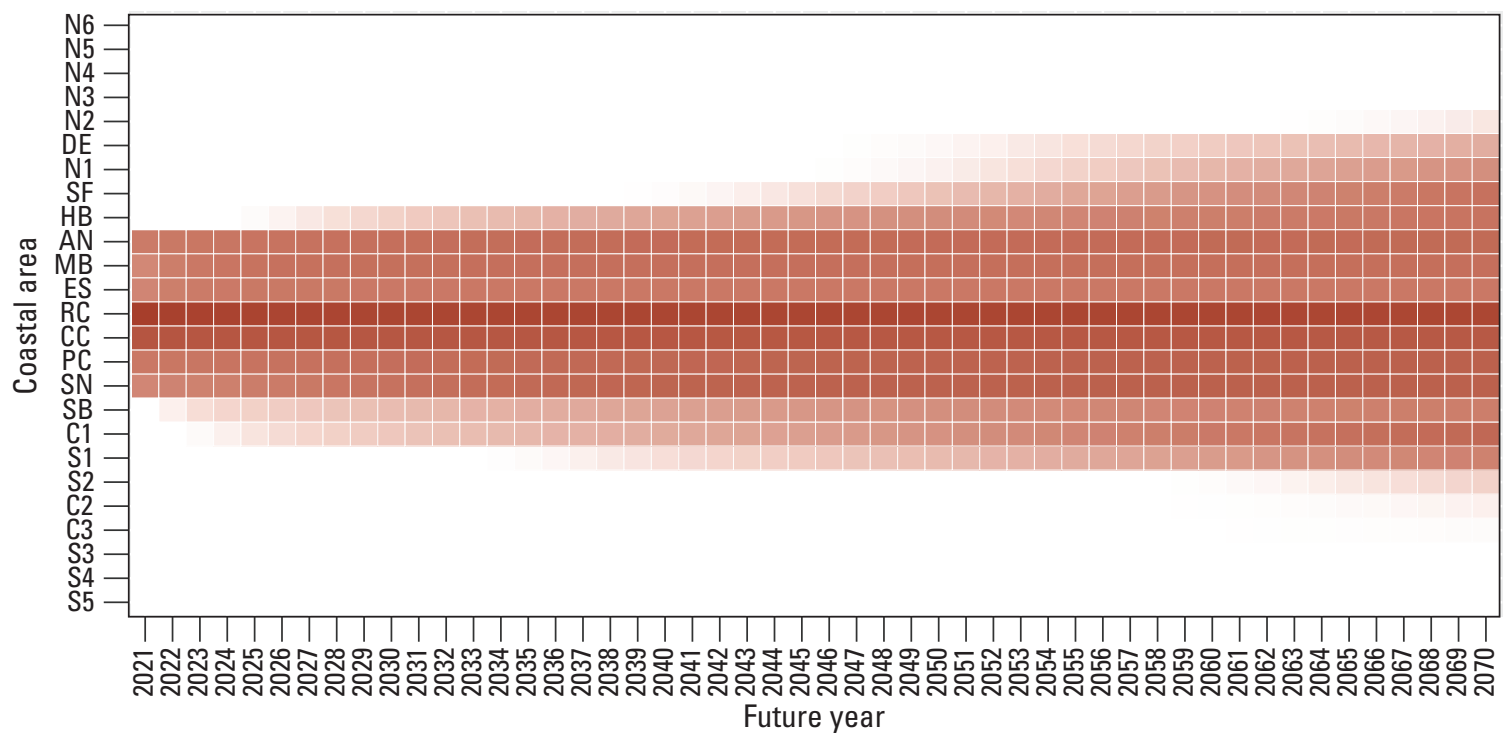

EXPLANATION

Mean expected $\log (\mathbf{N})$

0.0

2.5

5.0

7.5

Figure 8. Future projection of population dynamics for southern sea otters, based on iterated posterior predictive simulations using an integrated population model, with all parameters set to their default (baseline) distributions. $A$, projected abundance of the population as a function of years into the future, with the solid line corresponding to the mean of the posterior distributions of projected values and the shaded area corresponding to the 80-percent credible interval; and $B$, heatmap plot of a matrix in which cell values correspond to the log-transformed mean projected abundance for a specific coastal area (rows of the matrix, ordered from north to south) in a given year (columns of the matrix). Moving from left to right of the heatmap plot, the changing color patterns illustrate projected changes over time in the density (color intensity) and distribution (vertical extent of shading in a column) of the population. 


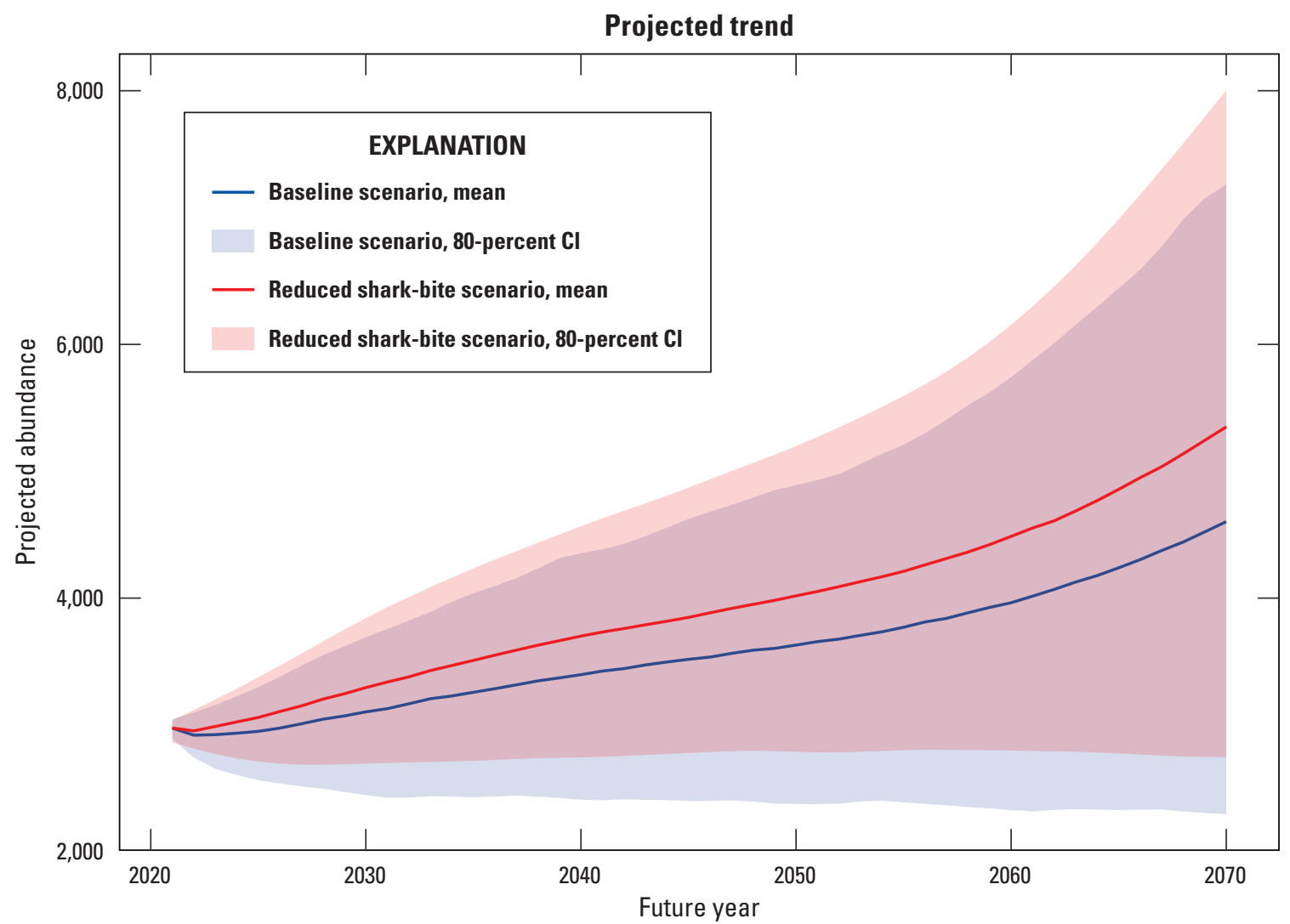

Figure 9. Future projections of population dynamics for southern sea otters, based on iterated posterior predictive simulations using an integrated population model. Results based on the posterior distributions of projected abundances from two future scenarios are shown: the blue line shows mean projected abundance over time for the baseline scenario (all parameters drawn from their default distributions), whereas the red line shows the mean projected abundance over time for an alternative scenario where hazards from shark bite are reduced by 20 percent relative to baseline levels. The shaded bands show the 80 -percent credible intervals for the baseline (blue) and alternative (red) scenarios. 


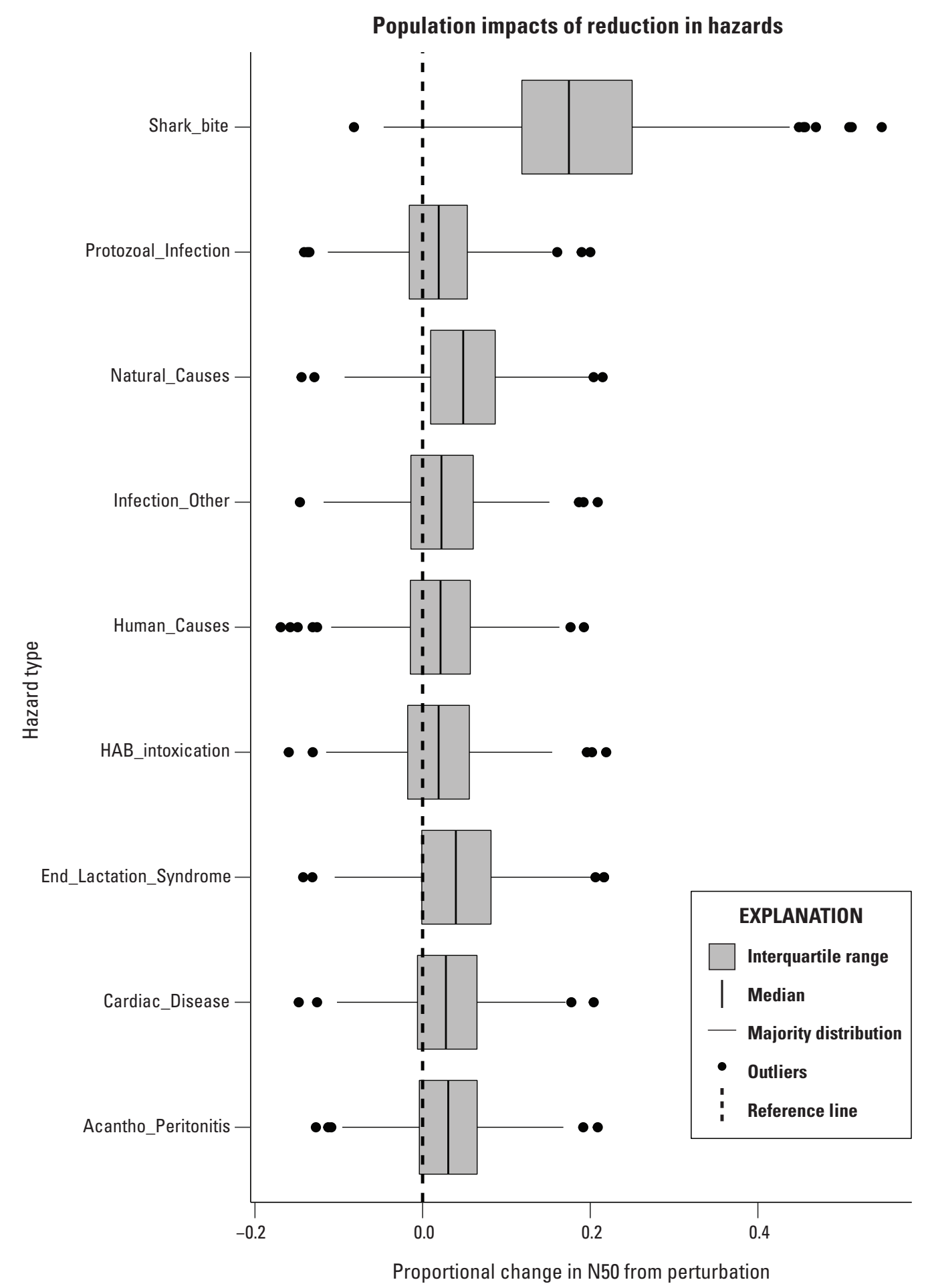

Figure 10. Relative impacts on population growth for nine categories of cause of death (COD; see table 1 for reference) for southern sea otters, estimated based on a perturbation analysis using an integrated population model. Net impacts are measured as the proportional change in simulated expected abundance after 50 years $\left(N_{50}\right)$ for scenarios with a 20-percent reduction in the hazards associated with the focal COD category, while holding constant all other cause-specific hazards, relative to scenarios without any change in hazards (a value of 0 [vertical dashed reference line] indicates no significant effect on population growth). Boxes encompass the interquartile range (IQR), whiskers encompass the full distribution excluding outliers (from the lower quartile minus 1.5 times IQR, to the upper quartile plus 1.5 times IQR), and points indicate outliers. 


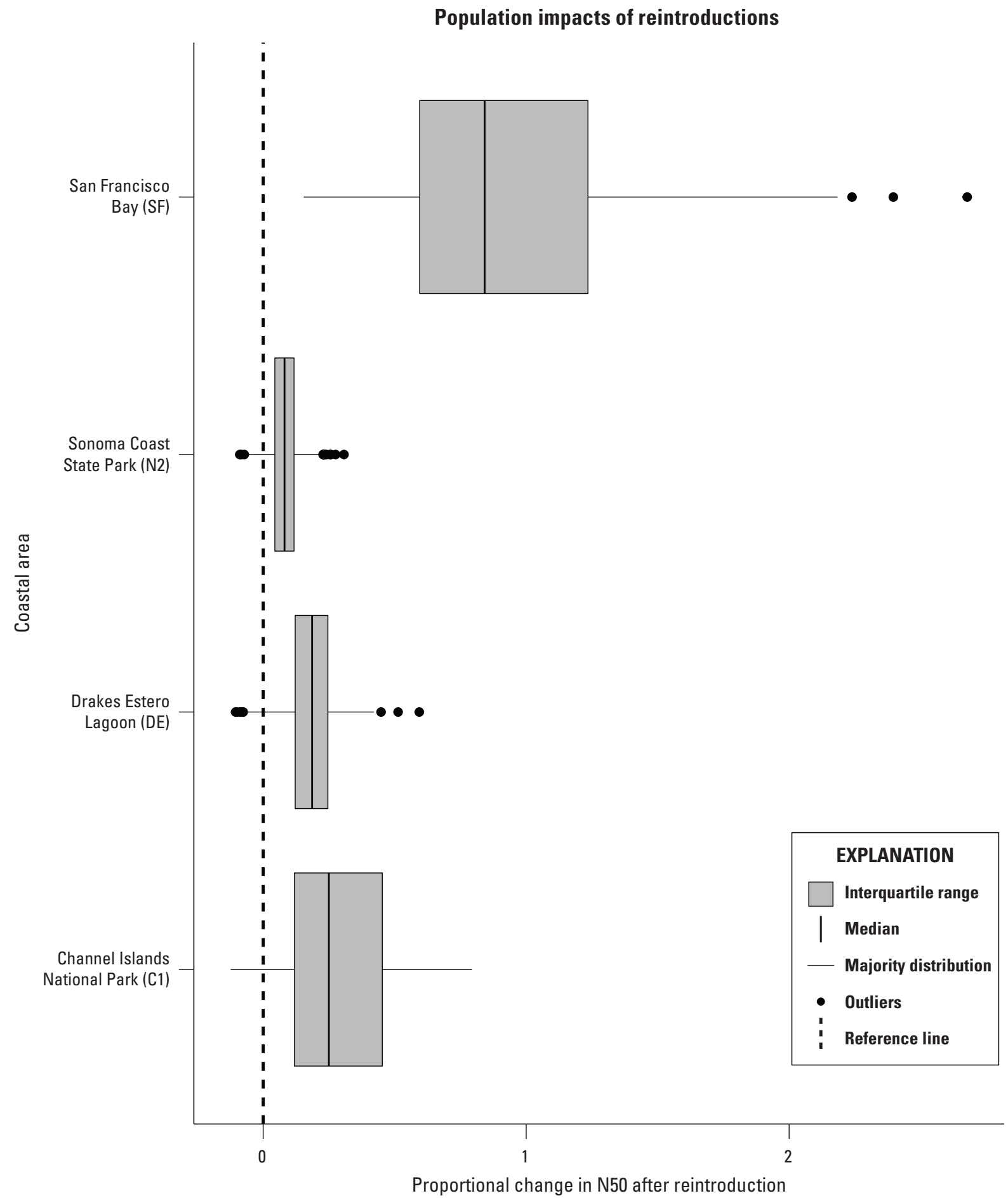

Figure 11. Relative impacts on population growth for a targeted reintroduction of southern sea otters to a specific coastal area, estimated based on a perturbation analysis using an integrated population model. In each case, the scenario involves the reintroduction of five juvenile animals (three females and two males), during each of 5 consecutive years, to one of four currently unoccupied habitat areas within the historic range: San Francisco Bay (coastal area SF), Drakes Estero Lagoon (coastal area DE), Sonoma Coast State Park (in coastal area N2), and the Channel Islands National Park (coastal area C1; see fig. 1 for reference). Net impacts are measured as the proportional change in simulated expected abundance after 50 years $\left(N_{50}\right)$ for scenarios with reintroduction relative to scenarios without reintroduction (a value of 0 [vertical dashed reference line] indicates no significant effect on population growth). Boxes encompass the interquartile range (IQR), whiskers encompass the full distribution excluding outliers (from the lower quartile minus 1.5 times IQR, to the upper quartile plus 1.5 times IQR), and points indicate outliers. 
A

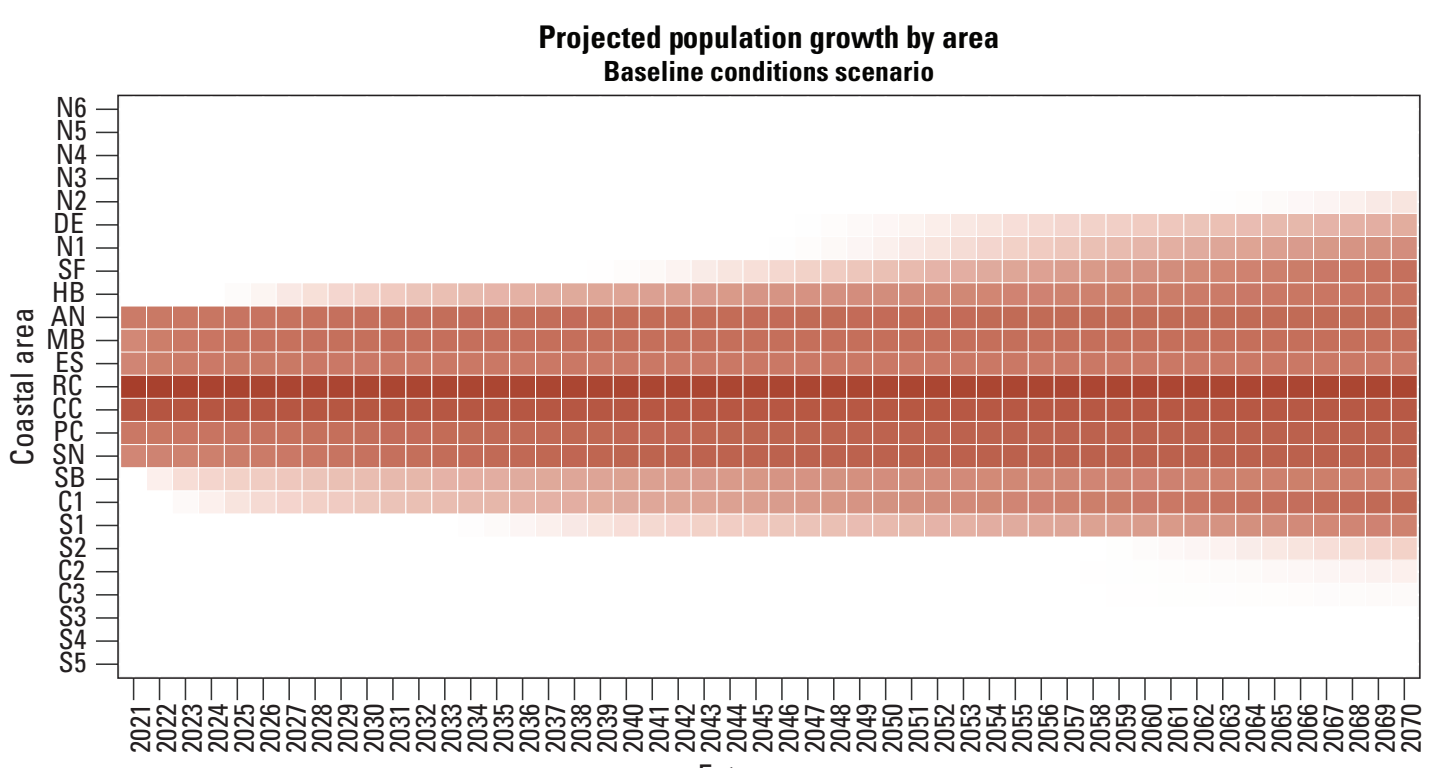

Future year

EXPLANATION

Mean expected $\log (\mathrm{N})$

0.0

2.5

5.0

7.5

B

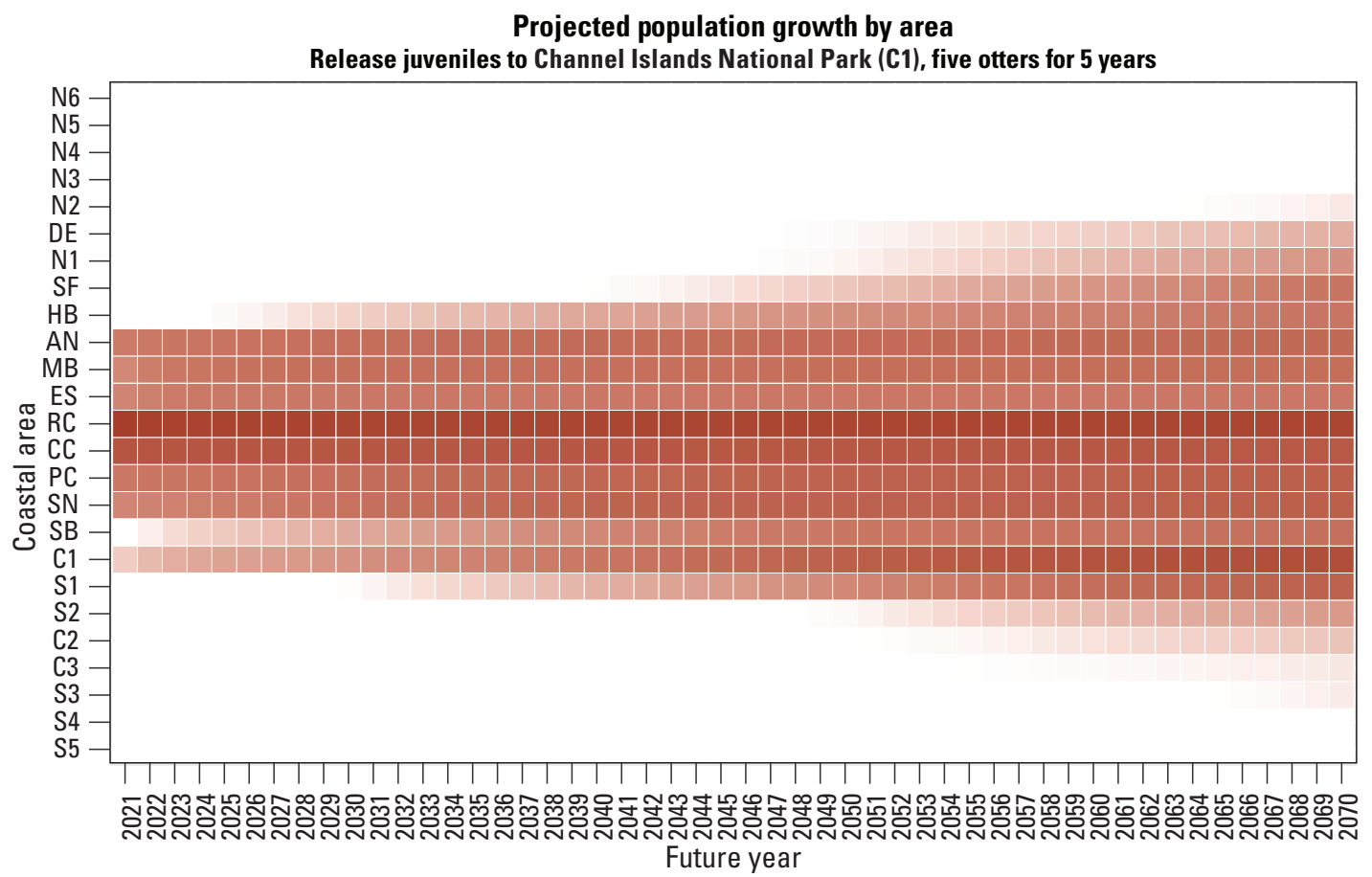

Figure 12. Heatmap plots illustrating projected spatiotemporal variation in southern sea otter abundance and distribution predicted by an integrated population model. $A$, projected dynamics under the baseline scenario (all parameters drawn from their default distributions); and $B$, projected dynamics under an alternative scenario where five juvenile animals (three females and two males) are reintroduced during each of 5 consecutive years to Channel Islands National Park in southern California (corresponding to the C1 coastal area). The heatmaps are visual representations of matrices whose cell values correspond to the log-transformed mean expected abundance for a specific coastal area (rows of the matrix) in a given year (columns of the matrix). Moving from left to right of each heatmap plot, the changing color patterns illustrate expected changes over time in the density (color intensity) and distribution (vertical extent of shading in a column) of the population. 


\section{Discussion}

The southern sea otter IPM provides a useful new analytical tool for resource managers, integrating multiple types of population data to provide inferences about spatial and temporal variation in different hazards and their relative impacts on survival and population growth. The results of the IPM model highlight differences in how specific hazards affect specific age/sex classes, and also the relationship between population density and the relative effects of hazards on survival (fig. 6). Our results illuminate how density-dependent and spatial variation in specific hazards can impact population growth, especially in the case of shark bite mortality (fig. 9). The unusually high sensitivity to shark bite mortality may reflect both its strong impacts on survival even at low population densities (fig. 7) as well as its spatial concentration at the northern and southern ends of the range (fig. 1.2). A reduction in this COD therefore leads to increased growth at the range peripheries and accelerated range expansion. The sensitivity of projected growth to perturbations in other cause-specific hazards was variable, with slightly greater than average impacts associated with "natural causes" and ELS.

Using the IPM to simulate future population dynamics provided several new insights. First, the baseline scenario showed a high degree of uncertainty around projected trends (fig. $8 \mathrm{~A}$ ): the mean projected trend corresponded to a 54-percent increase in abundance after 50 years, but the 80 -percent $\mathrm{CI}$ included projections ranging from a 23-percent decline to 146-percent increase. Uncertainty in future dynamics reflects multiple sources of variation in model-fitted parameters, as well as stochasticity in demographic processes, but it does not include major directional changes in causes of death such as those that might occur with future climate change. Such uncertainties must be assessed separately by specific scenario evaluations. Second, the projected growth was not spatially uniform; rather, areas near the center of the currently occupied range remained approximately stable, and peripheral areas increased slowly and eventually colonized unoccupied areas to the north and south, including the Channel Islands (fig. $8 B$ ). Third, the mean predicted rate of range expansion along the mainland coastline (excluding estuaries and islands) was 3.7 kilometers per year ( $\mathrm{km} / \mathrm{yr}$ ) to the south and $2.9 \mathrm{~km} / \mathrm{yr}$ to the north, slightly lower than previously published theoretical estimates of $4.73 \mathrm{~km} / \mathrm{yr}$ (Tinker and others, 2008b) and $4.8 \mathrm{~km} / \mathrm{yr}$ (Lubina and Levin, 1988) and similar to empirically observed rates of range spread from 1983 to 2003 of $4.6 \mathrm{~km} / \mathrm{yr}$ to the south and $2.2 \mathrm{~km} / \mathrm{yr}$ to the north (Tinker and Hatfield, 2017). The slightly lower rates of range spread predicted by the IPM could reflect increased levels of shark-bite mortality at the northern and southern range peripheries, which appear to have been limiting range expansion in recent years (Tinker and others, 2016a; Nicholson and others, 2018; Moxley and others, 2019).

A management action for sea otters that has already demonstrated a measurable impact on local population growth is the reintroduction of stranded/rehabilitated subadult sea otters (Mayer and others, 2019). We used the IPM to evaluate the potential impact of similar reintroductions of subadult sea otters to their historical habitats outside the current range. In all cases, there were significant increases in expected growth potential associated with reintroduction programs, although a reintroduction to San Francisco Bay was projected to have the greatest potential effect (fig. 11). This prediction reflects the large expanse of potential habitat within the San Francisco Bay estuary system and the fact that a reintroduction would likely accelerate the establishment of a breeding population by many years. However, a recently published study by Rudebusch and others (2020) indicates a high potential for direct and indirect anthropogenic hazards for sea otters in this heavily human-altered system (which are not explicitly included in the IPM parameterization at present); thus, additional research into these potential complicating factors would be necessary for a more complete assessment. Reintroductions to other coastal areas north and south of the current range also were predicted to have substantial effects on future population growth (fig. 11). Examining trends by coastal area indicates that reintroductions can be impactful primarily because these actions are anticipated to accelerate the time of colonization of currently unoccupied areas to the north or south of the current range (fig. 12). These results can serve as the basis for more thorough evaluations of the feasibility of reintroductions into various target habitats that account for the specific characteristics of recipient areas, such as prey abundance, susceptibility to anthropogenic disturbance, potential conflicts with fisheries, or other documented threats. 
The IPM for southern sea otters provides resource managers with a useful tool for evaluating the impacts of different, specific hazards, forecasting future population dynamics and range expansion, and evaluating alternative management scenarios. It is nonetheless important to recognize limitations of the current formulation and parameterization of the IPM, as these can potentially affect conclusions drawn. One limitation of our analysis relates to the assumption that necropsies of recovered sea otter carcasses are representative of the distribution of causes of death in the wild population. Death assemblages of wildlife populations are often subject to biases associated with heterogeneities in detection probability. For sea otters, it has been suggested that causes of death that lead to a protracted moribund state are more likely to result in a sea otter stranding on a beach (and thus being detected), whereas causes of death that occur in the marine environment away from shore (such as fishing gear entanglement) could be less likely to produce a beach-cast carcass (Estes and others, 2003). Such a bias could lead to an underestimate of the prevalence of certain human-caused hazards (for example, fisheries bycatch or boat strikes) and hazards associated with rapid death at sea (for example, acute shark bite mortality) in our current analysis. Although we have no way to quantify and thus formally correct for such biases, there are several factors that suggest that these biases may not be overly severe. First, southern sea otters are unique among marine mammals in having a very high rate of carcasses recovery; it is estimated that over 50 percent of sea otters that die in coastal California are eventually recovered (Tinker and others, 2006a), and thus a fairly high likelihood that all common causes of death will be represented (to some degree) in the death assemblage. Secondly, the results of several field studies of radio-tagged sea otters in California (Tinker and others, 2006a, 2017a, 2019) have provided an opportunity to determine whether there is a cause-of-death bias in terms of which study animals died and were stranded on a beach (where they would have been detected even if not tagged) versus which ones died offshore (for example, in a kelp bed) and would not have been detected were they not equipped with a radio tag. We did not detect any differences in cause-of-death distribution between those two study groups, with one notable exception: a study animal that died at depth (a fact determined later from an archival time-depth recorder), possibly entangled in abandoned fishing gear on the sea bottom, remained underwater for an extended period such that when it eventually floated free and washed ashore, it was too decomposed to determine the cause of death. That single case demonstrated the potential for under-detection of rapid at-sea deaths that preclude prompt recovery of the carcass (and thus preclude the possibility of a necropsy).

Another limiting assumption is that the spatial and temporal structure included in our model is appropriate for capturing the scale of spatial and temporal variation in demographic processes, including variation in cause of death. Based on several published analyses of southern sea otter movements (Tarjan and Tinker, 2016; Breed and others, 2017) and area-based differences in survival and reproduction (Tinker and others, 2006a, 2019), we believe the spatial scale of our designated coastal areas (fig. 1) is appropriate for capturing the spatial scale of variation in most demographic processes, justifying an assumption of near-homogeneity within coastal areas. We recognize, however, that this assumption may be violated in some cases; for example, localized pulses of some causes of death are known to occur, such as clusters of die-offs from local HAB events (Miller and others, 2010c) or acute mortality from parasite exposure after severe rainfall (Miller and others, 2010b). The granularity of our model structure is simply too course to measure variation in such localized episodes, and more targeted analyses would be appropriate; nonetheless, we believe that our model should be sufficient to describe the predominant patterns of variation in sea otter mortality and cause of death. 
A key limitation of the competing risk formulation in our model is the assumption that different causes of death are functionally independent of each other. This simplifying assumption is justifiable to the extent that primary causes of death are mutually exclusive over short periods. However, the reality is more complicated, as sea otters generally experience multiple stressors over time that can act additively or synergistically to increase the chance of death (Kreuder and others, 2003; Miller and others, 2020). In some cases, multiple hazards have complex interactions: for example, exposure to HAB toxins sometimes leads to acute toxicity and death (Miller and others, 2010c), but in other cases a chronically high exposure to HAB toxins can increase the likelihood that a sea otter dies later from another hazard such as cardiac disease (Kreuder and others, 2005). It is common to identify multiple contributing factors (in addition to the primary cause of death) during necropsies of individual animals, yet the relative contribution of these factors to mortality trends at the population-level is difficult to quantify, and incorporation of contributing causes of death into a hazards-based mortality analysis can be challenging (Naugle and others, 2004; Heisey and others, 2006; Heisey and Patterson, 2006). Nonetheless, research into the nature of interactions between separate hazards could eventually allow for modification of the IPM to explicitly incorporate such interactions. Environmental or anthropogenic factors can contribute to mortality: for example, pathogen or nutrient discharge from terrestrial watersheds is a known or suspected contributor to sea otter mortality from protozoal and other infections, and from HAB blooms (Miller and others, 2002, 2010a, c; Johnson and others, 2009; Oates and others, 2012). Future versions of the IPM could be modified to allow for incorporation of underlying environmental or anthropogenic risk factors that could mediate the impacts of hazards identified in the IPM. Such modifications would of course require additional data and parameters, but there are examples of using information on terrestrial watersheds to predict hazard exposure for sea otters in coastal waters (VanWormer and others, 2016; Burgess and others, 2018). Similarly, as sample sizes increase over time it will be possible to partition certain hazard classes that represent heterogeneous groupings of related COD.

Despite these limitations, we believe that the IPM presented herein represents a major step toward a robust, fully quantitative, and data-driven tool for assessing sea otter recovery potential, evaluating threats, and evaluating alternative management options. As new data and information become available, they can be readily incorporated into this IPM to improve performance and update projections, following best practices of adaptive management.

\section{References Cited}

Abadi, F., Gimenez, O., Arlettaz, R., and Schaub, M., 2010, An assessment of integrated population models-Bias, accuracy, and violation of the assumption of independence: Ecology, v. 91, no. 1, p. 7-14, https://doi.org/10.1890/ 08-2235.1.

Besbeas, P., Freeman, S.N., and Morgan, B.J., 2005, The potential of integrated population modelling: Australian \& New Zealand Journal of Statistics, v. 47, no. 1, p. 35-48, https://doi.org/10.1111/j.1467-842X.2005.00370.x.

Breed, G.A., Golson, E.A., and Tinker, M.T., 2017, Predicting animal home-range structure and transitions using a multistate Ornstein-Uhlenbeck biased random walk: Ecology, v. 98, no. 1, p. 32-47, https://doi.org/10.1002/ecy.1615.

Burgess, T.L., Tinker, M.T., Miller, M.A., Bodkin, J.L., Murray, M.J., Saarinen, J.A., Nichol, L.M., Larson, S., Conrad, P.A., and Johnson, C.K., 2018, Defining the risk landscape in the context of pathogen pollutionToxoplasma gondii in sea otters along the Pacific Rim: Royal Society Open Science, v. 5, no. 7, p. 171-178, https://doi.org/10.1098/rsos.171178.

Caswell, H., 2001, Matrix population models - Construction, analysis, and interpretation ( $2 \mathrm{~d}$ ed.): Sunderland, Mass., Sinauer Associates, 722 p.

Chandler, R.B., and Clark, J.D., 2014, Spatially explicit integrated population models: Methods in Ecology and Evolution, v. 5, no. 12, p. 1351-1360, https://doi.org/ 10.1111/2041-210X.12153.

Chinn, S.M., Miller, M.A., Tinker, M.T., Staedler, M.M., Batac, F.I., Dodd, E.M., and Henkel, L.A., 2016, The high cost of motherhood-End-lactation syndrome in southern sea otters (Enhydra lutris nereis) on the central California coast, USA: Journal of Wildlife Diseases, v. 52, no. 2, p. 307-318, https://doi.org/10.7589/2015-06-158.

Estes, J.A., Hatfield, B.B., Ralls, K., and Ames, J., 2003, Causes of mortality in California sea otters during periods of population growth and decline: Marine Mammal Science, v. 19, no. 1, p. 198-216, https://doi.org/10.1111/j.17487692.2003.tb01102.x.

Gelman, A., 2005, Comment-Fuzzy and Bayesian p-values and u-values: Statistical Science, v. 20, no. 4, p. 380-381, https://doi.org/10.1214/088342305000000368.

Gelman, A., 2006, Prior distributions for variance parameters in hierarchical models (comment on article by Browne and Draper): Bayesian Analysis, v. 1, no. 3, p. 515-534, https://doi.org/10.1214/06-BA117A. 
Gelman, A., Goegebeur, Y., Tuerlinckx, F., and Van Mechelen, I., 2000, Diagnostic checks for discrete data regression models using posterior predictive simulations: Journal of the Royal Statistical Society, Applied Statistics, Series C, v. 49, no. 2, p. 247-268, https://doi.org/10.1111/14679876.00190 .

Gelman, A., Jakulin, A., Pittau, M.G., and Su, Y.-S., 2008, A weakly informative default prior distribution for logistic and other regression models: The Annals of Applied Statistics, v. 2, no. 4, p. 1360-1383, https://doi.org/10.1214/ 08-AOAS191.

Gerber, L.R., Tinker, T., Doak, D., Estes, J., and Jessup, D.A., 2004, Mortality sensitivity in life-stage simulation analysis - A case study of southern sea otters: Ecological Applications, v. 14, no. 5, p. 1554-1565, https://doi.org/ 10.1890/03-5006.

Ghosh, J.K., Delampady, M., and Samanta, T., 2007, An introduction to Bayesian analysis - Theory and methods: New York, NY, Springer Science \& Business Media.

Hatfield, B.B., Harris, M.D., Ames, J.A., Tinker, M.T., and Young, C., 2017, Summary of stranded southern sea otters, 1985-2016: U.S. Geological Survey data release, (ver. 2.0, September 2018), accessed September 1, 2019, at https://doi.org/10.5066/F71J98P4.

Hatfield, B.B., Yee, J.L., Kenner, M.C., and Tomoleoni, J.A., 2019, California sea otter (Enhydra lutris nereis) census results, spring 2019: U.S. Geological Survey Data Series 1118, 12 p., https://doi.org/10.3133/ds1118.

Hatfield, B.B., Yee, J.L., Kenner, M.C., Tomoleoni, J.A., and Tinker, M.T., 2018a, Annual California sea otter census_-2018 spring census summary: U.S. Geological Survey data release, https://doi.org/10.5066/P98012HE.

Hatfield, B.B., Yee, J.L., Kenner, M.C., Tomoleoni, J.A., and Tinker, M.T., 2018b, California sea otter (Enhydra lutris nereis) census results, spring 2018: U.S. Geological Survey Data Series 1097, 10 p., https://doi.org/10.3133/ds1097.

Heisey, D.M., Joly, D.O., and Messier, F., 2006, The fitting of general force-of-infection models to wildlife disease prevalence data: Ecology, v. 87, no. 9, p. 2356-2365, https://doi.org/10.1890/0012-9658(2006)87[2356:TFOG FM]2.0.CO;2.

Heisey, D.M., and Patterson, B.R., 2006, A review of methods to estimate cause-specific mortality in presence of competing risks: The Journal of Wildlife Management, v. 70, no. 6, p. 1544-1555, https://doi.org/10.2193/0022-541X(2006)70 [1544:AROMTE]2.0.CO;2.
Jameson, R.J., and Johnson, A.M., 1993, Reproductive characteristics of female sea otters: Marine Mammal Science, v. 9, no. 2, p. 156-167, https://doi.org/10.1111/j.17487692.1993.tb00440.x.

Johnson, C.K., Tinker, M.T., Estes, J.A., Conrad, P.A., Staedler, M., Miller, M.A., Jessup, D.A., and Mazet, J.A.K., 2009, Prey choice and habitat use drive sea otter pathogen exposure in a resource-limited coastal system: Proceedings of the National Academy of Sciences of the United States of America, v. 106, no. 7, p. 2242-2247, https://doi.org/ 10.1073/pnas.0806449106.

Joly, D.O., Heisey, D.M., Samuel, M.D., Ribic, C.A., Thomas, N.J., Wright, S.D., and Wright, I.E., 2009, Estimating cause-specific mortality rates using recovered carcasses: Journal of Wildlife Diseases, v. 45, no. 1, p. 122-127, https://doi.org/10.7589/0090-3558-45.1.122.

Klimley, A.P., Anderson, S.D., Pyle, P., and Henderson, R.P., 1992, Spatiotemporal patterns of white shark (Carcharodon carcharias) predation at the South Farallon Islands, California: Copeia, v. 1992, no. 3, p. 680-690, https://doi.org/10.2307/1446143.

Kreuder, C., Miller, M.A., Jessup, D.A., Lowenstine, L.J., Harris, M.D., Ames, J.A., Carpenter, T.E., Conrad, P.A., and Mazet, J.A.K., 2003, Patterns of mortality in southern sea otters (Enhydra lutris nereis) from 1998-2001: Journal of Wildlife Diseases, v. 39, no. 3, p. 495-509, https://doi.org/ 10.7589/0090-3558-39.3.495.

Kreuder, C., Miller, M.A., Lowenstine, L.J., Conrad, P.A., Carpenter, T.E., Jessup, D.A., and Mazet, J.A.K., 2005, Evaluation of cardiac lesions and risk factors associated with myocarditis and dilated cardiomyopathy in southern sea otters (Enhydra lutris nereis): American Journal of Veterinary Research, v. 66, no. 2, p. 289-299, https://doi.org/10.2460/ajvr.2005.66.289.

Lafferty, K.D., and Tinker, M.T., 2014, Sea otters are recolonizing southern California in fits and starts: Ecosphere, v. 5, no. 5, p. 1-11, https://doi.org/10.1890/ES13-00394.1.

Lubina, J.A., and Levin, S.A., 1988, The spread of a reinvading species - Range expansion in the California sea otter: American Naturalist, v. 131, no. 4, p. 526-543, https://doi.org/10.1086/284804.

Mayer, K.A., Tinker, M.T., Nicholson, T.E., Murray, M.J., Johnson, A.B., Staedler, M.M., Fujii, J.A., and Van Houtan, K.S., 2019, Surrogate rearing a keystone species to enhance population and ecosystem restoration: Oryx, p. 1-11, https://doi.org/10.1017/S0030605319000346. 
Miller, M.A., Byrne, B.A., Jang, S.S., Dodd, E.M., Dorfmeier, E., Harris, M.D., Ames, J., Paradies, D., Worcester, K., Jessup, D.A., and Miller, W.A., 2010a, Enteric bacterial pathogen detection in southern sea otters (Enhydra lutris nereis) is associated with coastal urbanization and freshwater runoff: Veterinary Research (Les Ulis), v. 41, no. 1, 13 p., https://doi.org/10.1051/vetres/2009049.

Miller, M.A., Conrad, P.A., Harris, M., Hatfield, B., Langlois, G., Jessup, D.A., Magargal, S.L., Packham, A.E., ToyChoutka, S., Melli, A.C., Murray, M.A., Gulland, F.M., and Grigg, M.E., 2010b, A protozoal-associated epizootic impacting marine wildlife-Mass-mortality of southern sea otters (Enhydra lutris nereis) due to Sarcocystis neurona infection: Veterinary Parasitology, v. 172, no. 3-4, p. 183-194, https://doi.org/10.1016/j.vetpar.2010.05.019.

Miller, M.A., Kudela, R.M., Mekebri, A., Crane, D., Oates, S.C., Tinker, M.T., Staedler, M., Miller, W.A., Toy-Choutka, S., Dominik, C., Hardin, D., Langlois, G., Murray, M., Ward, K., and Jessup, D.A., 2010c, Evidence for a novel marine harmful algal bloom - Cyanotoxin (microcystin) transfer from land to sea otters: PLoS One, v. 5, no. 9, 11 p., https://doi.org/10.1371/journal.pone.0012576.

Miller, M.A., Gardner, I.A., Kreuder, C., Paradies, D.M., Worcester, K.R., Jessup, D.A., Dodd, E., Harris, M.D., Ames, J.A., Packham, A.E., and Conrad, P.A., 2002, Coastal freshwater runoff is a risk factor for Toxoplasma gondii infection of southern sea otters (Enhydra lutris nereis): International Journal for Parasitology, v. 32, no. 8, p. 997-1006, https://doi.org/10.1016/S0020-7519(02)00069-3.

Miller, M.A., Grigg, M.E., Miller, W.A., Dabritz, H.A., James, E.R., Melli, A.C., Packham, A.E., Jessup, D., and Conrad, P.A., 2007, Toxoplasma gondii and Sarcocystis neurona infections of pacific coastal sea otters in California, USAEvidence for land-sea transfer of biological pathogens: The Journal of Eukaryotic Microbiology, v. 54, p. 48S-49S.

Miller, M.A., Moriarty, M.E., Henkel, L., Tinker, M.T., Burgess, T.L., Batac, F.I., Dodd, E., Young, C., Harris, M.D., Jessup, D.A., Ames, J., Conrad, P.A.., Packham, A.E., and Johnson, C.K., 2020, Predators, disease, and environmental change in the nearshore ecosystemMortality in southern sea otters (Enhydra lutris nereis) from 1998-2012: Frontiers in Marine Science, v. 7, no. 582, 24 p., https://doi.org/10.3389/fmars.2020.00582.

Monson, D.H., Estes, J.A., Bodkin, J.L., and Siniff, D.B., 2000, Life history plasticity and population regulation in sea otters: Oikos, v. 90, no. 3, p. 457-468, https://doi.org/ 10.1034/j.1600-0706.2000.900304.x.
Moxley, J.H., Nicholson, T.E., Van Houtan, K.S., and Jorgensen, S.J., 2019, Non-trophic impacts from white sharks complicate population recovery for sea otters: Ecology and Evolution, v. 9, no. 11, p. 6378-6388, https://doi.org/10.1002/ece3.5209.

Naugle, D.E., Aldridge, C.L., Walker, B.L., Cornish, T.E., Moynahan, B.J., Holloran, M.J., Brown, K., Johnson, G.D., Schmidtmann, E.T., Mayer, R.T., Kato, C.Y., Matchett, M.R., Christiansen, T.J., Cook, W.E., Creekmore, T., Falise, R.D., Thomas Rinkes, E., and Boyce, M.S., 2004, West Nile virus - Pending crisis for greater sage-grouse: Ecology Letters, v. 7, no. 8, p. 704-713, https://doi.org/10.1111/ j.1461-0248.2004.00631.x.

Nicholson, T.E., Mayer, K.A., Staedler, M.M., Fujii, J.A., Murray, M.J., Johnson, A.B., Tinker, M.T., and Van Houtan, K.S., 2018, Gaps in kelp cover may threaten the recovery of California sea otters: Ecography, v. 41, no. 11, p. 1751-1762, https://doi.org/10.1111/ecog.03561.

Oates, S.C., Miller, M.A., Hardin, D., Conrad, P.A., Melli, A., Jessup, D.A., Dominik, C., Roug, A., Tinker, M.T., and Miller, W.A., 2012, Prevalence, environmental loading, and molecular characterization of Cryptosporidium and Giardia isolates from domestic and wild animals along the central California coast: Applied and Environmental Microbiology, v. 78 , no. 24 , p. $8762-8772$, https://doi.org/10.1128/ AEM.02422-12.

Plummer, M., 2017, JAGS—Just Another Gibbs Sampler: http s://sourceforge.net/projects/mcmc-jags/files/

R Core Team, 2020, R-A language and environment for statistical computing: Vienna, Austria, R Foundation for Statistical Computing, https://www.r-project.org/.

Rhodes, J.R., Ng, C.F., de Villiers, D.L., Preece, H.J., McAlpine, C.A., and Possingham, H.P., 2011, Using integrated population modelling to quantify the implications of multiple threatening processes for a rapidly declining population: Biological Conservation, v. 144, no. 3, p. 1081-1088, https://doi.org/10.1016/j.biocon.2010.12.027.

Riedman, M.L., Estes, J.A., Staedler, M.M., Giles, A.A., and Carlson, D.R., 1994, Breeding patterns and reproductive success of California sea otters: The Journal of Wildlife Management, v. 58, no. 3, p. 391-399, https://doi.org/ $10.2307 / 3809308$.

Rudebusch, J., Hughes, B.B., Boyer, K.E., and Hines, E., 2020, Assessing anthropogenic risk to sea otters (Enhydra lutris nereis) for reintroduction into San Francisco Bay: PeerJ, v. 8, 27 p., https://doi.org/10.7717/peerj.10241. 
Schaub, M., and Abadi, F., 2011, Integrated population models-A novel analysis framework for deeper insights into population dynamics: Journal of Ornithology, v. 152, no. S1, p. 227-237, https://doi.org/10.1007/s10336010-0632-7.

Staedler, M.M., 2011, Individual variation in maternal care and provisioning in the southern sea otter (Enhydra lutris nereis) - Causes and consequences of diet specialization in a top predator: University of California, Santa Cruz, Master's thesis.

Tarjan, L.M., and Tinker, M.T., 2016, Permissible home range estimation (PHRE) in restricted habitats-A new algorithm and an evaluation for sea otters: PLoS One, v. 11, no. 3, 20 p., https://doi.org/10.1371/journal.pone.0150547.

Tempel, D.J., Peery, M.Z., and Gutiérrez, R.J., 2014, Using integrated population models to improve conservation monitoring - California spotted owls as a case study: Ecological Modelling, v. 289, p. 86-95, https://doi.org/ 10.1016/j.ecolmodel.2014.07.005.

Tinker, M.T., 2015, The use of quantitative models in sea otter conservation, in Larson, S., Bodkin, J.L., and Vanblaricom, G.R., eds., Sea otter conservation: Boston, MA, Academic Press, p. 257-300, https://doi.org/10.1016/B978-0-12801402-8.00010-X

Tinker, M.T., Bentall, G., and Estes, J.A., 2008a, Food limitation leads to behavioral diversification and dietary specialization in sea otters: Proceedings of the National Academy of Sciences of the United States of America, v. 105, no. 2, p. 560-565, https://doi.org/10.1073/pnas.0709263105.

Tinker, M.T., Doak, D.F., and Estes, J.A., 2008b, Using demography and movement behavior to predict range expansion of the southern sea otter: Ecological Applications, v. 18, no. 7, p. 1781-1794, https://doi.org/ 10.1890/07-0735.1.

Tinker, M.T., Doak, D.F., Estes, J.A., Hatfield, B.B., Staedler, M.M., and Bodkin, J.L., 2006a, Incorporating diverse data and realistic complexity into demographic estimation procedures for sea otters: Ecological Applications, v. 16, no. 6, p. 2293-2312, https://doi.org/10.1890/1051-0761(2006)016 [2293:IDDARC]2.0.CO;2.

Tinker, M.T., Estes, J.A., Ralls, K., Williams, T.M., Jessup, D., and Costa, D.P., 2006b, Population dynamics and biology of the California sea otter (Enhydra lutris nereis) at the southern end of its range: Minerals Management Service Outer Continental Shelf Study 2006-007, Coastal Research Center, Marine Science Institute, University of California, Santa Barbara, California, Minerals Management Service Cooperative Agreement Number 14-35-0001-31063, 239 p.
Tinker, M.T., and Hatfield, B.B., 2017, California sea otter (Enhydra lutris nereis) census results, Spring 2017: U.S. Geological Survey Data Series 1067, 9 p., https://doi.org/ $10.3133 /$ ds 1067 .

Tinker, M.T., Hatfield, B.B., Harris, M.D., and Ames, J.A., 2016a, Dramatic increase in sea otter mortality from white sharks in California: Marine Mammal Science, v. 32, no. 1, p. 309-326, https://doi.org/10.1111/mms. 12261.

Tinker, M.T., Staedler, M.M., Tarjan, L.M., Bental, G.B., Tomoleoni, J.A., and LaRoche, N.L., 2016b, Geospatial data collected from tagged sea otters in central California, 1998-2012: U.S Geological Survey data release, https://www.doi.org/10.5066/F76H4FH8

Tinker, M.T., Tomoleoni, J., LaRoche, N., Bowen, L., Miles, A.K., Murray, M., Staedler, M., and Randell, Z., 2017a, Southern sea otter range expansion and habitat use in the Santa Barbara Channel, California: U.S. Geological Survey Open-File Report 2017-1001, 76 p., https://doi.org/10.3133/ ofr20171001.

Tinker, M.T., Tomoleoni, J.A., Staedler, M.M., LaRoche, N.L., Randell, Z., Bowen, L., Murray, M.J., and Miles, A.K.,, 2017b, Data for southern sea otter range expansion and habitat use in the Santa Barbara Channel. U.S. Geological Survey data release, https://doi.org/10.5066/F7JS9NMV.

Tinker, M.T, Espinosa, S.M., Staedler, M.M., Tomoleoni, J.A., Fujii, J., Eby, R., Scoles, R., Kenner, M.C., Hatfield, B., Fuentes, C., Lindsay, J.K., Nicholson, T., Murray, M., Young, M., Mayer, K., Dodd, E., Fork, S. and Wasson, K., 2018, The population status and ecology of sea otters in Elkhorn Slough, California: Final report for California Coastal Conservancy and U.S. Fish and Wildlife Service, $109 \mathrm{p}$.

Tinker, M.T., Tomoleoni, J.A., Weitzman, B.P., Staedler, M., Jessup, D., Murray, M.J., Miller, M., Burgess, T., Bowen, L., Miles, A.K., Thometz, N., Tarjan, L., Golson, E., Batac, F., Dodd, E., Berberich, E., Kunz, J., Bentall, G., Fujii, J., Nicholson, T., Newsome, S., Melli, A., LaRoche, N., MacCormick, H., Johnson, A., Henkel, L., Kreuder-Johnson, C., and Conrad, P., 2019, Southern sea otter (Enhydra lutris nereis) population biology at Big Sur and Monterey, California-Investigating the consequences of resource abundance and anthropogenic stressors for sea otter recovery: U.S. Geological Survey Open-File Report 2019-1022, 225 p., https://doi.org/10.3133/ofr20191022.

Tinker, M.T., Yee, J.L., Laidre, K.L., Hatfield, B.B., Harris, M.D., Tomoleoni, J.A., Bell, T.W., Saarman, E., Carswell, L.P., and Miles, A.K., 2021, Habitat features predict carrying capacity of a recovering marine carnivore: The Journal of Wildlife Management, v. 85, no. 2, p. 303-323, https://doi.org/10.1002/jwmg.21985. 
U.S. Fish and Wildlife Service, 2012, Final supplemental environmental impact statement-Translocation of southern sea otters: Ventura, Calif., Ventura Fish and Wildlife Office, $348 \mathrm{p}$.

U.S. Fish and Wildlife Service, 2013, Southwest Alaska distinct population segment of the northern sea otter (Enhydra lutris kenyoni) — Recovery plan: Anchorage, Alaska, U.S. Fish and Wildlife Service, Region 7.

VanWormer, E., Carpenter, T.E., Singh, P., Shapiro, K., Wallender, W.W., Conrad, P.A., Largier, J.L., Maneta, M.P., and Mazet, J.A.K., 2016, Coastal development and precipitation drive pathogen flow from land to sea-Evidence from a Toxoplasma gondii and felid host system: Scientific Reports, v. 6, no. 29252, 9 p., https://doi.org/10.1038/ srep29252.
Williams, P.J., Hooten, M.B., Womble, J.N., Esslinger, G.G., Bower, M.R., and Hefley, T.J., 2017, An integrated data model to estimate spatiotemporal occupancy, abundance, and colonization dynamics: Ecology, v. 98, no. 2, p. 328-336, https://doi.org/10.1002/ecy.1643.

Zipkin, E.F., and Saunders, S.P., 2018, Synthesizing multiple data types for biological conservation using integrated population models: Biological Conservation, v. 217, p. 240-250, https://doi.org/10.1016/j.biocon.2017.10.017. 


\section{Appendix 1. Supplementary Tables and Figures}

The deviations from the mean $\log$ hazard rate for $\operatorname{COD} x$, in area $a$ at time $t$, are computed as:

$$
\Gamma_{x, a, t}=\varsigma_{x, a, t}+\phi_{x} \cdot\left(\frac{N_{a, t}}{K_{a}}\right)
$$

where
$N_{a, t} \quad$ is population density in area $a$ at year $t$,
$K_{a} \quad$ is population density at carrying capacity in area $a$,
$\phi_{x} \quad$ is a fitted parameter that determines additional density-dependent impacts on hazard due to COD $x$ (the degree to which mortality from the cause-specific hazard increases as $N_{a, t}$ approaches $K_{a}$ ), and
$\zeta_{x, a, t}$ is a random effect, with mean 0 and standard deviation $\sigma_{\zeta}$, that describes annual variation in hazard due to COD $x$ in area $a$ at year $t$.

Table 1.1. Symbols and variables used in equations 1-19 of the integrated population model defined in the main text, listed with Greek and Roman letters interspersed, ordered alphabetically, then ordered by Roman lower case, Roman upper case, and Greek. $\mathrm{SD}$ variables $(\sigma)$ are listed after the variable to which they correspond.

[Abbreviations: x, by; =, equals; SD, standard deviation; eq., equation]

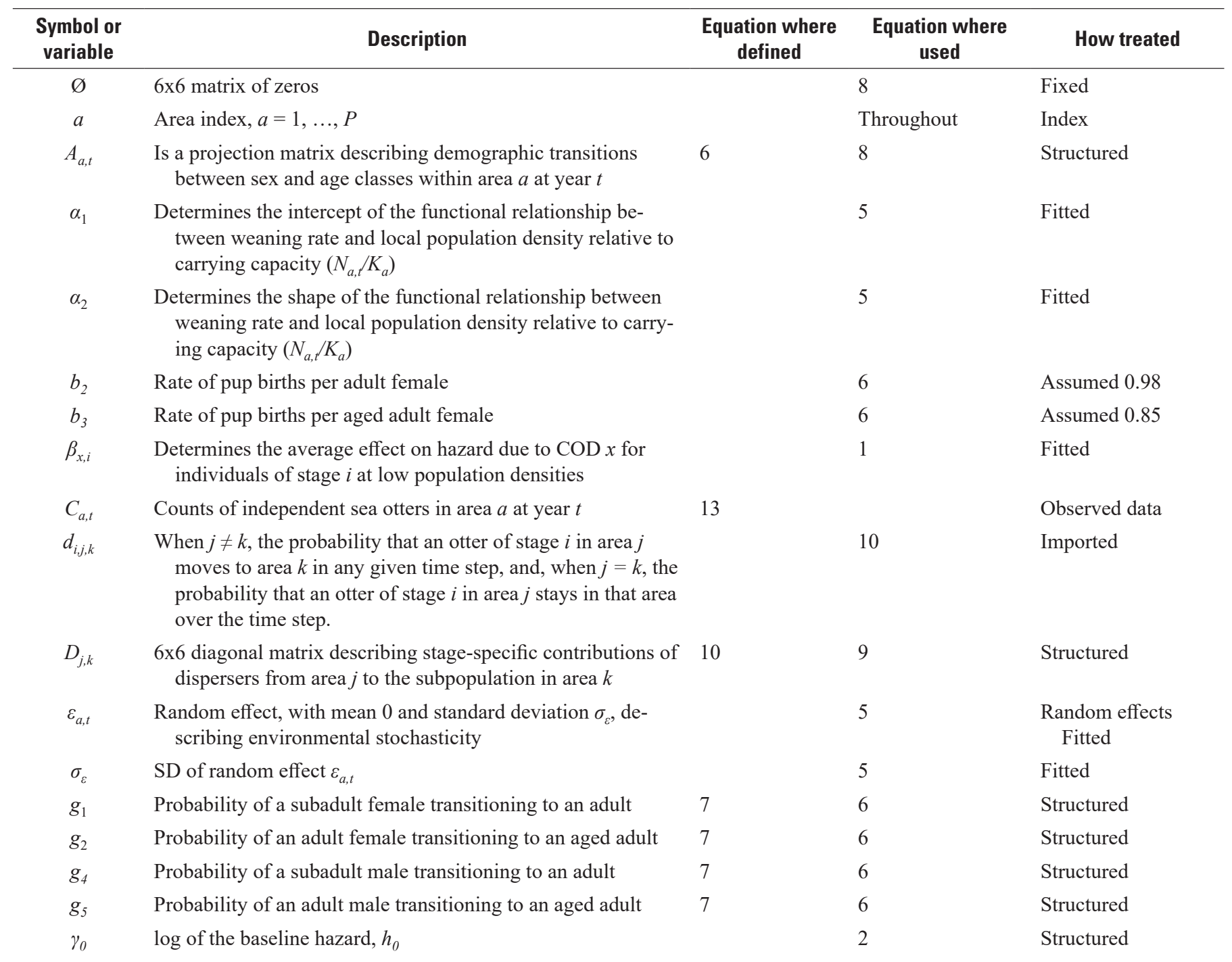


Table 1.1. Symbols and variables used in equations 1-19 of the integrated population model defined in the main text, listed with Greek and Roman letters interspersed, ordered alphabetically, then ordered by Roman lower case, Roman upper case, and Greek. $\mathrm{SD}$ variables $(\sigma)$ are listed after the variable to which they correspond.-Continued

[Abbreviations: $\mathrm{x}$, by; =, equals; SD, standard deviation; eq., equation]

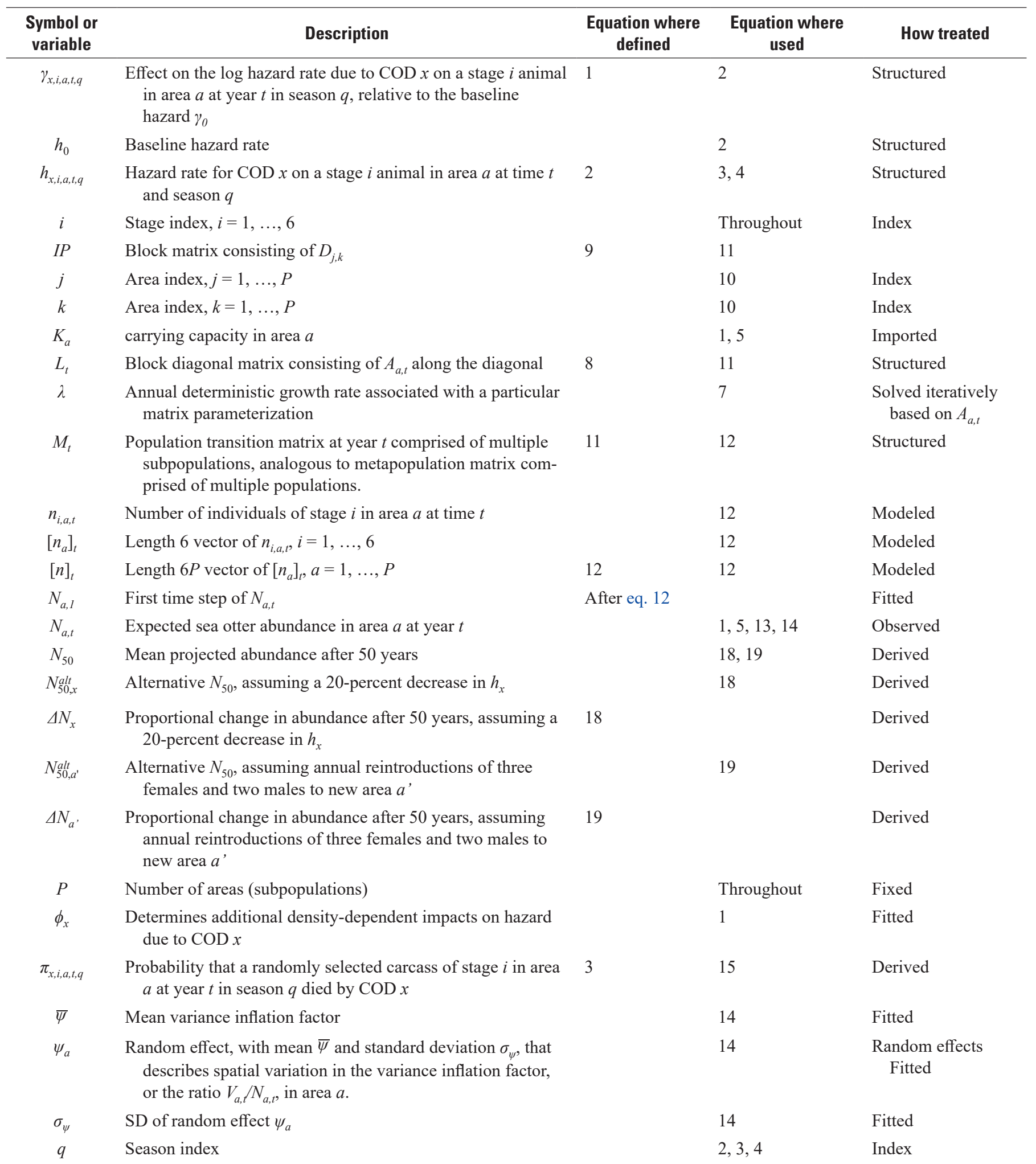


Table 1.1. Symbols and variables used in equations 1-19 of the integrated population model defined in the main text, listed with Greek and Roman letters interspersed, ordered alphabetically, then ordered by Roman lower case, Roman upper case, and Greek. SD variables $(\sigma)$ are listed after the variable to which they correspond.-Continued

[Abbreviations: x, by; =, equals; SD, standard deviation; eq., equation]

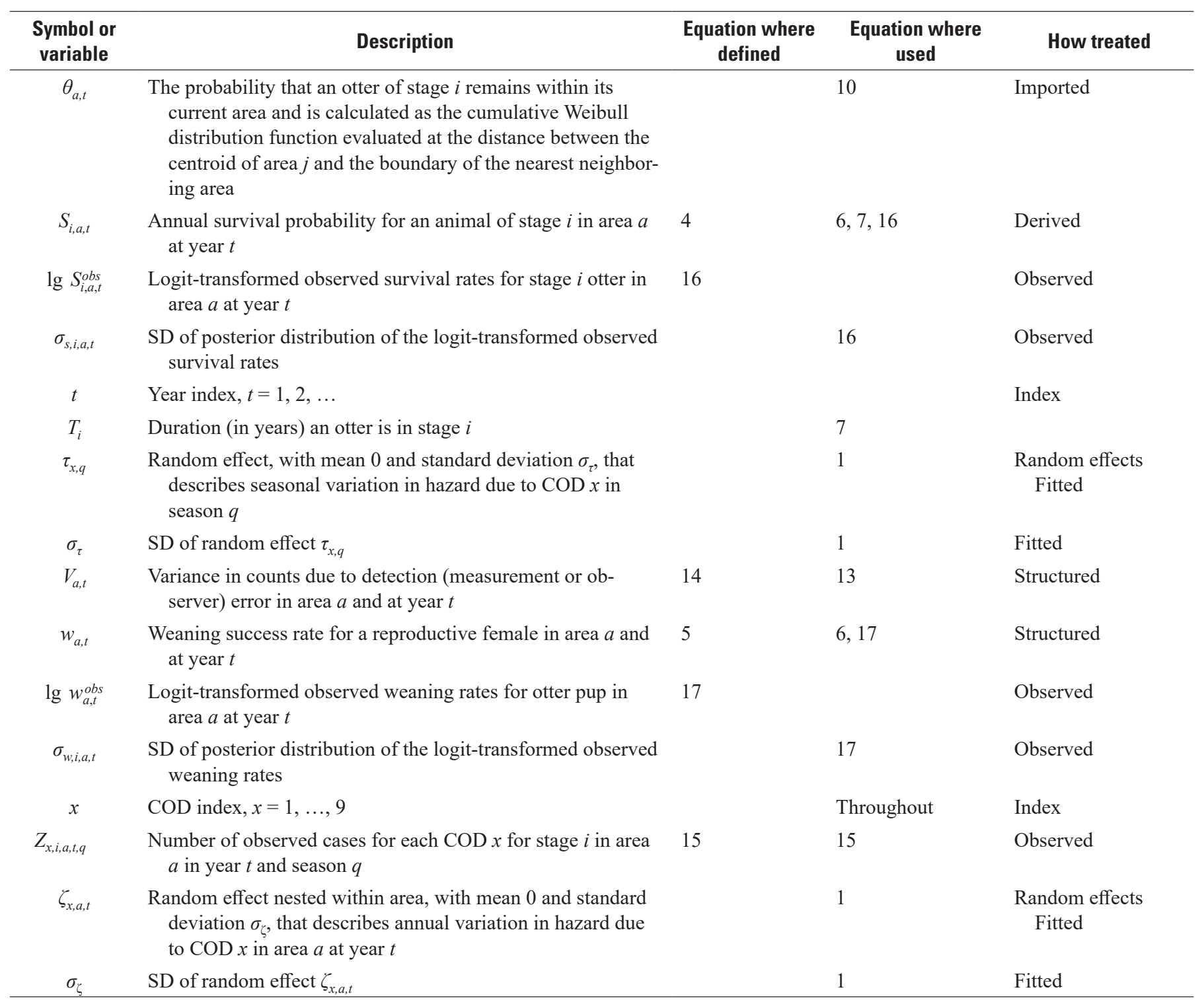


Table 1.2. Summary of parameters of an Integrated Population Model (IPM) for southern sea otters (Enhydra lutris nereis) fit to multiple datasets using Bayesian Markov Chain Monte Carlo methods. Definitions of all parameters are provided in the main text and summarized in table 1.1. The mean, standard deviation (SD), lower 95-percent credible interval (Cl95_LO) and upper 95-percent credible interval (CI95_HI) of the posterior distributions for each parameter are shown. The Gelman-Rubin convergence diagnostic, percent scale reduction factor (psrf), for each parameter is also presented: values less than 1.1 indicate convergence of independent chains during model fitting.

[Definitions of all parameters are provided in the main text. The mean, standard deviation (SD), lower 95-percent credible interval (CI95_LO) and upper 95-percent credible interval (CI95_HI) of the posterior distributions for each statistic are shown. The Gelman-Rubin convergence diagnostic (psrf) for each parameter is also presented: values less than 1.1 indicate convergence of independent chains during model fitting.]

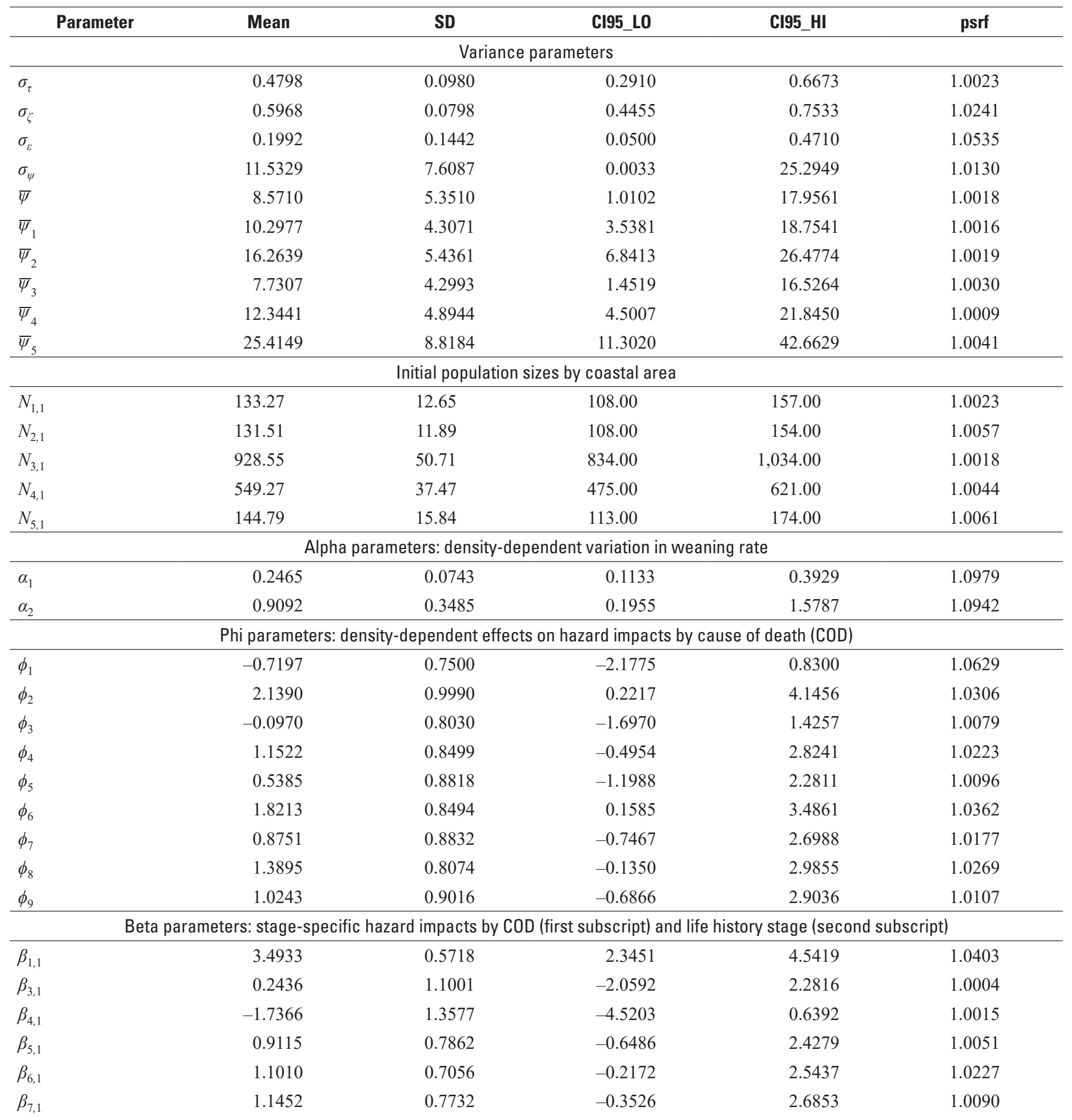


Table 1.2. Summary of parameters of an Integrated Population Model (IPM) for southern sea otters (Enhydra lutris nereis) fit to multiple datasets using Bayesian Markov Chain Monte Carlo methods. Definitions of all parameters are provided in the main text and summarized in table 1.1. The mean, standard deviation (SD), lower 95-percent credible interval (CI95_LO) and upper 95-percent credible interval (CI95_HI) of the posterior distributions for each parameter are shown. The Gelman-Rubin convergence diagnostic, percent scale reduction factor (psrf), for each parameter is also presented: values less than 1.1 indicate convergence of independent chains during model fitting.-Continued

[Definitions of all parameters are provided in the main text. The mean, standard deviation (SD), lower 95-percent credible interval (CI95_LO) and upper 95-percent credible interval (CI95_HI) of the posterior distributions for each statistic are shown. The Gelman-Rubin convergence diagnostic (psrf) for each parameter is also presented: values less than 1.1 indicate convergence of independent chains during model fitting.]

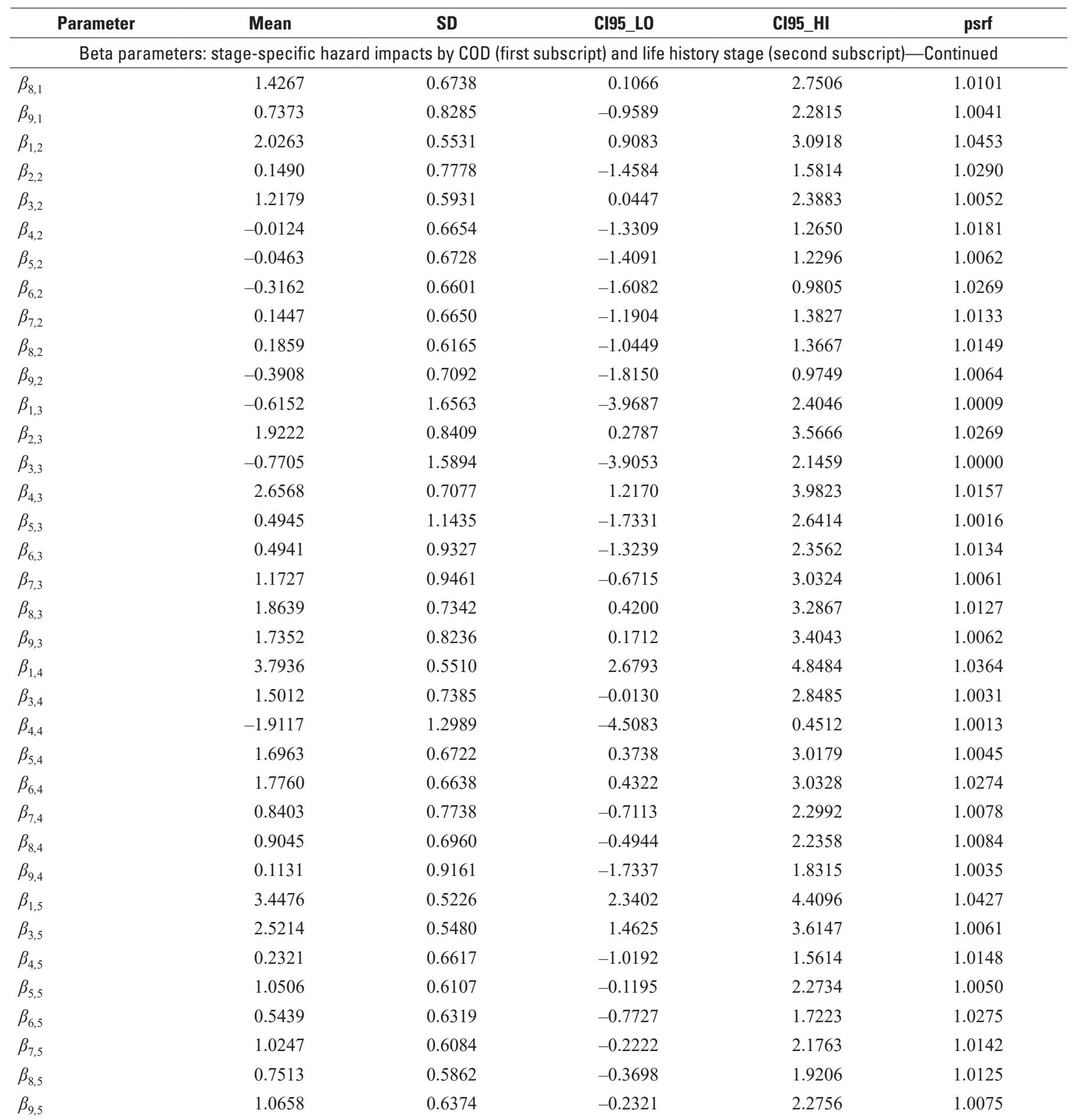


Table 1.2. Summary of parameters of an Integrated Population Model (IPM) for southern sea otters (Enhydra lutris nereis) fit to multiple datasets using Bayesian Markov Chain Monte Carlo methods. Definitions of all parameters are provided in the main text and summarized in table 1.1. The mean, standard deviation (SD), lower 95-percent credible interval (CI95_LO) and upper 95-percent credible interval (CI95_HI) of the posterior distributions for each parameter are shown. The Gelman-Rubin convergence diagnostic, percent scale reduction factor (psrf), for each parameter is also presented: values less than 1.1 indicate convergence of independent chains during model fitting.-Continued

[Definitions of all parameters are provided in the main text. The mean, standard deviation (SD), lower 95-percent credible interval (CI95_LO) and upper 95-percent credible interval (CI95_HI) of the posterior distributions for each statistic are shown. The Gelman-Rubin convergence diagnostic (psrf) for each parameter is also presented: values less than 1.1 indicate convergence of independent chains during model fitting.]

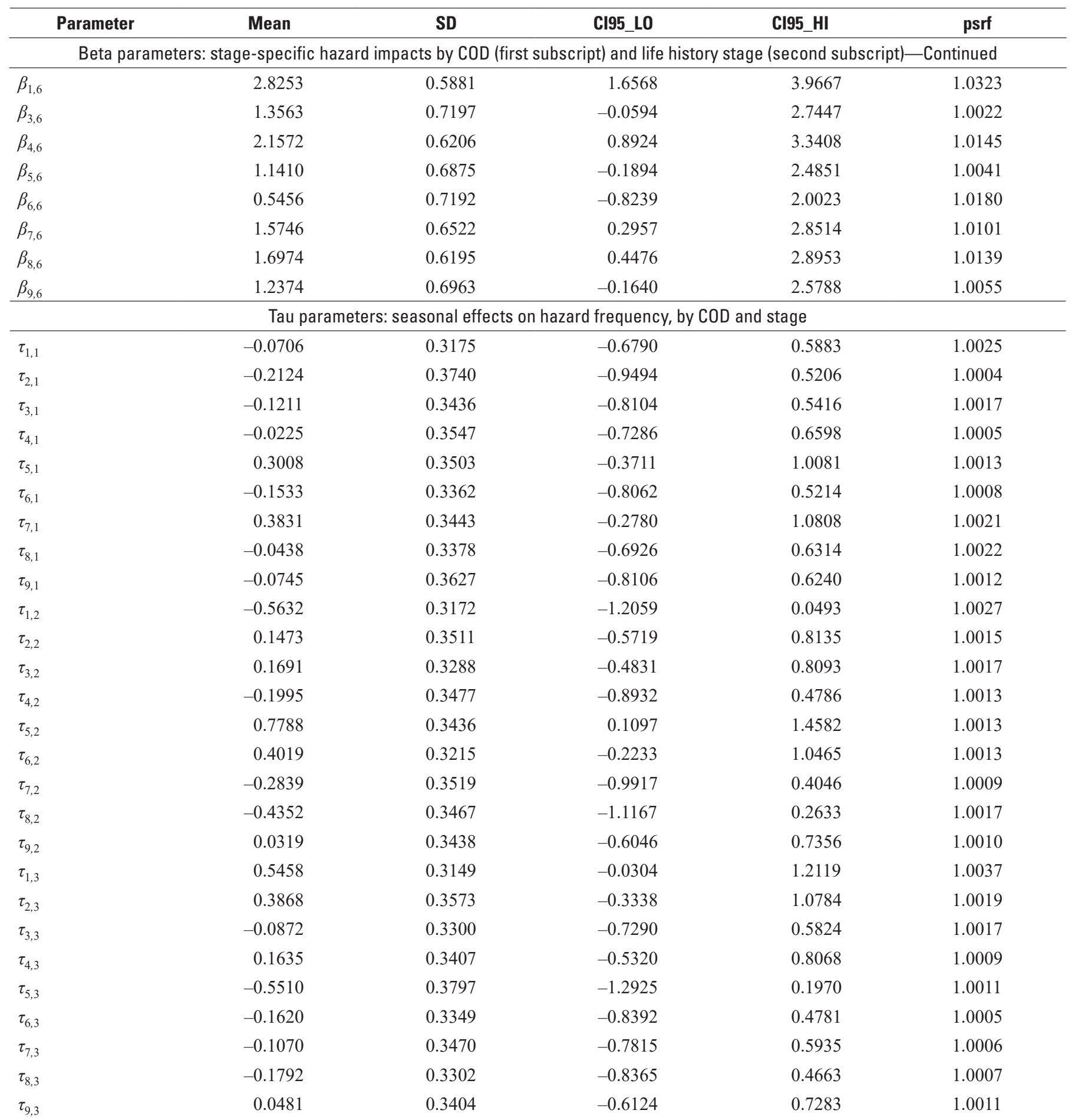




\section{An Integrated Population Model for Southern Sea Otters}

Table 1.2. Summary of parameters of an Integrated Population Model (IPM) for southern sea otters (Enhydra lutris nereis) fit to multiple datasets using Bayesian Markov Chain Monte Carlo methods. Definitions of all parameters are provided in the main text and summarized in table 1.1. The mean, standard deviation (SD), lower 95-percent credible interval (CI95_LO) and upper 95-percent credible interval (CI95_HI) of the posterior distributions for each parameter are shown. The Gelman-Rubin convergence diagnostic, percent scale reduction factor (psrf), for each parameter is also presented: values less than 1.1 indicate convergence of independent chains during model fitting.-Continued

[Definitions of all parameters are provided in the main text. The mean, standard deviation (SD), lower 95-percent credible interval (CI95_LO) and upper 95-percent credible interval (CI95_HI) of the posterior distributions for each statistic are shown. The Gelman-Rubin convergence diagnostic (psrf) for each parameter is also presented: values less than 1.1 indicate convergence of independent chains during model fitting.]

\begin{tabular}{lccccc}
\hline Parameter & Mean & SD & Cl95_LO & Cl95_HI & psrf \\
\hline & \multicolumn{1}{c}{ Tau parameters: seasonal effects on hazard frequency, by COD and stage一Continued } & \\
\hline$\tau_{1,4}$ & 0.4249 & 0.3246 & -0.1691 & 1.1022 & 1.0043 \\
$\tau_{2,4}$ & -0.1369 & 0.3790 & -0.9162 & 0.5812 & 1.0004 \\
$\tau_{3,4}$ & -0.0009 & 0.3451 & -0.6636 & 0.7048 & 1.0012 \\
$\tau_{4,4}$ & -0.0291 & 0.3698 & -0.8158 & 0.6493 & 1.0009 \\
$\tau_{5,4}$ & -0.5969 & 0.4118 & -1.4249 & 0.1921 & 1.0003 \\
$\tau_{6,4}$ & -0.2362 & 0.3542 & -0.9759 & 0.4222 & 1.0004 \\
$\tau_{7,4}$ & -0.0646 & 0.3667 & -0.8219 & 0.6471 & 1.0008 \\
$\tau_{8,4}$ & 0.6217 & 0.3385 & -0.0458 & 1.2783 & 1.0008 \\
$\tau_{9,4}$ & -0.0590 & 0.3629 & -0.7997 & 0.6430 & 1.0014 \\
\hline
\end{tabular}




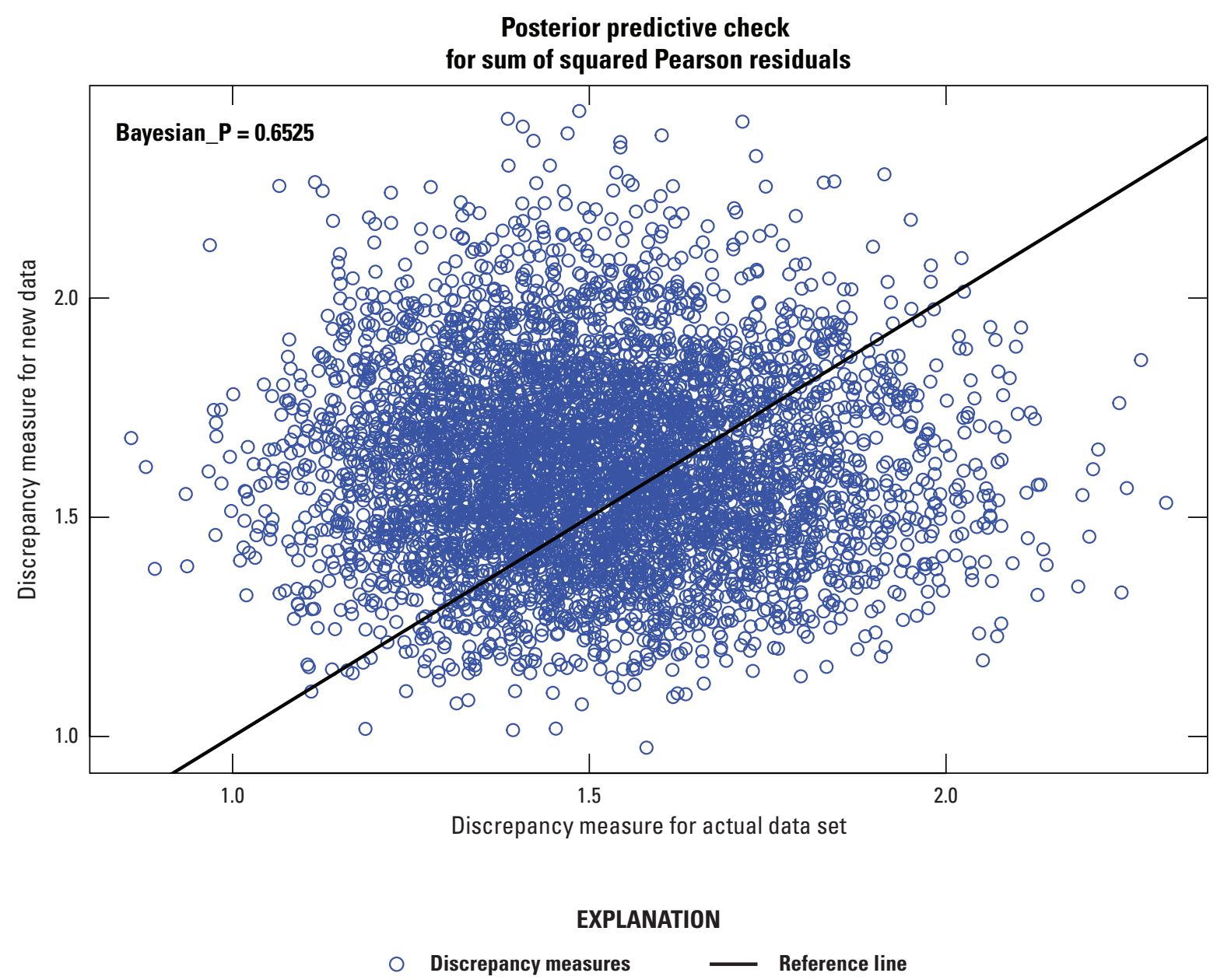

Figure 1.1. Diagnostic "posterior predictive check" plot from Bayesian model fitting of an integrated population model (IPM) for southern sea otters. The mean sum of squared Pearson residuals for new data generated from the model are plotted against the equivalent discrepancy measure generated from the actual observed data: in the case of a well-fit model, the scatterplot distribution should be clustered around the 1:1 line (shown as diagonal black line). The associated Bayesian P-value is also shown, which for a well-fit model should be greater than 0.2 and less than 0.8 . 
$\boldsymbol{A}$
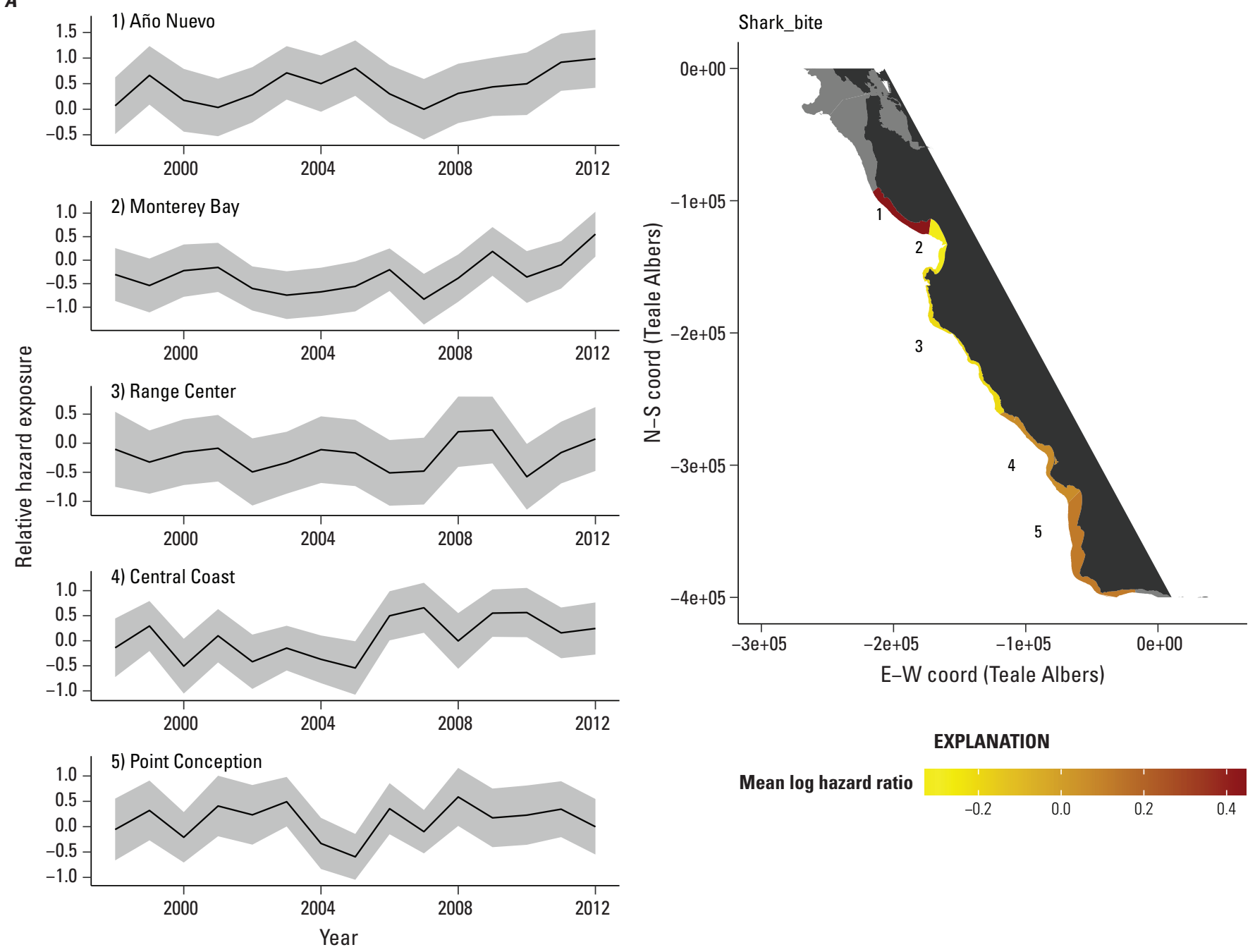

\section{EXPLANATION}

Mean log hazard ratio

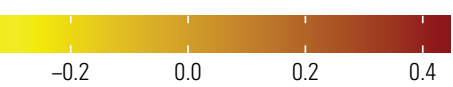

Figure 1.2. Plots of spatiotemporal variation in hazard exposure for southern sea otters, expressed as deviations from mean log hazard rates for nine categories of cause of death (COD) based on survey data and estimates from an integrated population model, denoted $\Gamma_{x, a, t}$ (eq. 1.1). $A$, shark bite; $B$, End Lactation Syndrome; $C$, harmful algal blooms intoxication; $D$, cardiac disease; $E$, protozoal infection; $F$, acantho peritonitis; $G$, other infection; $H$, natural causes; and $I$, human causes. Maps show spatial trends in $\Gamma_{x, a, t}$ when averaged across years (values indicated by color gradient as shown in legend at bottom), whereas line plots show temporal trends in $\Gamma_{x, a, t}$ for each of five coastal areas. For maps and trend plots, positive values represent higher than average levels of exposure to a given hazard. 

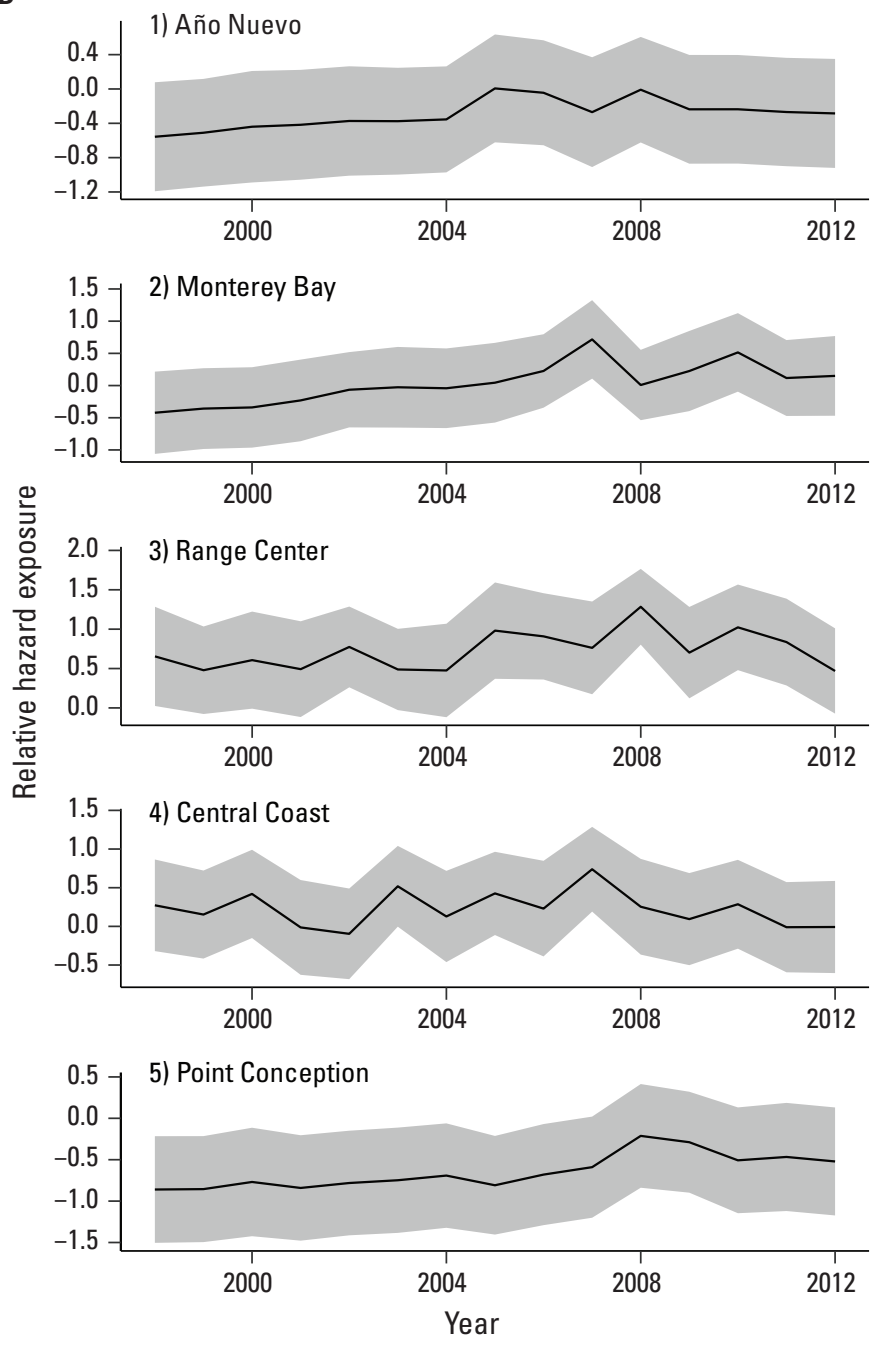

Figure 1.2.-Continued

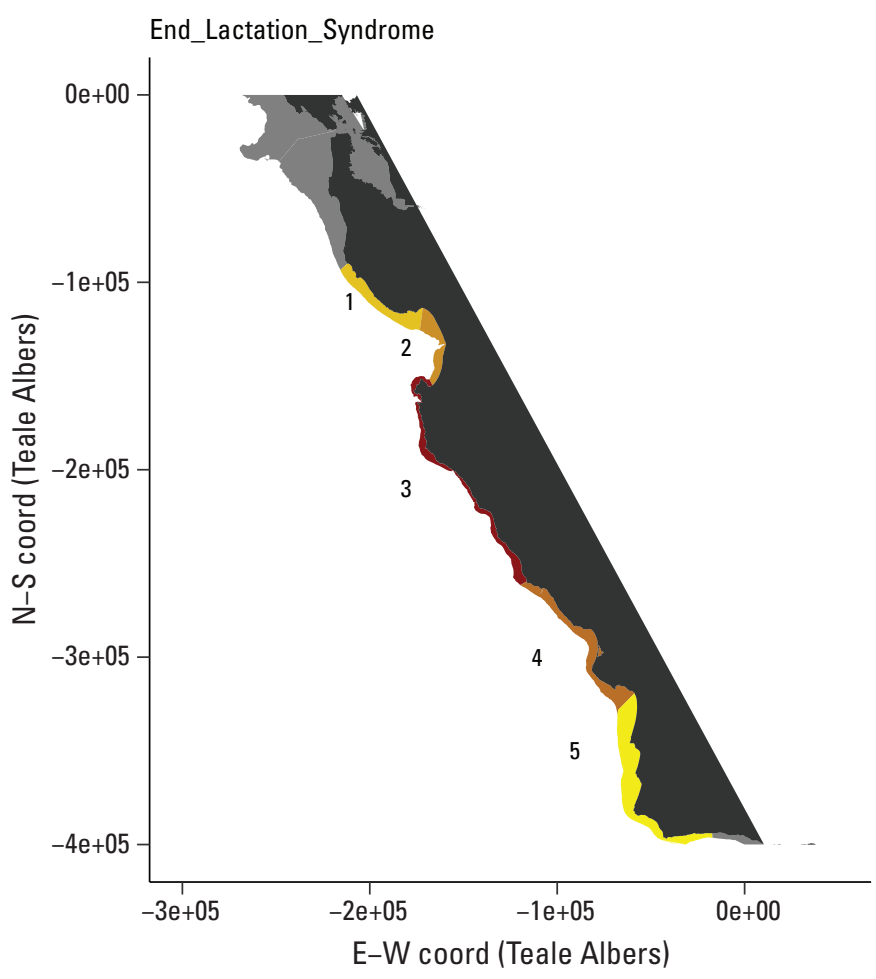

EXPLANATION
Mean log hazard ratio 
c
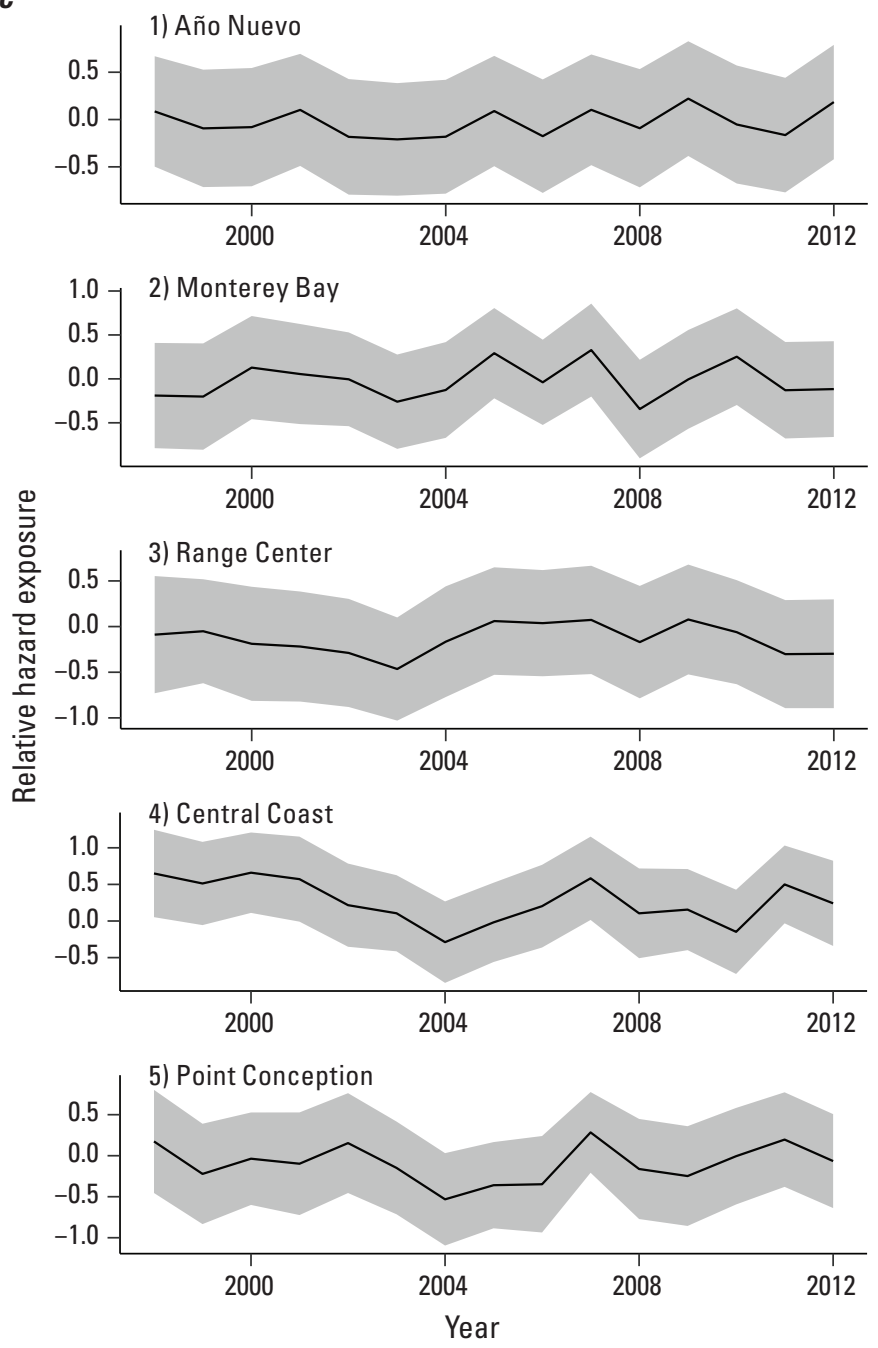

Figure 1.2.-Continued

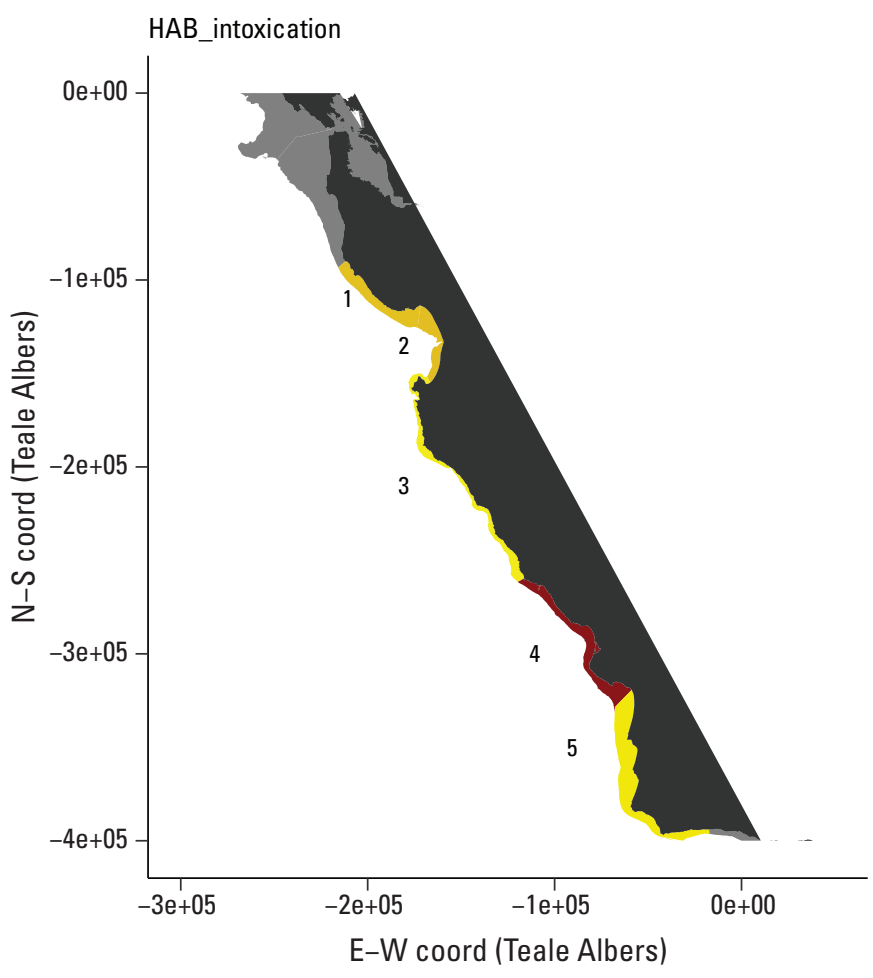

EXPLANATION

Mean log hazard ratio 
D
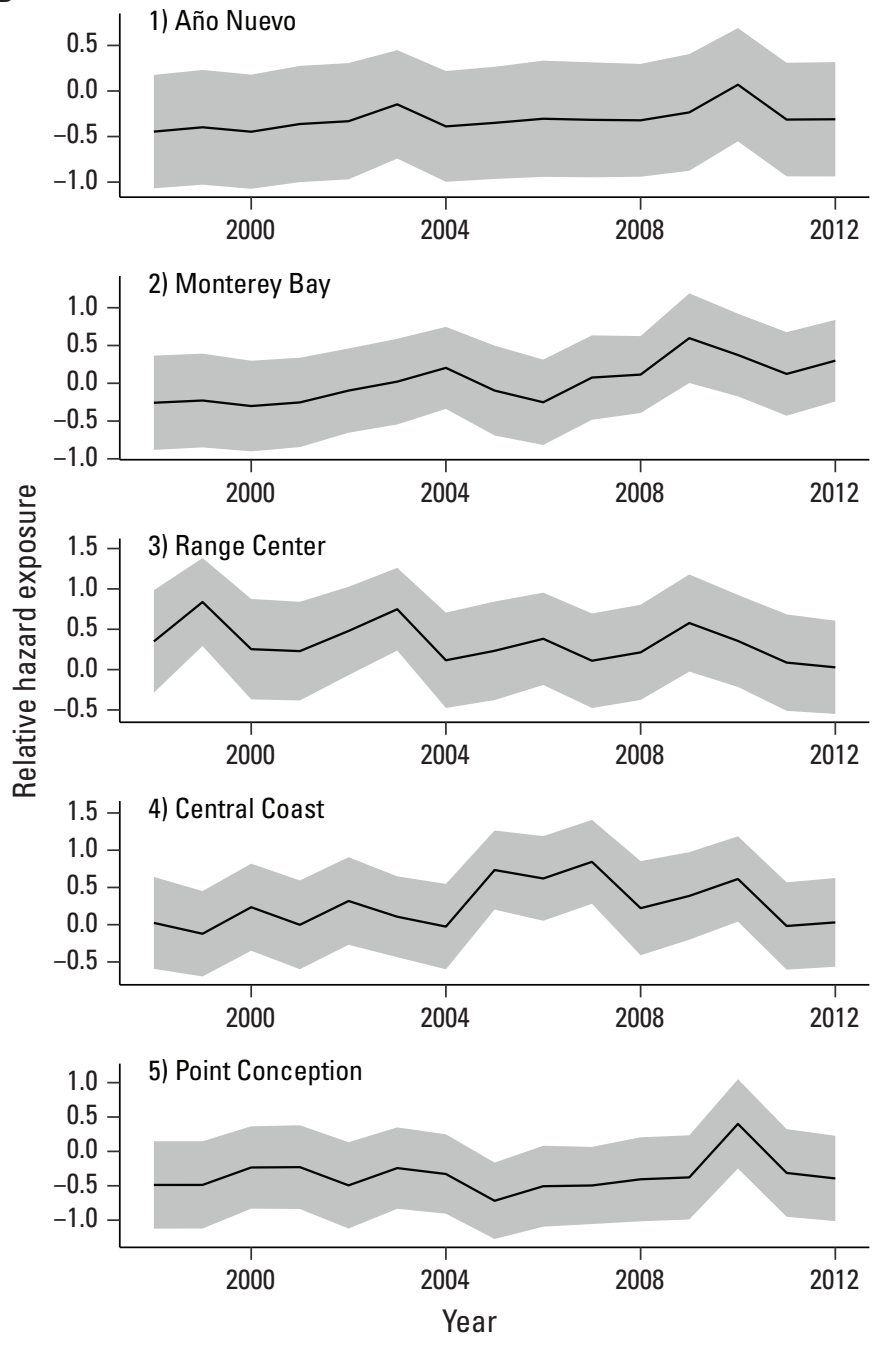

Figure 1.2.-Continued

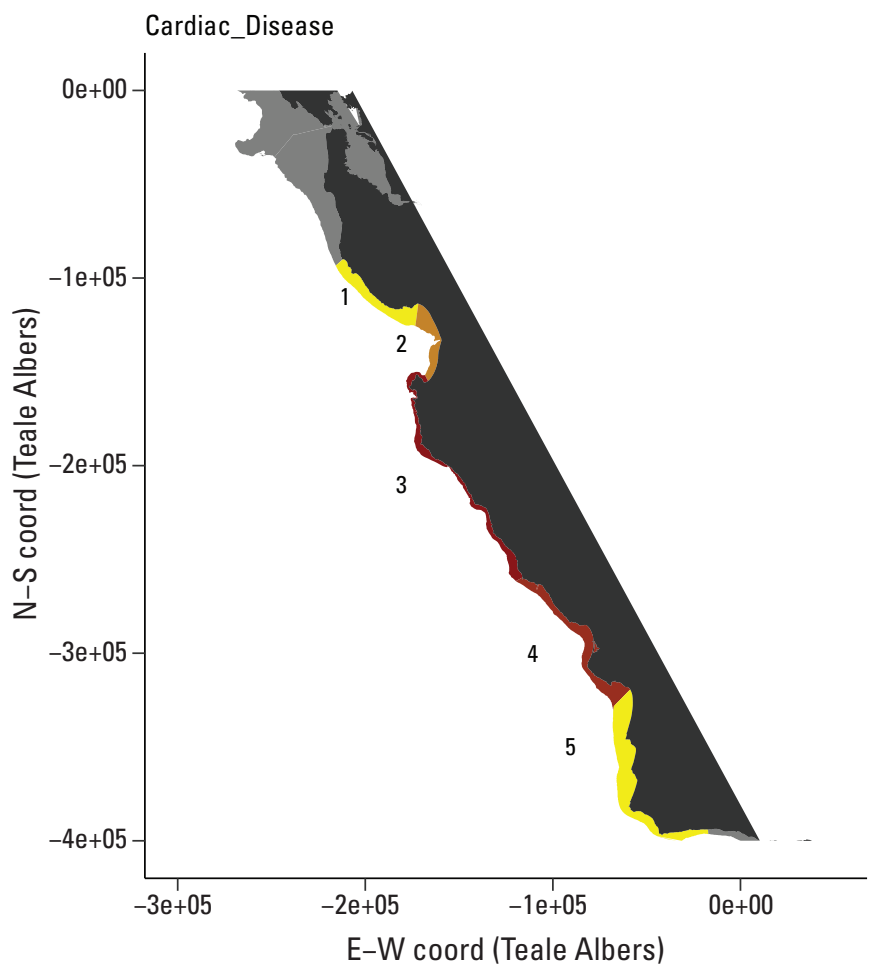

EXPLANATION
Mean log hazard ratio 
E
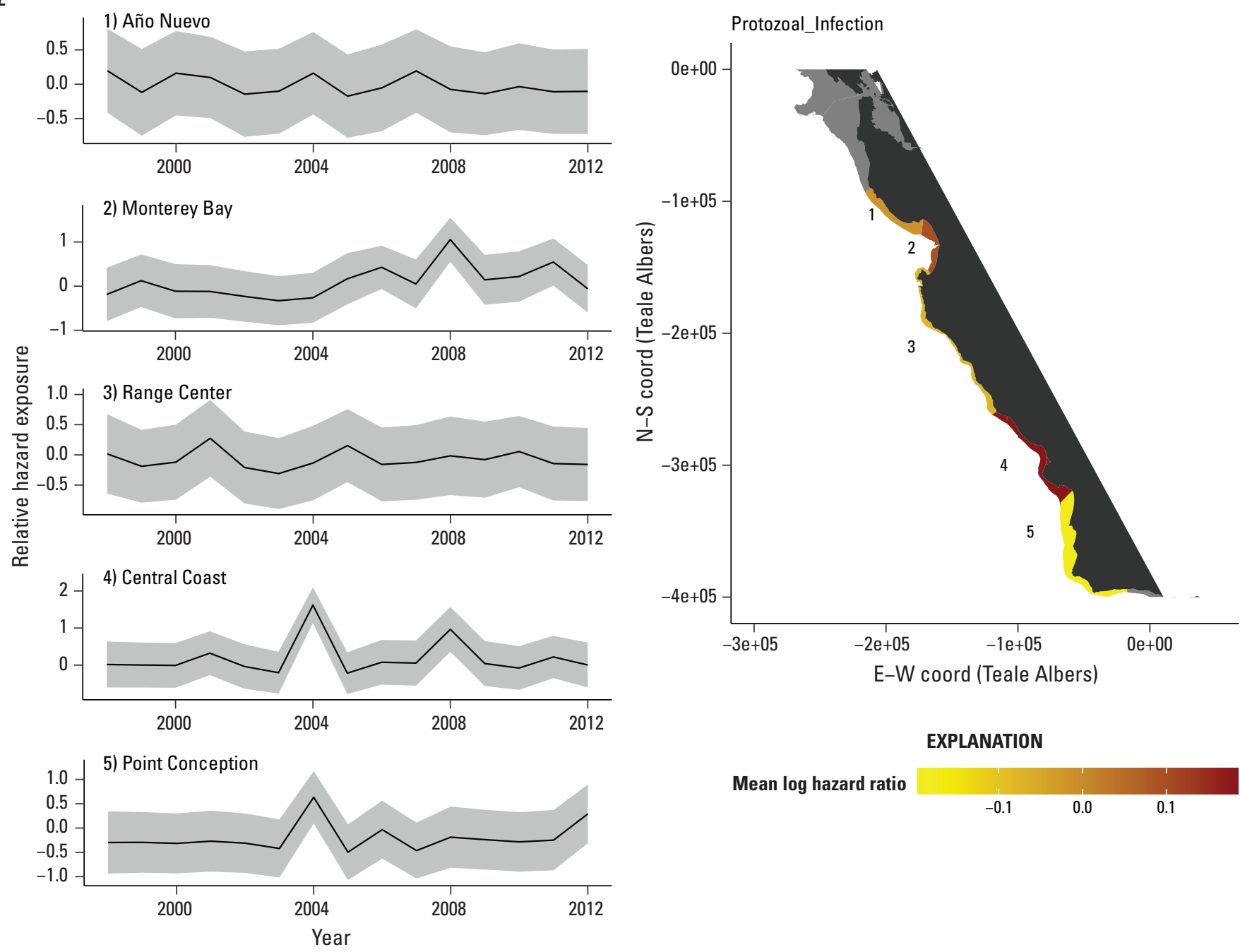

EXPLANATION

Mean log hazard ratio

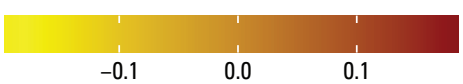

Figure 1.2.-Continued 

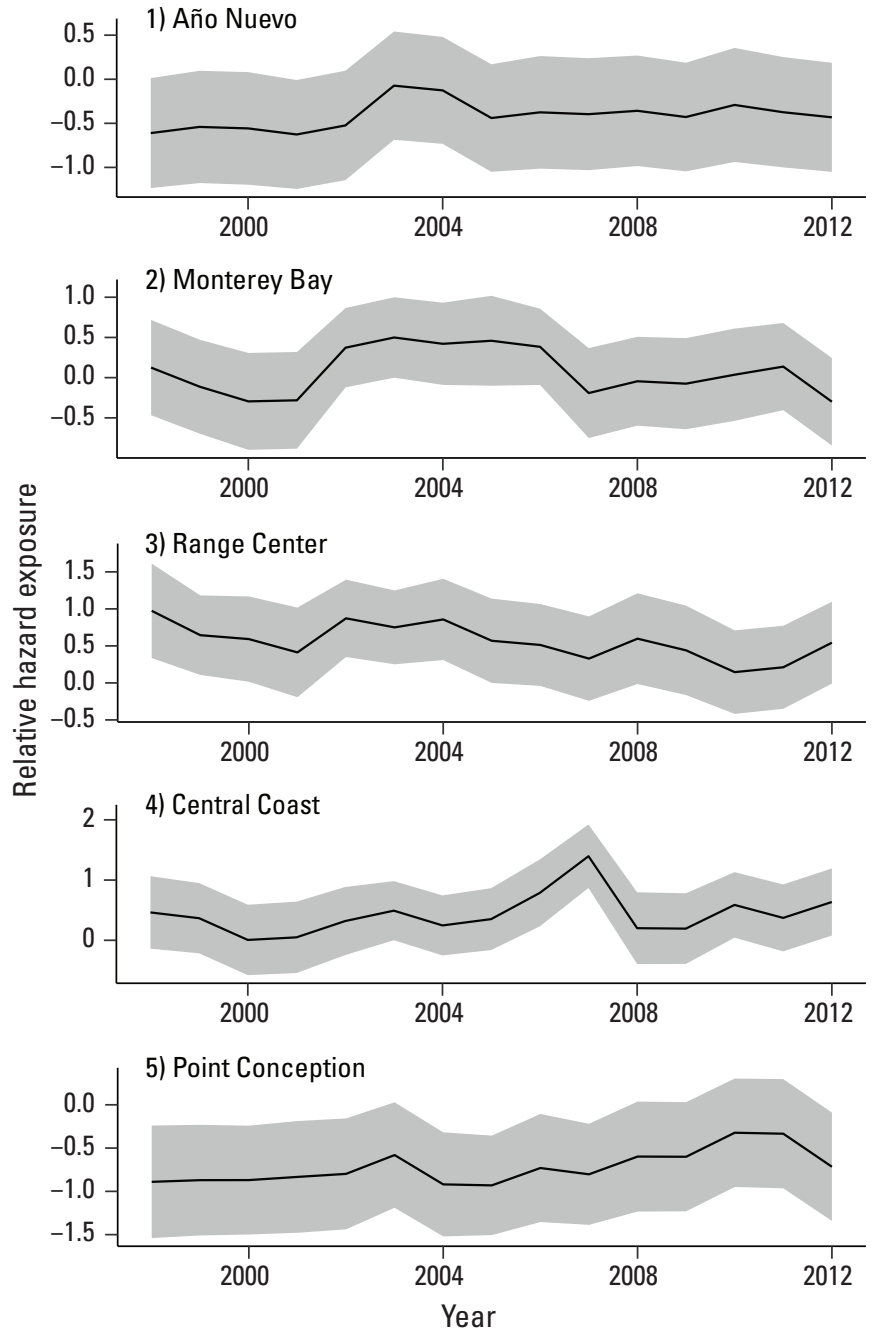

Figure 1.2.-Continued

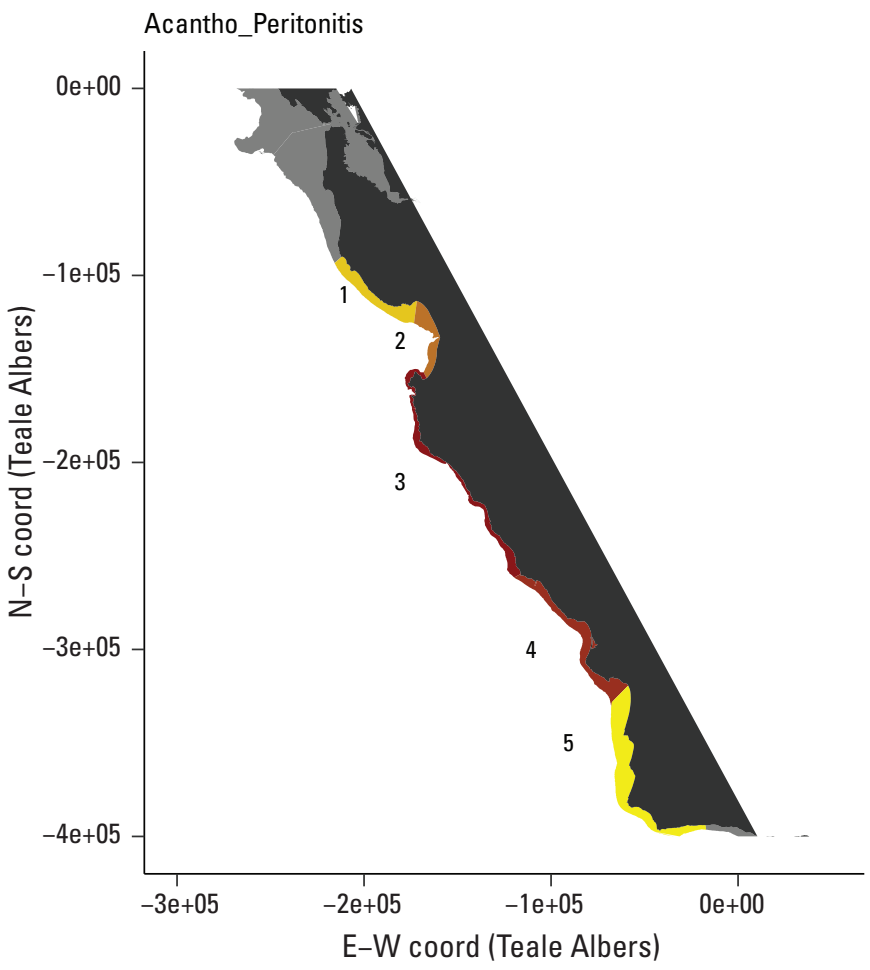

EXPLANATION

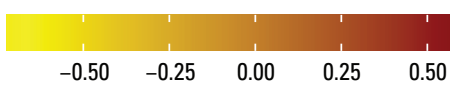

Mean log hazard ratio 
G
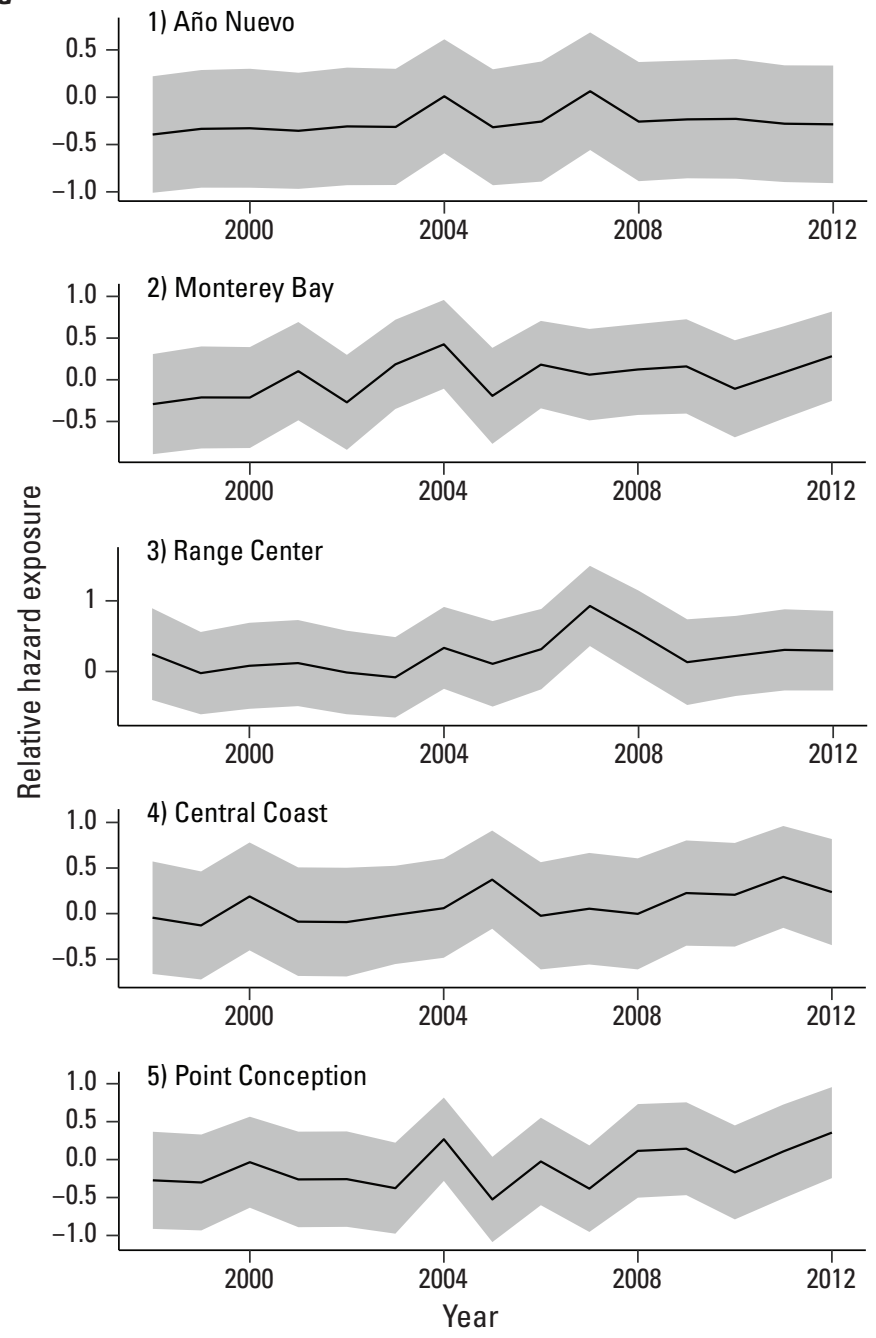

Figure 1.2.-Continued

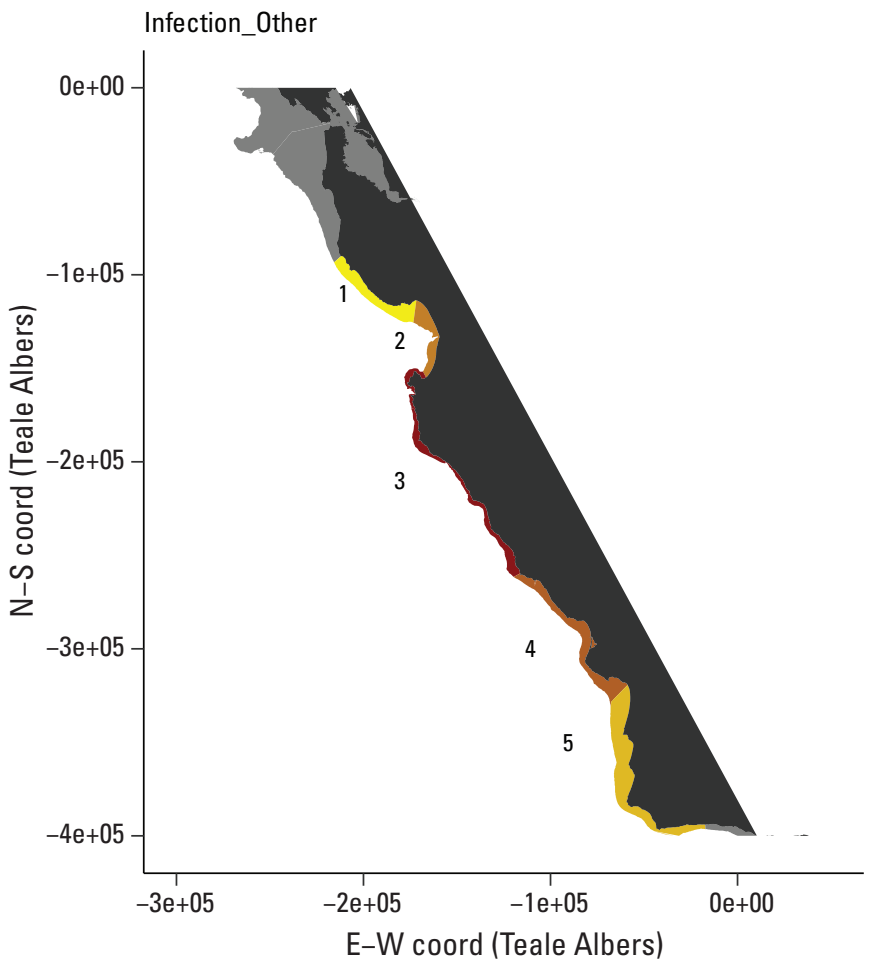

EXPLANATION

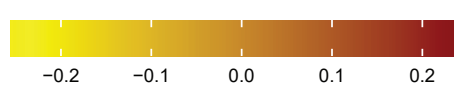

Mean log hazard ratio 
H
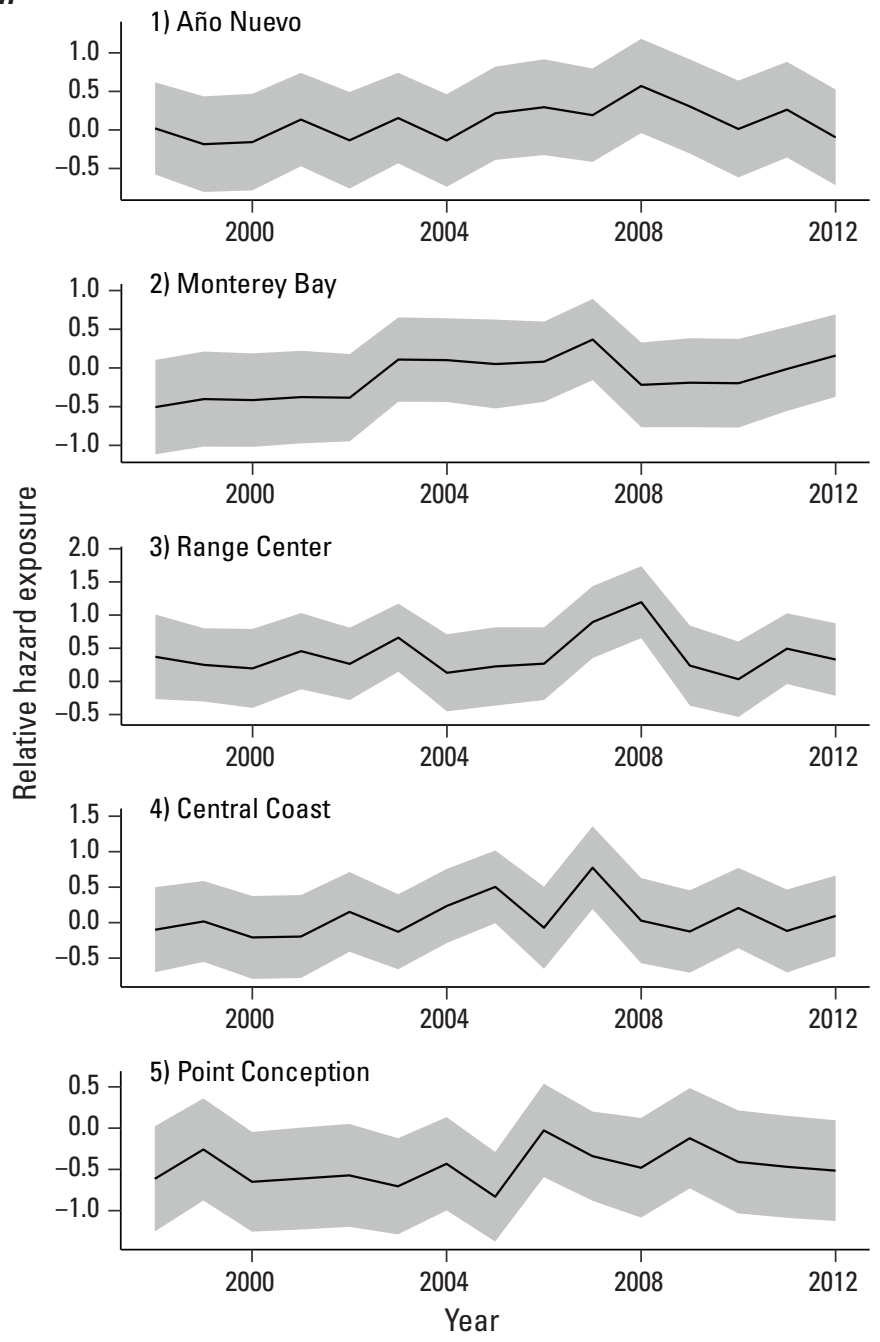

Figure 1.2.-Continued

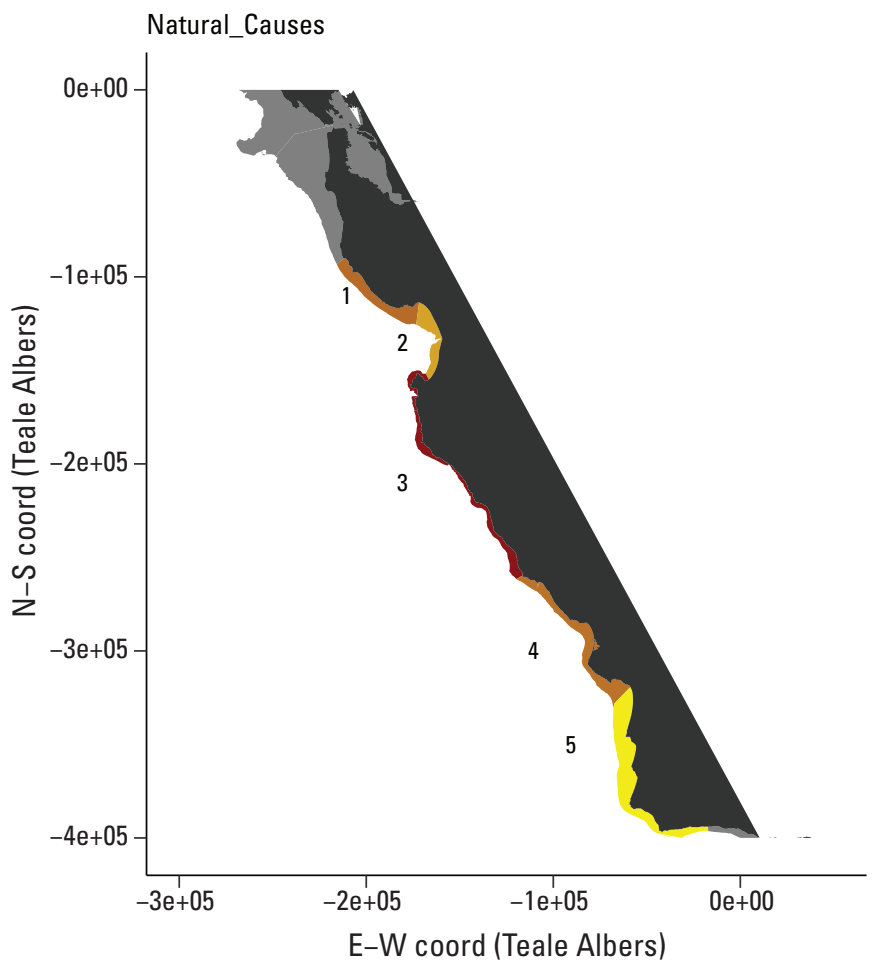

EXPLANATION

Mean log hazard ratio 

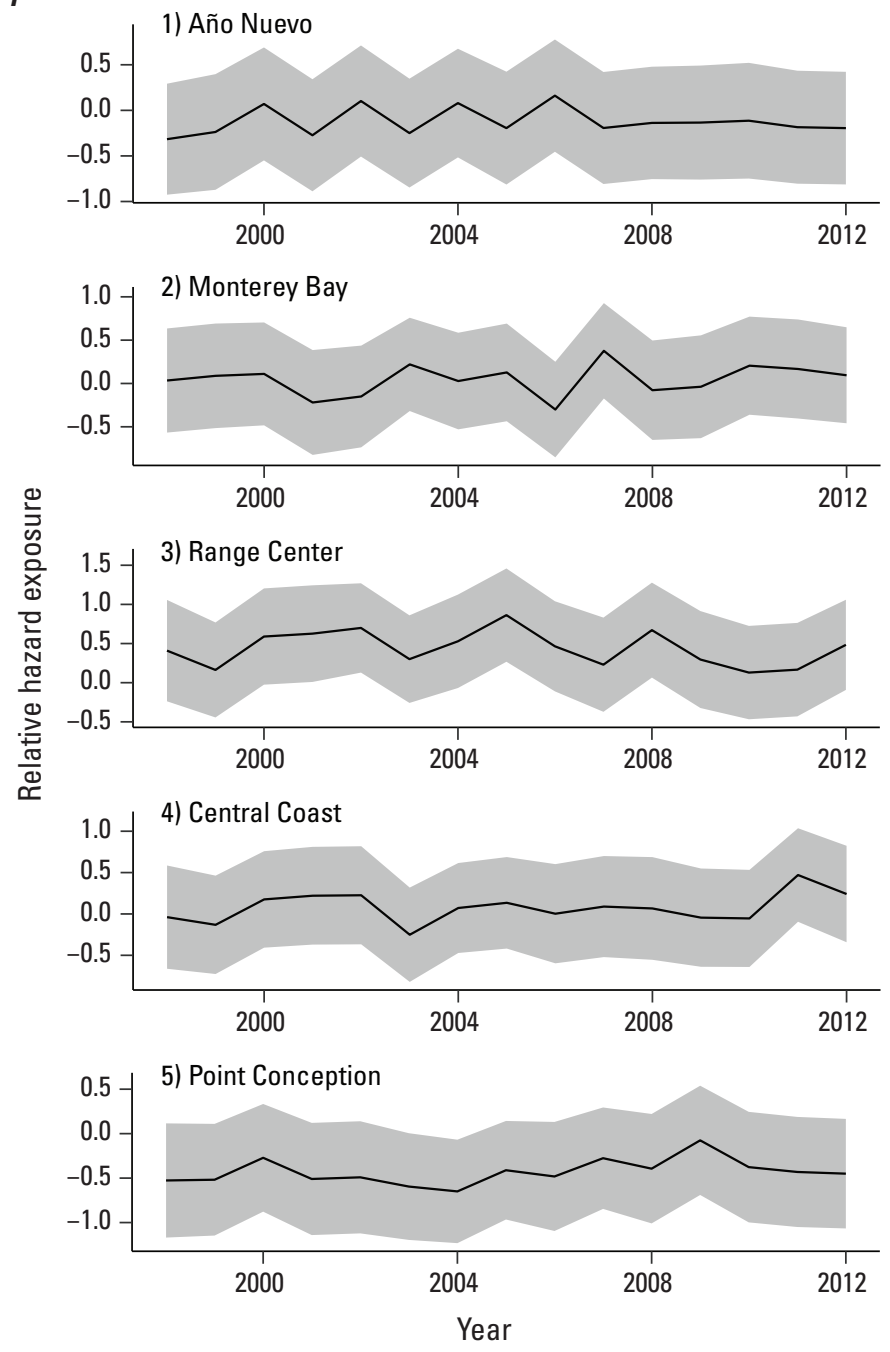

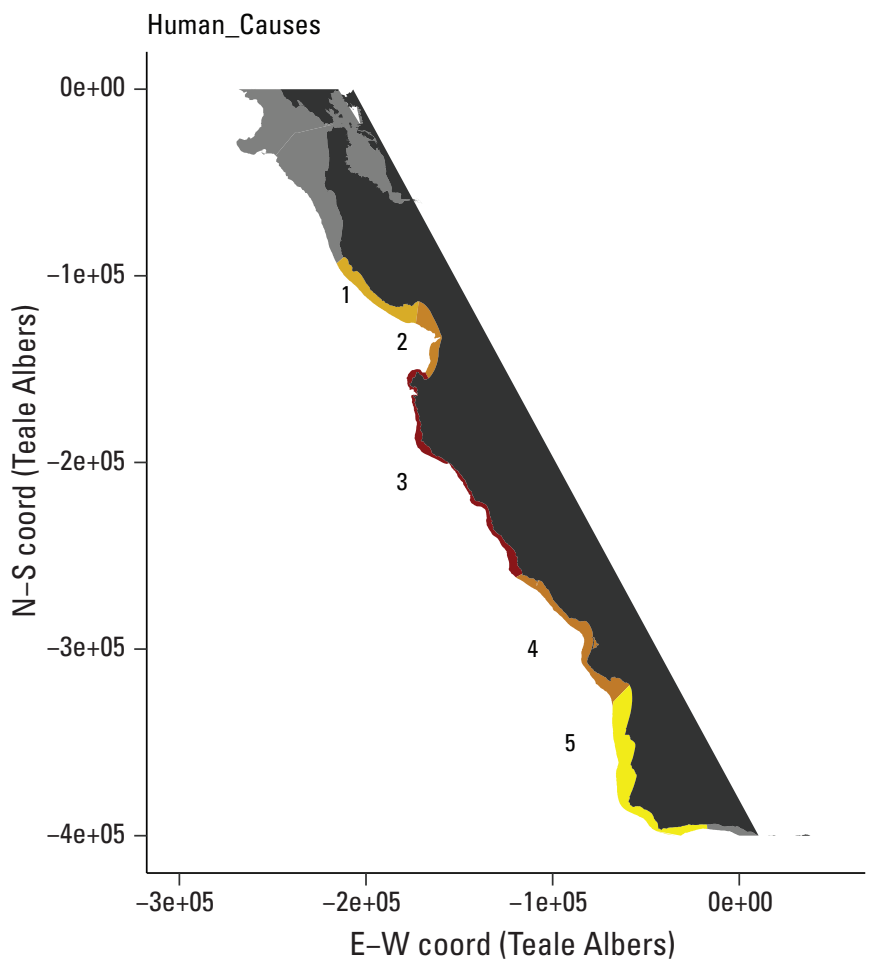

EXPLANATION

Figure 1.2.-Continued 
For more information concerning the research in this report, contact the

Director, Western Ecological Research Center

U.S. Geological Survey

3020 State University Drive East

Sacramento, California 95819

https://www.usgs.gov/centers/werc

Publishing support provided by the U.S. Geological Survey

Science Publishing Network, Sacramento Publishing Service Center 


\section{$\frac{\mathbb{2}}{3}$}

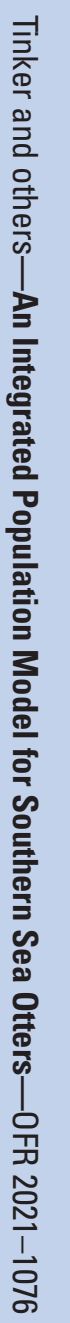

